Pontifícia Universidade Católica $_{\text {a }}$

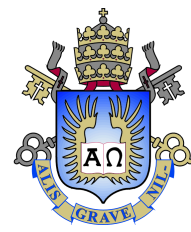

Paulo Ivson Netto Santos

\title{
Information Visualization for Managing \\ Large-Scale Engineering Projects
}

Tese de Doutorado

Thesis presented to the Programa de Pós-Graduação em Informática of PUC-Rio in partial fulfillment of the requirements for the degree of Doutor em Ciências - Informática.

Advisor: Prof. Waldemar Celes Filho 

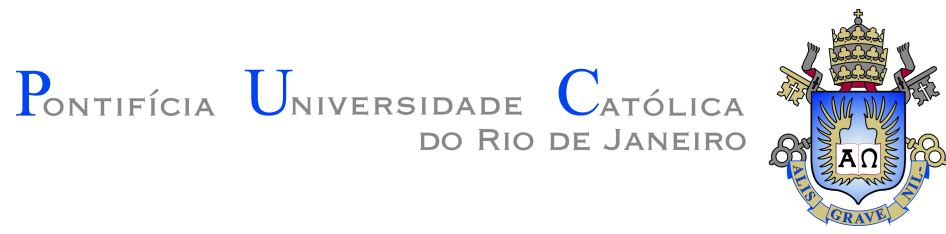

Paulo Ivson Netto Santos

\section{Information Visualization for Managing Large-Scale Engineering Projects}

Thesis presented to the Programa de Pós-Graduação em Informática of PUC-Rio in partial fulfillment of the requirements for the degree of Doutor em Ciências - Informática. Approved by the undersigned Examination Committee.

Prof. Waldemar Celes Filho

Advisor

Departamento de Informática - PUC-Rio

Profa. Maria Cristina Ferreira de Oliveira

USP

Prof. João Luiz Dihl Comba

UFRGS

Profa. Simone Diniz Junqueira Barbosa

Departamento de Informática - PUC-Rio

Prof. Marcelo Gattass

Departamento de Informática - PUC-Rio

Prof. Márcio da Silveira Carvalho Vice Dean of Graduate Studies

Centro Técnico Científico - PUC-Rio

Rio de Janeiro, April the 13th, 2018 
All rights reserved.

\section{Paulo Ivson Netto Santos}

Paulo Ivson holds a Master degree in Computer Science with emphasis in Computer Graphics from PUC-Rio, where he also Graduated in Computer Engineering. Since graduation, he has participated in R\&D projects at Tecgraf Institute / PUC-Rio with partners in the Oil \& Gas, AEC/FM and Manufacturing industries. The student's research interests include Visualization, Real-Time Rendering, Computer-Aided Design, Building Information Modeling and Lean Production.

Ficha Catalográfica

Santos, Paulo Ivson Netto

Information Visualization for Managing Large-Scale Engineering Projects / Paulo Ivson Netto Santos; advisor: Waldemar Celes Filho. - 2018.

132 f: il. color. ; $30 \mathrm{~cm}$

Tese (Doutorado) - Pontifícia Universidade Católica do Rio de Janeiro, Departamento de Informática, 2018.

Inclui bibliografia

1. Informática - Teses. 2. Visualização de Informação;. 3. 3D CAD;. 4. Modelagem da Informação da Construção;. I. Celes Filho, Waldemar. II. Pontifícia Universidade Católica do Rio de Janeiro. Departamento de Informática. III. Título.

CDD: 004 
To my love Natalia, for inspiring me to improve every day. 


\section{Acknowledgments}

I would first like to thank my dear Natalia who has endured my ramblings for almost 10 years now. Thank you for your love, your patience and your support. Without you I would never have gotten this far. You taught me to follow my dreams and never give up.

I would like to thank my advisor prof. Waldemar for his astute guidance, insightful suggestions, and genuine commitment to improving our research together. I'm happy to have shared my academic accomplishments with you since undergraduate studies. I hope I've made you proud.

I also need to thank everyone else who have always believed in me, giving me opportunities to grow both personally and professionally: prof. Gattass for inviting me to Tecgraf, prof. Alberto for his faith in my skills, and prof. Thadeu for always being there both as a mentor and a friend. I hope one day to be as great as you are.

Thanks to all my friends who have also contributed to my academic and professional adventures. This particular thesis would not be possible without the help of Andre, Chico, Lucas, and Wallas who dedicated their time to the systematic review and also provided many insightful conversations.

Last but not least, I thank my mother, father, and brother for giving me more than I could have ever asked in my life. None of this would be possible without you.

The present work was done with support from CNPq, Conselho Nacional de Desenvolvimento Científico e Tecnológico - Brasil (process 140933/2014-0). 


\section{Abstract}

Netto Santos, Paulo Ivson; Celes Filho, Waldemar (Advisor). Information Visualization for Managing Large-Scale Engineering Projects. Rio de Janeiro, 2018. 132p. Tese de Doutorado - Departamento de Informática, Pontifícia Universidade Católica do Rio de Janeiro.

Large-scale engineering projects such as buildings and city infrastructure require millions in investments and tight coordination between expert teams across several years of design, construction, and operation. To tackle these challenges, the Architecture Engineering and Construction (AEC) industry is actively developing methods and tools based on Building Information Modeling (BIM). BIM promotes the use of 3D CAD models as a centralized database for all physical and functional characteristics of a facility and its related project/life-cycle information. The inherent complexity of a BIM model offers a critical visualization challenge: how to best display relevant information required by different engineering analyses? This work contributes to answering this question through both theoretical and practical approaches. The thesis first presents a systematic literature review on the current state of information visualization (VIS) in BIM research. The review analyzes in detail currently employed visualizations in diverse use cases across an engineering project's life cycle. Based on these findings, the thesis describes the design and evaluation of a novel 4D construction planning system that overcomes many limitations of previous work. Engineering collaborators used the software to review the real-world construction plans of an Oil \& Gas industrial plant. The developed visualizations made evident schedule uncertainties, workspace conflicts and other constructability issues. The thesis contributes to BIM research with important visualization guidelines and also contributes to VIS research by raising awareness to interesting challenges in a increasingly relevant engineering domain.

\section{Keywords}

Information Visualization; 3D CAD; Building Information Modeling; 


\section{Resumo}

Netto Santos, Paulo Ivson; Celes Filho, Waldemar. Visualização

de Informação para Gestão de Grandes Projetos de Engenharia. Rio de Janeiro, 2018. 132p. Tese de Doutorado Departamento de Informática, Pontifícia Universidade Católica do Rio de Janeiro.

Grandes projetos de engenharia como prédios e infraestrutura urbana demandam milhões em investimentos e estreita colaboração entre equipes de especialistas ao longo de vários anos de projeto, construção e operação. Para vencer estes desafios, a indústria de Arquitetura, Engenharia e Construção (AEC) está ativamente desenvolvimento métodos e ferramentas baseadas na Modelagem da Informação da Construção (BIM). BIM promove o uso de modelos CAD 3D como uma base de dados centralizada para todas as características físicas e funcionais de uma instalação e suas informações associadas de projeto e ciclo de vida. A complexidade inerente de um modelo BIM oferece um desafio crítico de visualização: como melhor apresentar informações relevantes necessárias para diferentes análises de engenharia? Este trabalho contribui para responder esta questão através de uma abordagem teórica e prática. A tese primeiro apresenta uma revisão sistemática da literatura sobre o estado atual de visualização de informação (VIS) em pesquisas BIM. A revisão analisa em detalhe as visualizações adotadas em diversos casos de uso ao longo das fases do ciclo de vida de um projeto de engenharia. Baseado nesses resultados, a tese descreve a especificação e avaliação de um novo sistema 4D para planejamento da construção que supere várias limitações de trabalhos anterioes. Colaboradores de engenharia utilizaram o software para revisar os planos reais de construção de uma planta industrial de Óleo e Gás. As ferramentas de visualização desenvolvidas tornaram evidente incertezas no cronograma, conflitos de espaço de trabalho e outros problemas de construtibilidade. A tese contribui para pesquisas em BIM com importantes recomendações de visualização e também contribui para pesquisas de VIS ao trazer à tona desafios interessantes em um domínio de engenharia cada vez mais relevante.

\section{Palavras-chave}

Visualização de Informação; 3D CAD; Modelagem da Informação da Construção; 


\section{Table of contents}

$\begin{array}{llr}1 & \text { Introduction } & 15\end{array}$

2 Main Challenges in the Construction Industry 18

3 Systematic Literature Review $\quad 21$

3.1 Related Work 21

3.1.1 BIM Use Cases $\quad 22$

3.1.2 Visualization in BIM 23

$\begin{array}{lll}3.2 & \text { Systematic Review Methodology } & 25\end{array}$

$\begin{array}{ll}3.3 \text { Classification Framework } & 27\end{array}$

$\begin{array}{lll}\text { 3.3.1 Life Cycle Phases } & 28\end{array}$

$\begin{array}{ll}\text { 3.3.2 Use Cases } & 29\end{array}$

3.3.3 Information and Data Types 31

3.3.4 Visualizations 34

3.4 Application Areas of Visualization 35

$\begin{array}{ll}3.4 .1 & \text { Statistical Distribution } \\ 3.4 .1 .1 & 36\end{array}$

3.4.1.1 Life Cycle Analysis $\quad 36$

3.4.1.2 Use Case Analysis 38

$\begin{array}{lll}3.4 .1 .3 & \text { Overall Remarks } & 39\end{array}$

$\begin{array}{ll}3.4 .2 \text { Historical Development } & 39\end{array}$

3.4.2.1 Absolute Totals Over Time $\quad 39$

3.4.2.2 Percentage of Totals Over Time 41

3.4.3 Summary of Findings 42

3.5 Critical Analysis of Visualization Techniques 43

3.5.1 Clash Detection 44

3.5.1.1 Visualizations $\quad 45$

$\begin{array}{ll}3.5 .2 & \text { Task Scheduling }\end{array}$

3.5.2.1 Visualizations 49

3.5.3 Progress Tracking 54

3.5.3.1 Visualizations $\quad 54$

$\begin{array}{ll}3.5 .4 & \text { Energy Analysis }\end{array}$

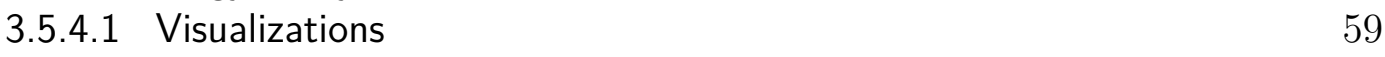

3.5.5 Maintenance Management 63

3.5.5.1 Visualizations $\quad 64$

$\begin{array}{ll}\text { 3.5.6 Summary of Findings } & 68\end{array}$

$\begin{array}{lll}\text { 3.6 Proposed Design Guidelines } & 70\end{array}$

4 CasCADe Visualization System $\quad \mathbf{7 4}$

4.1 Related Work $\quad 75$

4.1.1 Work Space, Site Utilization and Safety 75

4.1.2 Coordinated Multiple Views 76

4.1.3 Abstract Graphical Overlays $\quad 76$

$\begin{array}{lll}4.1 .4 & \text { Exploded Views } & 76\end{array}$

$\begin{array}{lll}\text { 4.1.5 Space-Time Cube } & 77\end{array}$ 
$\begin{array}{lll}\text { 4.1.6 Limitations of Previous Approaches } & 77\end{array}$

$\begin{array}{lll}4.2 & \text { Designing CasCADe } & 77\end{array}$

4.2.1 User-Centered Methodology 78

$\begin{array}{lll}\text { 4.2.2 Task and Data Requirements } & 78\end{array}$

$\begin{array}{lll}4.3 & \text { Proposed Visualization Framework } & 80\end{array}$

$\begin{array}{lll}\text { 4.3.1 Background Concepts } & 80\end{array}$

4.3.2 Cascading Visualization 81

4.4 Analytical Features of the CasCADe System 82

4.4.1 Overview Schedule 82

$\begin{array}{lll}\text { 4.4.2 Prioritize Tasks } & 84\end{array}$

4.4.3 Examine Metadata 86

$\begin{array}{lll}4.4 .4 & \text { Inspect Relationships } & 87\end{array}$

$\begin{array}{lll}4.4 .5 & \text { Plan Site Layout } & 89\end{array}$

$\begin{array}{lll}4.5 & \text { Implementation } & 89\end{array}$

$\begin{array}{ll}4.6 & \text { User Evaluation }\end{array}$

$\begin{array}{lll}\text { 4.6.1 Schedule Uncertainties } & 91\end{array}$

$\begin{array}{ll}\text { 4.6.2 Workspace Conflicts } & 92\end{array}$

4.6.3 Custom Risk Metric $\quad 92$

$\begin{array}{lll}4.7 & \text { User Feedback } & 93\end{array}$

$5 \quad$ Future Research Directions $\quad 95$

$\begin{array}{llr}6 & \text { Conclusions } & 97\end{array}$

$\begin{array}{lr}\text { Bibliography } & 98\end{array}$ 


\section{List of figures}

Figure 1.1 The current work seeks to fill an important research gap between Visualization (VIS) and Building Information Modeling (BIM).

Figure 3.1 Systematic research method employed in the current literature review.

Figure 3.2 List of search keywords (leaf nodes) arranged by the chosen criteria to include or exclude previous work.

Figure 3.3 Heat map and histograms showing the statistical distribution of visualization applications in BIM. The horizontal axis contains Life Cycle Phases from Subsection 3.3.1 and the vertical axis follows the Use Cases from Subsection 3.3.2. Each heat map cell indicates its corresponding number of visualization applications. Darker cells indicate higher quantities.

Figure 3.4 Total number of visualization applications in BIM over the years.

Figure 3.5 Percentage of total number of visualization applications in BIM over the years.

Figure 3.6 Visualization techniques (right) applied to the main BIM use cases. Similar techniques are organized by common themes (middle) within each view type (left).

Figure 3.7 Correlations among Views, Visualizations, Marks, Channels, and Information in "Clash Detection". Flow widths indicate frequency of use and colors distinguish visualization techniques. 46

Figure 3.8 Examples of the top 4 visualizations in "Clash Detection". 47

Figure 3.9 Correlations among Views, Visualizations, Marks, Channels, and Information in "Task Scheduling". Flow widths indicate frequency of use and colors distinguish visualization techniques.

Figure 3.10 Examples of the top 4 visualizations in "Task Scheduling". 51

Figure 3.11 Correlations among Views, Visualizations, Marks, Channels, and Information in "Progress Tracking". Flow widths indicate frequency of use and colors distinguish visualization techniques.

Figure 3.12 Examples of the top 4 visualizations in "Progress Tracking". 56

Figure 3.13 Example of Time-Distance Diagram for tracking progress of construction works [Elbeltagi \& Dawood, 2011].

Figure 3.14 Correlations among Views, Visualizations, Marks, Channels, and Information in "Energy Analysis". Flow widths indicate frequency of use and colors distinguish visualization techniques.

Figure 3.15 Examples of the top 4 visualizations in "Energy Analysis". 61 
Figure 3.16 Correlations among Views, Visualizations, Marks, Channels, and Information in "Maintenance Management". Flow widths indicate frequency of use and colors distinguish visualization techniques.

Figure 3.17 Examples of the top 4 visualizations in "Maintenance Management".

Figure 3.18 Ranking of all visualization techniques (right) employed across the 5 main BIM use cases (left).

Figure 4.1 CasCADe's unique 4D visualization combines the intuitive task sequencing from PERT/Gantt charts with the spatial awareness conveyed by 3D CAD models to bring forth problems and inconsistencies in engineering construction schedules.

Figure 4.2 The proposed cascading visualization enables an overview of the entire schedule (a) and highlights future construction works (b).

Figure 4.3 Sequential snapshots of CasCADe's 4D animation.

Figure 4.4 Techniques for identifying and focusing on activities of interest: (a) color-coding highlights schedule discrepancies; (b) focus+context shortcuts use transparency to bring forth occluded geometries.

Figure 4.5 Examples of visual tools for detailed task analysis: (a) horizontal lines distinguish nearby finish dates; (b) overlay texts present contextual information and vertical lines display assembly locations; (c) linked views convey additional schedule information while green/blue highlights and links identify predecessor/successor relationships; (d) semi-transparent volumes indicate task durations, occupied areas and workspace conflicts (in red).

Figure 4.6 CasCADe made evident schedule uncertainties: (a) many parallel assemblies with unusually high durations; (b) these assemblies (blue bars) would compete for resources with the critical path (in red).

Figure 4.7 Example of workspace conflict found by the engineering collaborators: (a) simultaneous scheduling of two vessels is made evident by overlapping geometries and volumes (in red); (b) safety risks would prevent execution of these activities on floors above one another.

Figure 4.8 The collaborators used CasCADe's customized metric to color-code high-priority activities: (a) heat exchanger in red with unusually long duration; (b) workspace conflict between the process plant's stack (red) and its two adjacent furnaces (green). 


\section{List of tables}

Table 3.1 Overview of visualization applications in "Clash Detection". Rows are ordered by frequency of use.

Table 3.2 Overview of visualization applications in "Task Scheduling". Rows are ordered by frequency of use.

Table 3.3 Overview of visualization applications in "Progress Tracking". Rows are ordered by frequency of use.

Table 3.4 Overview of visualization applications in "Energy Analysis". Rows are ordered by frequency of use.

Table 3.5 Overview of visualization applications in "Maintenance Management". Rows are ordered by frequency of use.

Table 3.6 Proposed design guidelines based on the visualization issues observed in current BIM applications.

Table 4.1 Design requirements for 4D analysis of construction schedules. White dots (o) indicate items addressed separately by related work. Data Type (DT): category (C), quantity (Q) or relationship (R). Physical Support (PS): individual components (IC) or spatial region (SR). Time Dependence (TD): static (S) or dynamic (D).

Table 4.2 Visual analysis functions implemented in CasCADe, their motivating use cases and related research from the visualization community. Items in italic indicate repeated occurrences of the same function. 


\title{
List of abreviations
}

\author{
AEC - Architecture, Engineering and Construction \\ BIM - Building Information Modeling \\ CAD - Computer-Aided Design \\ CII - Construction Industry Institute \\ COBie - Construction Operations Building Information Exchange \\ IPD - Integrated Project Delivery \\ PERT - Program Evaluation and Review Technique \\ VIS $\quad-$ Visualization
}


"Nobody made a greater mistake than he who did nothing because he could only do a little."

- Edmund Burke, A Vindication of Natural Society (1756). 


\section{1 \\ Introduction}

Capital construction projects are large-scale engineering enterprises in terms of costs and durations. Typical investments range from hundreds of thousands to millions of dollars. Design and construction can last several years, while operation and maintenance span decades. Examples include modern buildings, city infrastructure, and Oil \& Gas process plants. Their size and complexity demand tight coordination between diverse engineering experts (e.g. structural, mechanical, electrical) and stakeholders (e.g. owners, contractors, suppliers).

To overcome these challenges, the Architecture, Engineering and Construction (AEC) industry is actively researching methods and tools based on Building Information Modeling (BIM) [Eastman et al., 2011; Hardin \& McCool, 2015]. BIM employs 3D CAD models as a central database for all physical, functional, and life-cycle information of a facility [BuildingSMART, 2017]. This integrated environment enables automated data analysis and virtual simulations that improve quality of designs and work plans. Engineers benefit from faster access to higher quality information that reduces uncertainties and improves productivity.

From its inception, BIM has been used for design checking and virtual construction planning [Collier \& Fischer, 1995; Fischer \& Aalami, 1996; McKinney et al., 1996]. Over time, it has evolved to encompass diverse aspects of construction projects, such as: work safety [Zhou et al., 2012b], asset management [Love et al., 2013], and environmental sustainability [Azhar et al., 2011; Schlueter \& Thesseling, 2009; Wong \& Zhou, 2015]. Lean production management can also take advantage of the integrated information in Building Information Models [Sacks et al., 2010; Tezel \& Aziz, 2017]. By adopting open data standards [Laakso \& Kiviniemi, 2012], BIM creates a shared knowledge resource that increases collaboration among owners, contractors and suppliers [Grilo \& Jardim-Goncalves, 2010; Sebastian, 2011; Taylor \& Bernstein, 2009]. 


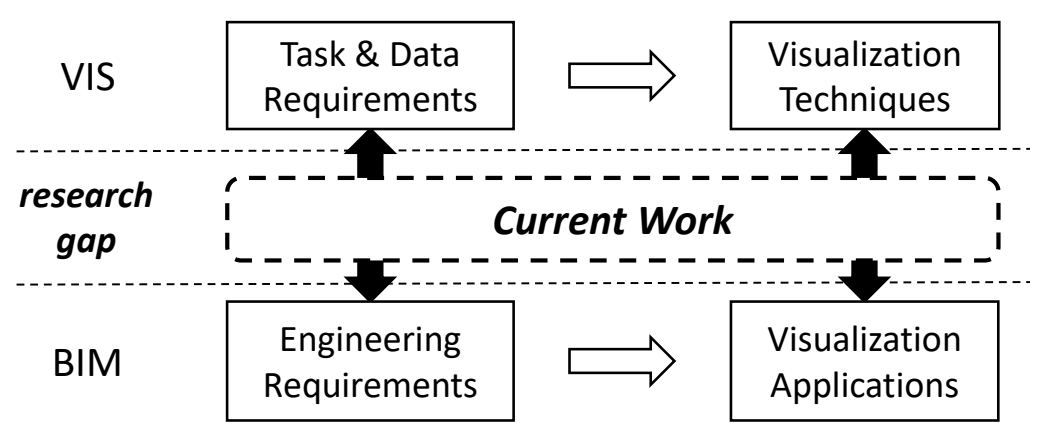

Figure 1.1: The current work seeks to fill an important research gap between Visualization (VIS) and Building Information Modeling (BIM).

In recent years, research have investigated the benefits and limitations of Building Information Modeling. Real-world case studies have shown its potential to reduce project costs and durations [Barlish \& Sullivan, 2012; Bryde et al., 2013]. For these reasons, governments around the world are encouraging the use of BIM in public enterprises [Gurevich et al., 2017; Khosrowshahi \& Arayici, 2012; Porwal \& Hewage, 2013]. Meanwhile, leading experts have developed guidelines and frameworks to accelerate its implementation [Arayici et al., 2011; Cerovsek, 2011; Jung \& Joo, 2011; Love et al., 2014; Smith \& Tardiff, 2009; Succar, 2009]. Despite these efforts, Building Information Modeling is yet to be widely adopted in the construction industry [Azhar, 2011; Gu \& London, 2010; Howell \& Batcheler, 2003; Miettinen \& Paavola, 2014]. Typical barriers are high risks/costs of organizational change [Eadie et al., 2014; Ghaffarianhoseini et al., 2017; Won et al., 2013] and deficiencies in existing visual analysis tools [Aibinu \& Venkatesh, 2014; Heesom \& Mahdjoubi, 2004; Howard \& Björk, 2008; Tse et al., 2005].

BIM systems face a major visualization challenge: how to best display relevant information for different analyses throughout a facility's life cycle? 3D CAD representations often struggle with perceptual issues related to visual clutter and occlusion. BIM further enriches these virtual designs with diverse attributes and relationships among individual components and spatial regions. The resulting information complexity calls upon innovative techniques for effective visual analysis and exploration. However, this subject still remains largely uncharted by both BIM and VIS studies (see Figure 1.1).

The present thesis seeks to bridge this gap in order to improve management of large-scale engineering projects. We do so through both theoretical and practical approaches. First, Chapter 2 presents an overview of the main challenges faced by the construction industry worldwide. Afterwards, Chapter 3 describes a systematic literature review on the current state of information 
visualization in BIM research. The study analyzes in detail the techniques employed in diverse use cases across a construction project. We consolidate these findings in a set of design guidelines for future research in BIM.

The second part of the thesis builds upon these recommendations to develop CasCADe: a novel 4D construction planning system (Chapter 4). Its innovative visualization framework was designed to overcome many limitations of previous work. Engineering collaborators evaluated the software against realworld construction plans of an Oil \& Gas industrial plant. We describe how its analytical features made evident schedule uncertainties, workspace conflicts and other constructability issues. Finally, Chapter 5 highlights future research directions based on the insights derived throughout our work.

This thesis contributes to BIM research with important visualization guidelines for future applications. It also contributes to VIS research by raising awareness to interesting challenges in a increasingly relevant engineering domain. We hope our theoretical and practical findings promote greater cooperation between practitioners in both fields. 


\section{2}

\section{Main Challenges in the Construction Industry}

The majority of large-scale construction projects suffer from cost overruns and failure to meet deadlines [Aibinu \& Jagboro, 2002; Kaliba et al., 2009; Koushki et al., 2005]. For decades, research have tried to identify the main success factors of these high-cost and high-risk enterprises [Alzahrani \& Emsley, 2013; Ashley et al., 1987; Chan et al., 2004; Chua \& Kog, 1999]. At the same time, experts have reported on many unsolved problems related to productivity, quality, safety, and others. The following paragraphs summarize selected publications from around the world organized around these issues.

Costs. In 1988, a survey among Nigerian professionals found three main reasons for cost escalation: (1) inadequate resource management, (2) poor relationship with subcontractors and suppliers, and (3) price fluctuation of materials [Okpala \& Aniekwu, 1988]. Two decades later, a study by the US National Institute of Standards and Technology found a waste of $\$ 15.8$ billion annually due to inefficient work processes and systems interoperability [Gallaher et al., 2004]. Results like these have prompted researchers to try and model cost escalation using stochastic simulation techniques [Touran \& Lopez, 2006]. Nevertheless, a recent analysis across 57 countries found that, from 401 electricity infrastructure projects, $75 \%$ suffered an average of $66 \%$ overrun on their original budget [Sovacool et al., 2014].

Delays. For almost two decades, surveys in the Middle East have highlighted many causes of construction project delays: resource shortages, company financial difficulties, deficiencies in design work, frequent change orders, and poor supply chain infrastructure [Assaf \& Al-Hejji, 2006; Faridi \& El-Sayegh, 2006; Al-Momani, 2000; Odeh \& Battaineh, 2002; Sweis et al., 2008]. Several studies in Southeast Asia found similar delay factors related to inefficient work coordination, improper planning, lack of consistent scope, and substandard contract relations [Doloi et al., 2012; Kumaraswamy \& Chan, 1998; Ogunlana et al., 1996; Sambasivan \& Soon, 2007]. The Nigerian construction industry also reported delays related to shortages of materials, poor contract management, and inadequate resource management [Aibinu \& Odeyinka, 2006]. 
Productivity. Since 2004, research in the UK identified the need to develop more comprehensive performance measurement frameworks in the construction industry [Bassioni et al., 2004]. In Malaysian residential projects, the most important factors that impact productivity are related to material shortages, frequent change orders, late designs, and inadequate site planning [Abdul Kadir et al., 2005]. A survey in Uganda identified similar problems of lack of tools/equipment, poor communication, inaccurate drawings, and poor construction methods [Alinaitwe et al., 2007]. Another recent work highlighted issues such as lack of design clarity, excessive change orders during execution, and lack of coordination among design disciplines [Jarkas \& Bitar, 2014].

Quality and Rework. Twenty years ago, a case study found that the lack of attention to quality in construction increases rework amounting up to $12.4 \%$ of total project costs [Love et al., 1999]. In the Japanese construction industry, main causes of poor design quality are related to insufficient budget and lack of constructability analysis [Andi \& Minato, 2003]. Later analysis of defects in Australian residential construction revealed that one house in eight had quality issues, and that the cost of rectification was $4 \%$ of overall contract value [Mills et al., 2009]. Around the same time, research identified frequent change orders and errors/omissions in contracts as the primary causes of rework [Love \& Li, 2000]. A quantitative study in the Swedish construction industry revealed costs of rework at around $4.4 \%$ of overall budget, increasing project durations by $7.1 \%$ [Josephson et al., 2002]. Another survey among 161 Australian projects showed that, contrary to expectation, rework costs do not differ relative to project type [Love, 2002]. The same authors later developed an alternative procurement model to reduce rework in construction projects [Love et al., 2004]. More recent research analyzed data from 359 construction projects in the Construction Industry Institute (CII) and found major causes of rework related to design errors, owner and design changes, and construction errors [Hwang et al., 2009].

Safety and Risks. A study has shown that the total costs of accidents had risen from $6.5 \%$ of total costs in 1979 to somewhere between $7.9 \%$ and $15.0 \%$ of the total costs in 1996 [Everett \& Frank, 1996]. Ten years later, another survey estimated total costs of fatal and nonfatal injuries at $\$ 11.5$ billion in 2002, amounting to $15 \%$ of the costs for all private industry [Waehrer et al., 2007]. Research highlighted that contractors show more willingness to accept risks that are contractual and legal-related rather than other types, such as safety [Kartam \& Kartam, 2001]. Economic risks range from inflation to shortage in material and labor supply, while owner risks include unrealistic schedules and improper design changes [El-Sayegh, 2008]. 
Stakeholder Relations. Construction claims and disputes have been found to be major factors in cost and time overruns [Semple et al., 1994]. Research demonstrated that transactional costs from conflict resolution can account for a large portion of the total contract value [Gebken \& Gibson, 2006]. A study in Oman has shown that frequent change orders can also be a source of legal dispute [Alnuaimi et al., 2010]. Interviews with construction firms in Hong Kong confirmed that cooperation is a major factor for construction project success [Phua \& Rowlinson, 2004]. Collaboration frameworks between governments and private industry can improve procurement processes while promoting a stable political, social, and economical environment [Zhang, 2005]. Another recent work demonstrated that long-term supply chain collaboration and partnering help to solve construction performance problems [Meng, 2012].

Sustainability. In recent years, the quest for sustainability has put the construction industry under immense pressure from governments and general public [Adetunji et al., 2003]. In spite of this, very few of the major companies in the UK positively embrace these ideas [Myers, 2005]. Analytical decision models have been proposed to automate sustainability appraisal in infrastructure projects [Ugwu \& Haupt, 2007]. A similar line of work applies Life-Cycle Assessment methodology to evaluate the impact of chosen materials in the whole built environment [Ortiz et al., 2009]. Another research demonstrated that strategic metrics can be integrated into a framework for benchmarking construction sustainability [Presley \& Meade, 2010]. A recent assessment in the US highlighted the importance of considering the whole supply chain when evaluating environmental, economical, and social sustainability metrics [Kucukvar \& Tatari, 2013].

As demonstrated by these research, effective management of large-scale construction projects remains a challenging issue. It is in this context that engineers have turned to information technology to improve designs and work processes. Building Information Modeling consists of a paradigm shift in using intelligent 3D CAD models as an integrated knowledge base of a facility. Faced with this scenario, companies around the world are scrambling to better understand the potential benefits of BIM and how to best realize them. We hope this thesis provides valuable guidelines for researchers and practictioners in order to increase the success of BIM in the field. 


\section{3}

\section{Systematic Literature Review}

The present chapter describes a systematic review of information visualization techniques in practical applications of Building Information Modeling. Its goal is to guide future research in implementing appropriate visualization techniques for different BIM use cases. This study was designed to answer the following research questions:

1. What are the main use cases of BIM that employ visualization?

2. What are the project life-cycle phases where each use case applies?

3. What kinds of information are required by each use case?

4. What are the current methods for visualizing this information?

5. What are the pros and cons of the current visualization methods?

6. Which other visualization methods could have been employed?

We have organized the results and contributions of this literature review in four sections. We first propose a conceptual framework to classify previous BIM research (Section 3.3). We use this framework to identify the main application areas of visualization across a facility's life cycle (Section 3.4). Afterwards, we conduct a critical analysis of the visualization techniques employed in these selected use cases (Section 3.5). Based on this discussion, we propose a set of design guidelines for improving analytical features of BIM systems (Section 3.6).

\section{1}

\section{Related Work}

Previous studies have focused either on understanding BIM adoption in the industry or on evaluating some of its visualization challenges. The former typically employed surveys to enumerate main BIM use cases across life cycle phases. The latter typically analyzed BIM visualization systems and eventually proposed alternatives to improve on specific applications. The current thesis builds upon these previous results to conduct a rigorous categorization of 
visualization in BIM. To the best of our knowledge, no previous work has assembled such a comprehensive analysis.

\subsection{1}

\section{BIM Use Cases}

Previous research have extensively analyzed the adoption of Building Information Modeling across a facility's life cycle. Hartmann et al. [2008] studied 26 case studies of 3D/4D model applications on construction projects. Most of these enterprises used BIM for only one of these analyses: design review, cost estimating or construction planning. Two years later, Kreider et al. [2010] found that design coordination and review were perceived as both the most beneficial and the most frequently used applications. Around the same time, Becerik-Gerber \& Rice [2010] conducted an online survey in the US construction industry. The study concluded that BIM is more suitable for larger projects with no particular bias to one type of building over another. The technology was mainly used for design and clash detection with almost no adoption in sustainability analysis or facility management.

Becerik-Gerber \& Kensek [2010] combined online surveys with student workshops to identify major BIM research topics. Top choices included BIM for construction management and BIM for sustainable design, with lower interest in BIM for facility management. Park et al. [2011] confirmed this trend with a statistical analysis of how construction engineers perceived the effectiveness of 3D/4D CAD. Keeping within this theme, Becerik-Gerber et al. [2012] conducted surveys and interviews to assess the current status of BIM implementations in facility management. The authors found that organizations had already started implementing BIM for locating components, real-time data access, and checking maintainability. However, Eadie et al. [2013] found that over $70 \%$ of construction companies did not provide a 3D model and COBie dataset [East, 2007] at the conclusion of a project.

A review of more than 180 BIM articles in existing buildings was conducted by Volk et al. [2014]. The study highlighted many unexplored applications of facility management: renovations and deconstruction planning, remote monitoring, and sustainability analysis such as reuse/recycling and emissions. In the following year, Azhar et al. [2015] overviewed BIM case studies focusing on life-cycle applications. Main uses involved comparison of design options, construction scheduling, and maintenance management. Farnsworth et al. [2015] interviewed 18 contracting firms and identified main BIM applications in clash detection, constructability analysis, and work scheduling. In the same period, Yalcinkaya \& Singh [2015] applied Latent Semantic Analysis 
(LSA) to rank main BIM uses over 975 academic papers. The algorithm found emerging areas related to energy management, safety management, code checking, and facility management. Meanwhile, Yalcinkaya \& Singh [2015] found only incipient adoption of BIM in infrastructure industry, mainly in the design phase.

Gledson \& Greenwood [2016] surveyed the extent of BIM adoption in the UK. Their work highlighted main applications towards construction planning (site layout planning, field work simulation, construction scheduling, and workspace conflict analysis). Meanwhile, Gerges et al. [2017] showed that BIM implementation in the Middle East focused more on design coordination and clash analysis. Another review by Guo et al. [2017] studied Building Information Modeling for construction safety management. The authors identified benefits related to job hazard area identification, safety training, and on-site safety monitoring. A recent work by Gholizadeh et al. [2018] studied the diffusion patterns of BIM in the US construction industry. The three most widely adopted functions were 3D visualization, clash detection, and constructability analysis. The least adopted functions were code validation, material tracking, facility management, and energy analysis. Results pointed towards facility management as having greater potential for adoption in the coming years.

\subsection{2}

\section{Visualization in BIM}

Another line of research has been studying the effectiveness of visualization in Building Information Modeling. Early works by McKinney et al. [1998] and Aouad [1999] praised the benefits of 4D animation to highlight inconsistencies in construction plans. A year later, Pilgrim et al. [2000] conducted a user evaluation of new visualization techniques for building thermal analysis. The study found that the 3D representation of the building combined with color coding improved upon the time taken to locate and report analytical results with increased accuracy. Later, research by Boton et al. [2013], Kubicki et al. [2007], and Kuo et al. [2011] reported on the benefits of a coordinatedmultiple-view interface for integrated problem management.

Chang et al. [2009] involved 58 users in a systematic procedure to determine the ideal color scheme for a 4D model. The authors concluded that a diverging-sequential color scheme is ideal for representing task progress and delays. They also recommended against traditional 4D animations that changed geometry visibility since it hindered the users' judgment and lowered their understanding of the construction sequence. A few years later, Castronovo et al. [2014] interviewed professionals regarding current 4D visualization methods. 
The study indicated several visualization guidelines: use adapted views for each actor, use color schemes for 3D elements to dictate the activity type and progression, use shadows and luminance difference to distinguish highlighted elements, and use transparency to distinguish importance. In a different approach, Tory et al. [2013] proposed a new schedule visualization tool that augmented traditional Gantt charts and network diagrams. It implemented several graphical representations and highlights for constraints, task dependencies, and differences among multiple schedules. From the observed improvements in schedule analysis tasks, the authors suggested implementing similar techniques in 4D CAD visualization to combine spatial and non-spatial data.

Studies have also analyzed the perceived benefits of visualization in industry practice. Nielsen \& Erdogan [2004] surveyed the use of visualization in construction companies. They found that visualization improves comprehension and clarifies construction methods. Engineers preferred 3D CAD drawings and animations over 2D representations. In the following year, Bouchlaghem et al. [2005] reviewed three research projects that made use of visualization in design and construction. During conceptual design, visualization helped designers to work collaboratively and to communicate ideas more efficiently. The authors concluded that visualization can bridge the gap between designers and site teams in identifying constructability problems.

A more recent study by Golparvar-Fard et al. [2013] identified many remaining challenges related to improving analytical features of existing BIM systems. Around the same time, Yang \& Ergan [2014] focused on evaluating various visualization techniques for facility operators. This user study found that visualization improved the accuracy and efficiency of facility operators' decisions when compared to tabular interfaces. The authors recommended that 3D-based interfaces should provide easy means of navigating and changing viewpoints so that users unfamiliar with a facility don't get disoriented. Another industry survey was conducted by Leite et al. [2016] to assess challenges in visualization, information modeling, and simulation. Results indicated that visualization was mainly used for construction scheduling, progress monitoring, and productivity management. Future directions included visual decision-making tools based on real-time data and higher level of automation in BIM analysis systems. 


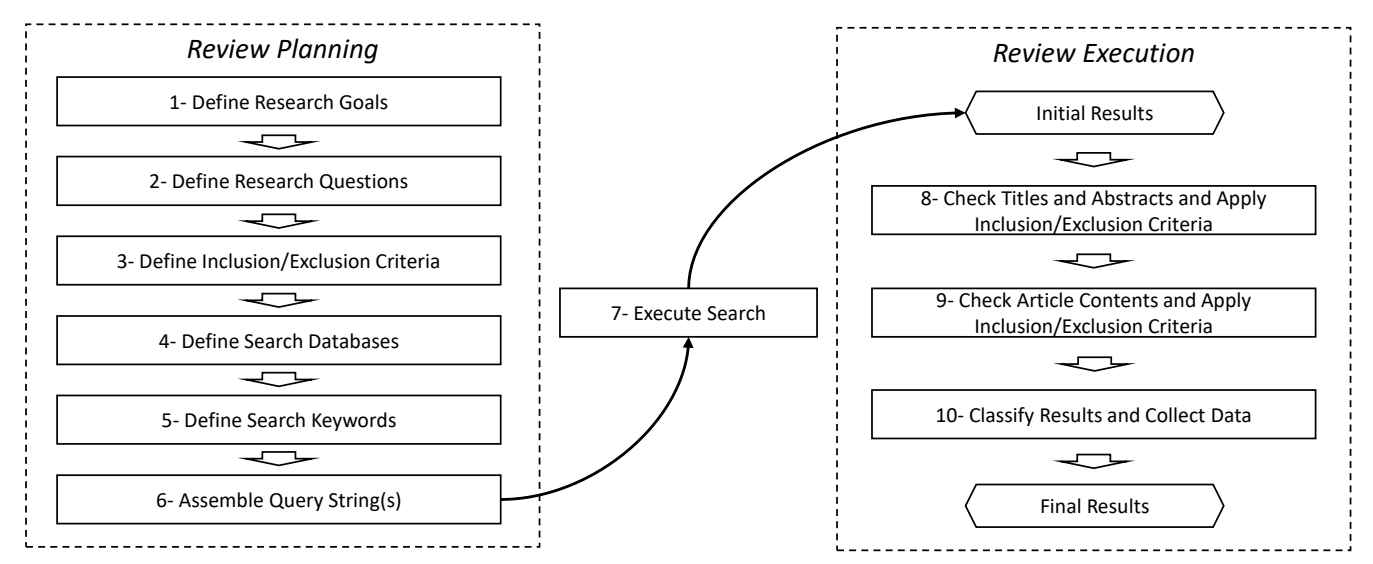

Figure 3.1: Systematic research method employed in the current literature review.

\section{2}

\section{Systematic Review Methodology}

Systematic literature reviews have been successfully employed in numerous areas of science [Budgen \& Brereton, 2006; Isenberg et al., 2013; Petticrew \& Roberts, 2008; Sterne et al., 2011]. They provide a means to present a fair evaluation of a research topic by using a trustworthy, rigorous, and auditable methodology [Kitchenham, 2004]. We have employed this scheme to maximize the reach of our analysis and also to enable other practitioners to reproduce our findings in future work. As shown in Figure 3.1, the systematic review conducted in this thesis consists of 10 main steps. Steps 6 through 10 were continually refined among the 5 review participants until they agreed on their results.

The beginning of the current chapter already presented the main goals and research questions of our literature review. From them we devised the following criteria for selecting primary studies:

- Full papers.

- Academic research.

- Published in peer-reviewed international journals.

- Engineering and Computer Science subject areas.

- Written in English.

- Practical applications of BIM-based visualization systems and methods.

- Papers must present visual evidence of employed BIM-based visualizations (i.e. at least 1 figure where BIM information is graphically visualized). 
The last two criteria cannot be automatically resolved by the search engine and require manual inspection of individual articles. Since the review seeks to analyze high-quality reports of practical applications of BIM, we have chosen to exclude the following types of articles:

- Research focused on cultural heritage or historic buildings.

- Research focused on education or training.

- Short papers.

- Conceptual frameworks or methodologies in BIM.

- Technical descriptions of BIM-based visualization systems and methods with no practical application.

- Methods and tools to create, update or exchange BIM models.

- Algorithms to enable or improve rendering of BIM models in desktop, web, mobile, and immersive environments.

- Surveys on application areas, best practices or technology adoption in the construction industry.

Once again, the last five criteria require manual inspection of each article. Given these inclusion and exclusion criteria, we have chosen to conduct the search for articles using the Scopus digital library [Burnham, 2006]. It not only features a powerful search mechanism but also covers a wide journal range, especially in Engineering fields [Falagas et al., 2008; Moya-Anegón et al., 2007].

Moving on to Step 5, we selected the search keywords indicated in Figure 3.2. The keywords were derived from the themes of Visualization, BIM, Construction Industry, and Practical Application. Additional keywords were selected to try and automatically exclude unwanted themes, such as: Historical BIM and Education. The final query string was then assembled: "TITLEABS-KEY((visual* OR 4d OR 5d OR 6d OR 7d OR 8d OR nd) AND (cad OR bim) AND (building OR construction OR facility) AND ("case stud*" OR implement* OR appl* OR evaluat* OR valid*) AND NOT (heritage OR "historic* building" OR "monument" OR student OR curricul* OR teach* OR education)) AND ( LIMIT-TO ( SRCTYPE,"p " ) OR LIMIT-TO ( SRCTYPE, j " ) ) AND ( LIMIT-TO ( SUBJAREA,"ENGI " ) OR LIMIT-TO ( SUBJAREA,"COMP " ) ) AND ( LIMIT-TO ( DOCTYPE,"ar " ) ) AND ( LIMIT-TO ( LANGUAGE,"English " ) )". 


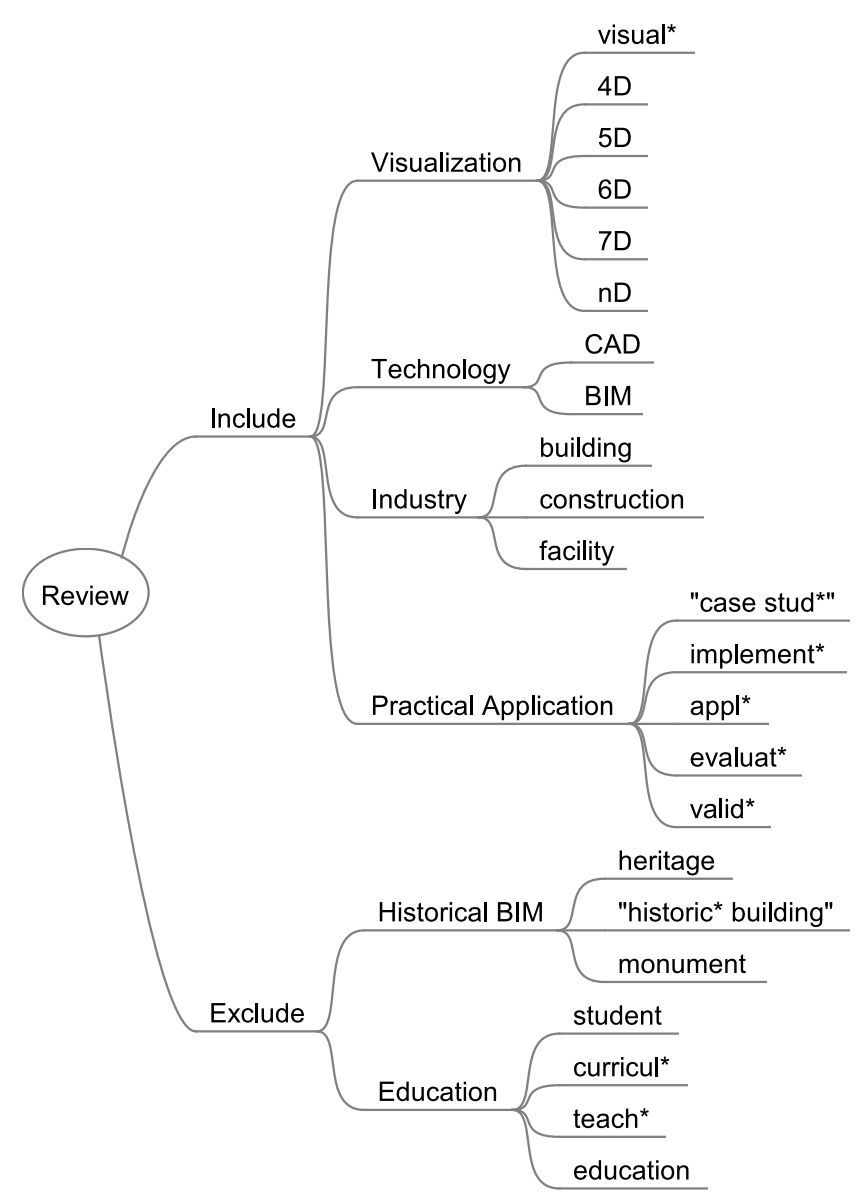

Figure 3.2: List of search keywords (leaf nodes) arranged by the chosen criteria to include or exclude previous work.

The search procedure was last conducted on January 13 of 2018 and returned 372 articles. We imported these references to Mendeley v1.17.12 [Elsevier, 2018] and each of the 5 reviewers was assigned a set of articles for further analysis. The first step was to check the titles and abstracts to perform initial article selection based on inclusion/exclusion criteria. This step reduced the dataset to 173 articles. In the second step, the reviewers obtained a copy of each document and again checked for all inclusion/exclusion criteria. The dataset was further reduced to 140 articles. Finally, each reviewer applied the proposed classification framework over these previous work. Results were cross-checked until all participants agreed on the different labels and categories for each individual article.

\section{3}

\section{Classification Framework}

Adequate design of visualization systems requires a clear understanding of task and data requirements of target users. Therefore, we propose a conceptual framework to classify visualization research in Building Information 
Modeling. The framework consists of 4 taxonomies designed to make evident context and motivation of previous solutions as well as to provide common ground for comparing their visualization techniques. The following subsections detail each of these classification schemes.

\subsection{1}

\section{Life Cycle Phases}

The first categorization identifies the phases of a facility's life cycle. The same research article may employ one or more visualization solutions across many stages of a construction project. We follow the organization of 3 main phases, with 3 sub-phases each, first proposed by Succar [2009]:

\section{Design}

- Conceptualization, Programming and Cost Planning: initial draft of construction scope for bidding.

- Architectural, Structural and Systems Design: main designs are produced by various engineering disciplines.

- Analysis, Detailing, Coordination and Specification: integration and verification of produced designs.

\section{Construction}

- Construction Planning and Construction Detailing: detailed planning of activities to be conducted in the field.

- Construction, Manufacturing and Procurement: components are purchased, fabricated, and assembled in the field.

- Commissioning, As-Built and Handover: testing of assembled systems and certification for facility operation.

\section{Operation}

- Occupancy and Operations: monitoring of facility use and systems performance.

- Asset Management and Facility Maintenance: life expectancy and maintenance of components.

- Decommissioning and Major Re-Programming: preparing steps for renovations or demolition. 


\subsection{2}

\section{Use Cases}

Building Information Modeling is used for diverse analyses throughout a facility's life cycle. We have assembled 35 different use cases from previous work (Section 3.1) to specify the task and data requirements for BIMbased visualizations. We propose organizing these use cases around themes that identify common goals and typical implementation synergies. Some of these themes naturally coincide with life cycle phases, while others represent more general analysis that can be performed across the entire project duration.

\section{Design Review}

- Requirements Analysis: verification if the design meets the defined engineering specifications.

- Structural and Mechanical Analysis: numerical computations to validate the facility's physical integrity.

- Regulatory Compliance Checking: search for violations of building codes and other technical/legal regulations.

- Clash Detection: identification and correction of spatial interferences among facility components.

- Change Management: tracking of sources and consequences of changes in design.

- Constructability Analysis: assessment of the ease of constructing a given design.

\section{Work Planning}

- Site Layout Planning: spatial organization and coordination of workforce, materials, machinery, and temporary structures.

- Quantity Take Off: computation of materials totals for procurement and fabrication.

- Risk Management: analysis of safety, quality, schedule, cost, environmental, and social factors that may prevent successful project execution.

- Cost Management: budgeting and tracking of expenses related to activities, resources, and others.

- Task Scheduling: estimation of duration and sequencing of activities in time.

- Workspace Conflict Analysis: identification of inconsistencies in work plans due to physical overlap of activities. 
- Field Work Simulation: detailed animations and numerical simulations of construction sequences, equipment operations, and resource movement.

\section{Work Execution}

- Digital Fabrication: use of geometric data and material specifications for automated fabrication of components.

- Resource Management: tracking of available, allocated and free workforce, materials, machinery, and temporary structures.

- Field Management: detailed coordination and live feedback of work in the field.

- Positioning and Navigation: use of digital drawings by field workers to assist in locating areas and components of interest.

- Progress Tracking: monitoring of task execution status and completion.

- Productivity Monitoring: use of metrics and indices to compute and compare actual productivity with original benchmarks.

- Quality Management: inspection and verification of activity results according to original requirements and tracking of change and rework orders.

- Procurement and Expediting: use of engineering specifications for the purchase of goods and tracking their shipping.

- Logistics Management: planning and control of storage areas and routes for the movement of workforce, materials, machinery, and temporary structures.

\section{Sustainability Analysis}

- Lighting Analysis: degree of illumination within an area of the facility due to incoming natural light and internal lighting fixtures.

- Thermal Analysis: amount of heat absorbed and emitted by individual components as well as internal/external areas.

- Ventilation Analysis: air circulation, speed, and movement around and across internal areas a facility.

- Energy Analysis: amount of electrical energy produced and consumed by the building's installations.

- Emission Analysis: environmental impact in terms of water, air, soil, thermal, radioactive, noise, light, and waste pollution.

- Natural Resource Use: assessment of how much natural resources are necessary to conduct a certain activity or to operate the facility. 


\section{Facility Management}

- Remote Operation: monitoring and electronic control of a facility's equipment and automation systems.

- Maintenance Management: assurance of component's correct functioning and physical integrity through periodic inspection and maintenance plans.

- Damage Assessment: evaluation of structural resistance and degree of failure in the face of natural and artificial sources of damage.

- Emergency Management: simulation of disaster scenarios and analysis of evacuation and contingency plans.

- Security Management: analysis of a facility's ability to isolate and keep safe its occupants and systems from outside threats.

- Signage Placement: evaluation of the best locations to place signs and markers to inform occupants and improve circulation.

- Space Management: control of the ownership and availability of physical spaces as well as their number of occupants.

\subsection{3}

\section{Information and Data Types}

Research have long identified that certain types of visualizations are more adequate for certain types of information [Tufte, 1983; Ware, 2004]. In addition, different kinds of analysis require different sets of data of varying importance [Bertini et al., 2011; Shneiderman, 1996]. The sum of these requirements motivates alternative visual representations that, when put together, may truly aid in understanding and exploring datasets [Borkin et al., 2013; Keim, 2002; Keim et al., 2006]. It is therefore necessary to categorize the available engineering and project information in Building Information Models to determine what are the more suitable visualizations.

We have assembled 160 information classified by six categorical, quantitative and relational data types: nominal, ordinal, binary, discrete, continuous, and relational. We propose a hierarchical taxonomy to organize these information, extending the traditional BIM "information dimensions" [Ding et al., 2014]. Common dimensions in the literature include Schedule (4D), Costs (5D), Sustainability (6D), and Facility Management (7D). We propose six additional dimensions: Risks (8D), Resource (9D), Supply Chain (10D), Security (11D), Mechanical Analysis (12D) and Quality (13D). The following listing provides some examples of information in each of these categories. 


\section{Scope (3D)}

- Spatial: component size, position, distances.

- Quantity: counts, lengths, areas, weight.

- Item: component ID, type, relationships.

- Technical: engineering specifications, standards.

\section{Schedule (4D)}

- Task: start, finish, duration, progress, workspace.

- Metric: productivity level.

\section{Cost (5D)}

- Total: cost per component, task, resource.

\section{Sustainability (6D)}

- Ambient: measures of ambient lighting, temperature, humidity.

- Material: heat transmission and absorption.

- Use: usage of energy, water, gas, fuel.

- Emission: emissions of pollutants in air, water, soil.

- Metric: degree of environmental sustainability.

\section{Facility (7D)}

- Occupancy: management of occupants across spaces.

- Degradation: efficiency loss and remaining lifetime.

- Sensor: sensor id, type, readings, automation control.

- Problem: issue type, description, causes, consequences.

- Work Log: staff id, actions taken, access routes.

- Metrics: efficiency, maintainability, reliability.

\section{Risk (8D)}

- ID: risk id and type.

- Quantity: probability, impact, count, rate.

- Relationships: causes and effects.

- Action: prevention and contingencies. 


\section{Resource (9D)}

- ID: resource id, type.

- Quantity: total capacity, available, allocated.

- Manufacturing: fabrication capacity, required materials.

\section{Supply Chain (10D)}

- Procurement: supplier orders, shipping, delivery.

- Logistics: storage areas, transportation, capacities.

\section{Security (11D)}

- Access Control: access points, perimeter protection.

- Sensor: covered area, operating status, detection.

- Assessment: thread probability, impact, security level.

\section{Mechanical Analysis (12D)}

- Physical: force/stress over component.

- Damage: structural integrity, physical damage.

\section{Quality (13D)}

- Inconsistency: inconsistency type and amount.

- Metrics: overall quality and compliance level. 


\subsection{4}

\section{Visualizations}

The majority of BIM information is associated with individual components and spatial regions of the 3D CAD model of a facility. Many analytical tasks involve locating which items contribute the most for a given analysis or which regions of space possess a certain attribute. For these reasons, it is often more intuitive to present these kinds of information directly within a 2D or $3 \mathrm{D}$ CAD view. However, there are cases where a traditional Chart view can better convey relevant features of the underlying data. More often than not, a combination of Spatial views (2D/3D CAD) and Abstract views (Chart) may provide the best results.

Besides this initial classification, we are also interested in evaluating which visualizations are more suitable to different BIM use cases. To this end, we analyze each approach according to the visual mechanisms it employs to convey information. This establishes a common ground for comparing visualizations against varying task and data requirements. We extend the notion of Marks and Channels from Munzner \& Maguire [2014] to enable comparisons within 2D CAD, 3D CAD and Chart views. Marks represent graphical entities while Channels convey information by changing one or more of their visual properties.

We propose specific Marks to differentiate the use of 2D or 3D geometries within CAD models. We are also interested in assessing the popularity of Text, Icon, and Glyph Marks. Moreover, we devised new Channels such as Shading and Outline Color to better understand how CAD geometries convey information. Likewise, Transparency and Visibility Channels distinguish between continuous and discrete visual encodings, respectively.

\section{View}

- $2 D C A D$ : schematic drawings, blueprints, and maps.

- $3 D C A D$ : high-fidelity representation of shapes and locations of physical entities.

- Chart: tables, hierarchies, graphs, diagrams, and plots.

\section{Mark}

- Original Geometry: shapes within a $2 \mathrm{D}$ or $3 \mathrm{D}$ view that identify the components of a facility.

- 2D Geometry: additional geometry overlaid on or embedded in a 2D or $3 \mathrm{D}$ view. 
- 3D Geometry: additional geometry embedded in a 3D view.

- Line: straight or curved lines overlaid or embedded in any view.

- Text: identifiers, messages, annotations, and other strings.

- Icon: image that represents a logical concept or physical entity.

- Glyph: abstract graphical symbols that convey data values via shape, size, color, position, and orientation.

\section{Channel}

- Color: hue used to fill the surface of a graphical entity.

- Shading: variation in color over a surface, typically due to lighting effects.

- Outline Color: hue used for contour lines around a graphical entity.

- Outline Weight: thickness of contour lines around a graphical entity.

- Outline Stipple: dashed patterns on contour lines around a graphical entity.

- Visibility: whether a graphical entity is drawn or not in a view.

- Transparency: degree of blending of a graphical entity with background.

- Shape: geometric form of a graphical entity.

- Size: length, width and/or height of a graphical entity.

- Orientation: tilt angles of graphical entities.

- Position: absolute spatial location within a given view.

- Texture: surface color patterns.

- Ordering: relative spatial location among similar graphical entities.

\section{4}

\section{Application Areas of Visualization}

This section presents the results of our literature review regarding the frequency of use of visualizations in Building Information Modeling. From the 140 articles returned by the systematic search procedure, we have identified 248 different applications of visualization. This is because many research articles apply their proposed solutions for more than one use case throughout the phases of a construction project. We seek to identify the main application areas of visualization, how they are related, and what are the trending research topics in recent history. 


\subsection{1}

\section{Statistical Distribution}

Figure 3.3 presents the statistical distribution of visualization applications in different use cases throughout a facility's life cycle. The top part of the figure contains a histogram that follows, from left to right, the temporal order of life cycle phases from Subsection 3.3.1. The right part of the figure presents another histogram organized according to the top use cases within each theme from Subsection 3.3.2. The central part of the figure consists of a 2D histogram (heat map) that correlates these two frequencies in a single view. Each cell indicates its corresponding number of visualization applications and is colored accordingly (darker cells indicate higher quantities).

\subsubsection{1}

\section{Life Cycle Analysis}

The life cycle histogram on the top follows a bell-like curve with a peak at "Construction Planning and Construction Detailing". This phase alone concentrates 107 (43\%) of all 248 visualization applications. The second most frequent phase corresponds to "Construction, Manufacturing and Procurement", with 65 occurrences ( $26 \%$ of total). These results are probably due to the success of $4 \mathrm{D}$ visualizations for construction planning since very early BIM research [Aouad, 1999; McKinney et al., 1998]. The "Construction" vertical section of the heat map naturally has its most frequent cells within "Work Planning" and "Work Execution" themes. As expected, there are very few research that apply "Design Review" and "Sustainability Analysis" use cases during construction.

According to the life cycle histogram, remaining visualization applications tend towards the "Design" phase. It exhibits an increasing trend from earlier stages towards "Construction". This is to be expected since the 3D CAD model becomes increasingly useful as it is enriched with progressively detailed design information. The heat map shows that the majority of visualizations were naturally applied in "Design Review" use cases (22 works), with a focus on "Clash Detection" (8 works). However, there are almost as many applications in "Sustainability Analysis" (19 works), focused mainly on "Energy Analysis" (6 works). This indicates great interest in using BIM for adapting a facility's design towards higher energy efficiency and lower environmental impact. 


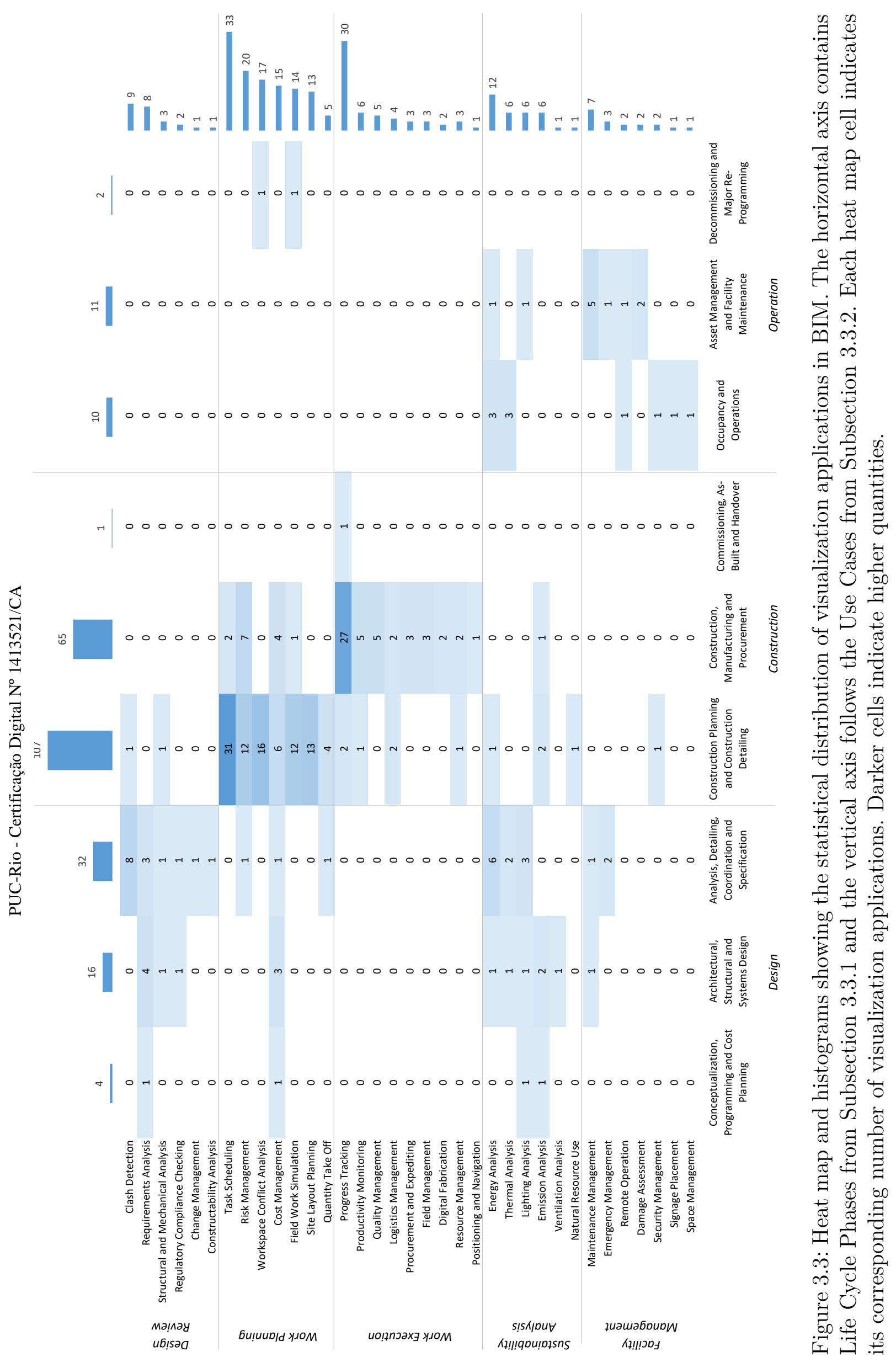


The life cycle histogram on the top also shows a significant gap in the last construction stage "Commissioning, As-Built and Handover". The heat map indicates a single visualization application focused on "Progress Tracking". This gap may help explain the relatively low frequency of applications in BIM for later operation and maintenance. Previous research have already called attention to technical barriers in carrying over BIM datasets to facility management [Azhar et al., 2015; Volk et al., 2014]. Our review has found an equal distribution of applications among "Occupancy and Operations" and "Asset Management and Facility Maintenance" phases. According to the heat map, both these phases involve applications in "Sustainability Analysis" and "Facility Management" themes. However, research in the first phase focus more on "Energy Analysis" and "Thermal Analysis" while the second naturally concentrates on "Maintenance Management". Note that there is almost no research in the "Decommissioning and Major Re-Programming" phase, with a few exceptions concerned with "Work Planning".

\subsubsection{2}

\section{Use Case Analysis}

The use case histogram to the right indicates the highest frequencies at "Task Scheduling" (33 works, 13\% of total) and "Progress Tracking" (30 works, $12 \%$ of total). The heat map shows, as expected, that the "Work Planning" and "Work Execution" themes concentrate in the construction planning and execution phases. In contrast, the "Facility Management" theme contains the lowest number of research (18 works for the entire theme, $7 \%$ of total). Although most work are applied during "Operation" phase, quite a few research have investigated "Facility Management" analysis still in the "Design" phase.

Note however, a significant difference in the distributions between "Work Planning" and "Work Execution" themes. In the former, almost all other use cases besides "Task Scheduling" show relatively high frequencies (from 13 to 20). In the latter, the "Progress Tracking" use case greatly overwhelms the others, which remain in the single digits. This indicates that BIM visualizations for construction planning are relatively more mature and widespread. On the other hand, despite notable interest in BIM for construction execution, there are still many kinds of analysis yet unexplored by current visualizations.

The use case histogram also shows that the "Sustainability Analysis" theme contains more works overall than the "Design Review" theme (32 vs 24). This result indicates greater research interest in environmental aspects of construction designs. The heat map reveals that "Sustainability Analysis" applications are relatively spread throughout all life cycle phases. In contrast, 
"Design Review" use cases are naturally concentrated in the "Design" phase (22 works). Even so, during design, the number of "Sustainability Analysis" applications almost matches others focused in "Design Review" (19 in the former vs 22 in the latter).

\subsubsection{3}

\section{Overall Remarks}

One of the benefits of BIM is enabling the use of the 3D CAD model to anticipate analysis from later life cycle phases. This allows improving designs and plans when these changes have relatively low impact on the overall construction project. The heat map already shows some interesting examples in this regard. For instance, a third of "Cost Management" and the majority of "Sustainability Analysis" applications were applied during "Design" phase. There are also a few examples of research interested in bringing "Facility Management" use cases in these early life cycle stages. We expect an increase in these trends in future applications of Building Information Modeling.

A more pessimistic viewpoint could state that Building Information Modeling is still deeply focused on construction planning and execution. The "Construction" phase alone consists of 173 applications or almost $70 \%$ of all results in our review. Nevertheless, another potential benefit of these kinds of visualizations remains clearly evident and yet unexplored. The visual analytics tools developed for construction scheduling and execution control could be used for other kinds of field work. There is still an important life cycle phase that could benefit from these: "Operation". We suggest as a major avenue for future work the adaptation of these successful planning systems to improve facility management.

\subsection{2}

\section{Historical Development}

This section analyzes the historical trends in research topics among the 248 visualization applications found by our systematic review.

\subsubsection{1}

\section{Absolute Totals Over Time}

Figure 3.4 displays stacked area charts with the frequency of visualization applications for the past years. Figure 3.4a summarizes the work in life cycle phases from Subsection 3.3.1. Figure 3.4b organizes the same results by use case themes from Subsection 3.3.2. 


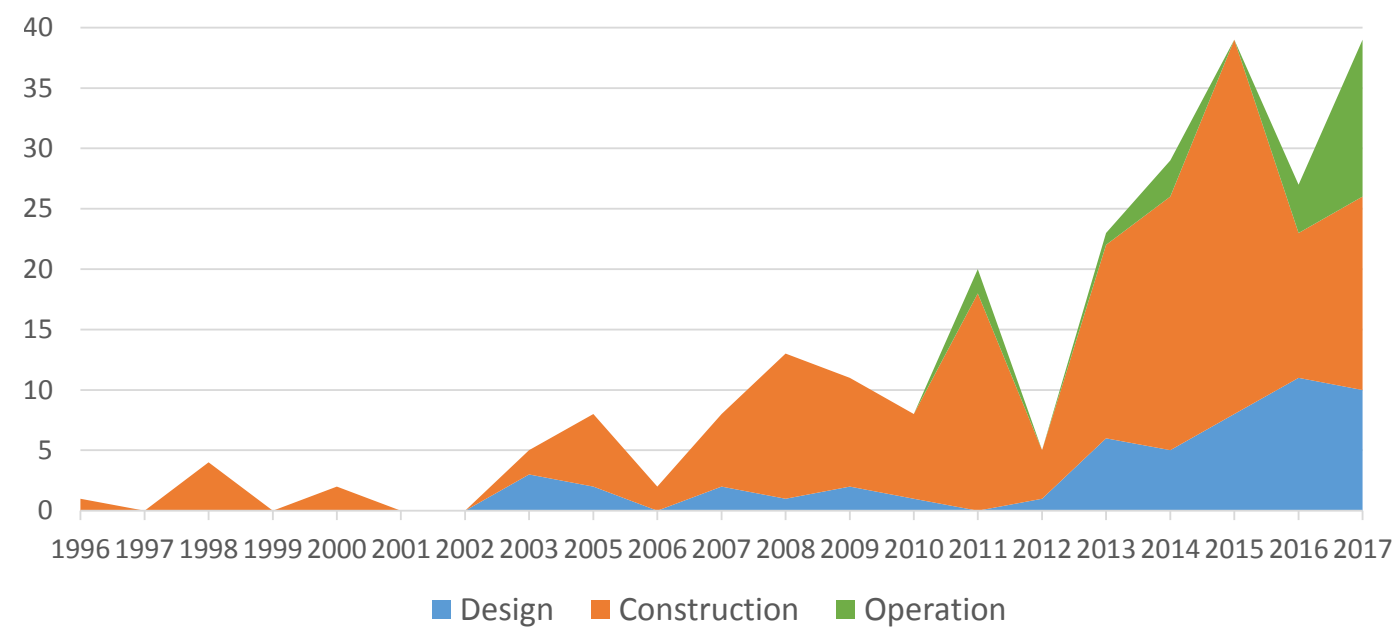

(a) By life cycle phase.

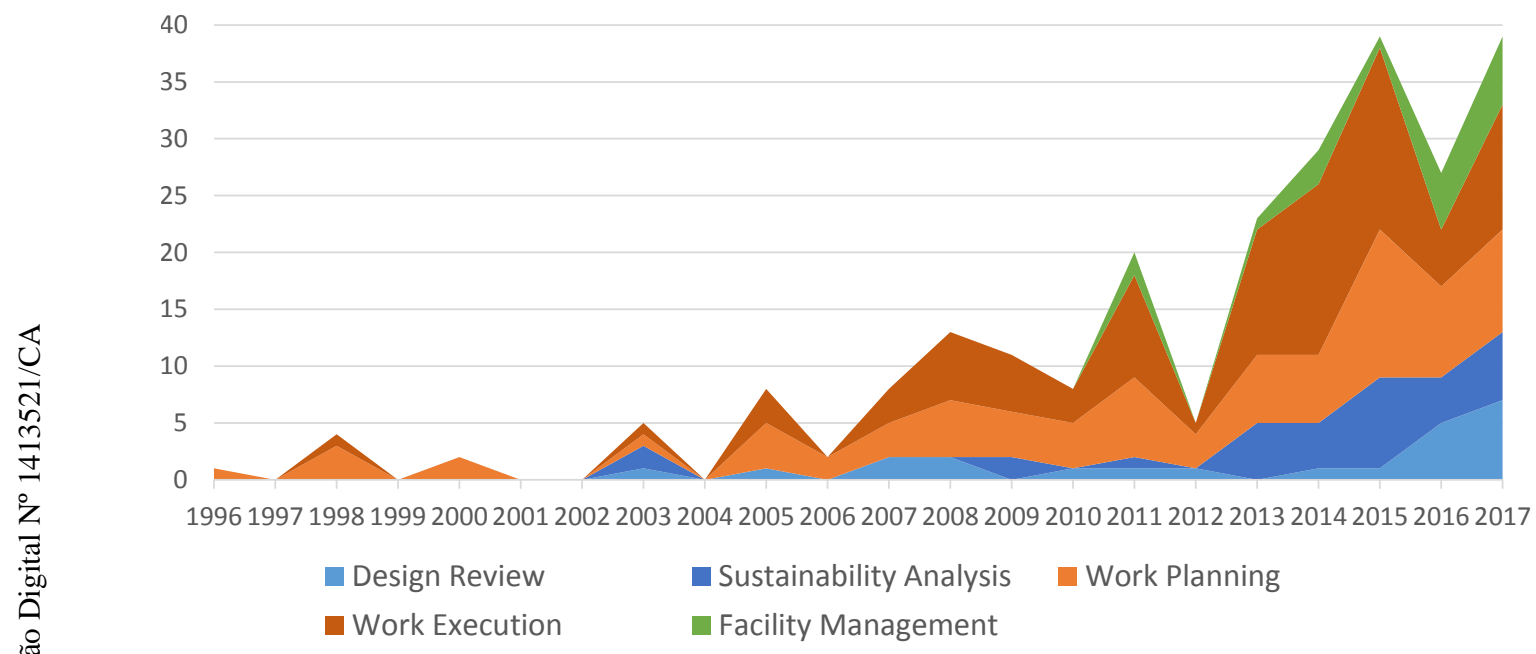

(b) By use case.

Figure 3.4: Total number of visualization applications in BIM over the years.

We have chosen a color scheme that attempts to follow the distribution of use cases across life cycle phases, as analyzed in Subsection 3.4.1. Shades of blue indicate use case themes more closely related to "Design" phase, shades of orange for the "Construction" phase, and green for "Operation" phase. Note that the combined shapes with similar colors in the bottom chart closely matches the related ones in the top chart. This suggests that each use case has always been applied to the same life cycle phases over the years.

Overall, Figure 3.4 shows a growing trend of visualization applications in BIM, going from 1 article in 1996 to 39 articles in 2017. According to Figure 3.4a, "Construction" has always been the major application area. As expected, its shape closely follows research in "Work Planning" and "Work Execution" in Figure 3.4b. Another natural correlation can be found between "Operation" phase in Figure 3.4a with "Facility Management" theme in Figure 3.4b. 
The charts indicate that, from the early 2000's, there has always been some interest in applying visualization for "Design". However, from 2012 onward, this phase saw a great increase in published works. Looking at Figure $3.4 \mathrm{~b}$, we find a strong correlation with the sudden growth in "Sustainability Analysis" during the same period. It is curious to note that this movement started around the same year as "Facility Management" research also gained momentum.

We hypothesize the increase in both these subject areas has been motivated mainly by the United Kingdom (UK). First, the UK is the second largest country in BIM research, only after the US. Second, sustainability was a key consideration across all activities in the London 2012 Olympic Games. Third, the games brought major investments in building and city infrastructure projects. Fourth, the UK government disclosed in 2013 an industrial strategy to promote the use of Building Information Modeling [HM Government, 2013; Khosrowshahi \& Arayici, 2012]. The report set ambitious goals of reducing whole-life greenhouse gas emissions by $50 \%$ and whole-life costs for built assets by $33 \%$. Together, these factors probably led to the observed growth in the use of BIM for sustainable building design and facility management.

\subsubsection{2}

\section{Percentage of Totals Over Time}

Figure 3.5 presents a different temporal view based on the percentage of total work in each life cycle phase (Figure 3.5a) and each use case theme (Figure 3.5b). These charts corroborate the aforementioned analysis and bring forth some interesting features. Figure 3.5a makes evident the dominance of BIM use in the "Construction" phase: until 2012 it held an average of $85 \%$ of all research. Figure 3.5b indicates that, until 2007, most of these research focused on "Work Planning". From that year onward, half of the research were also involved in "Work Execution" applications.

Figure 3.5a confirms ascending interest in "Design" and "Operation" from 2012 onward. In 2017, research in "Construction" decreased to 41\%, with an increase to $33 \%$ for "Operation" and $26 \%$ for "Design". The same movement is displayed by the converging lines in Figure 3.5b: the last year saw a fairly balanced interest of $15 \%$ to $25 \%$ among each use case. Extrapolating this recent trend would show the curves crossing each other in the upcoming years. Instead, we expect research interests to reach an equilibrium, with BIM applications spread equally across all use cases and all life cycle phases. 


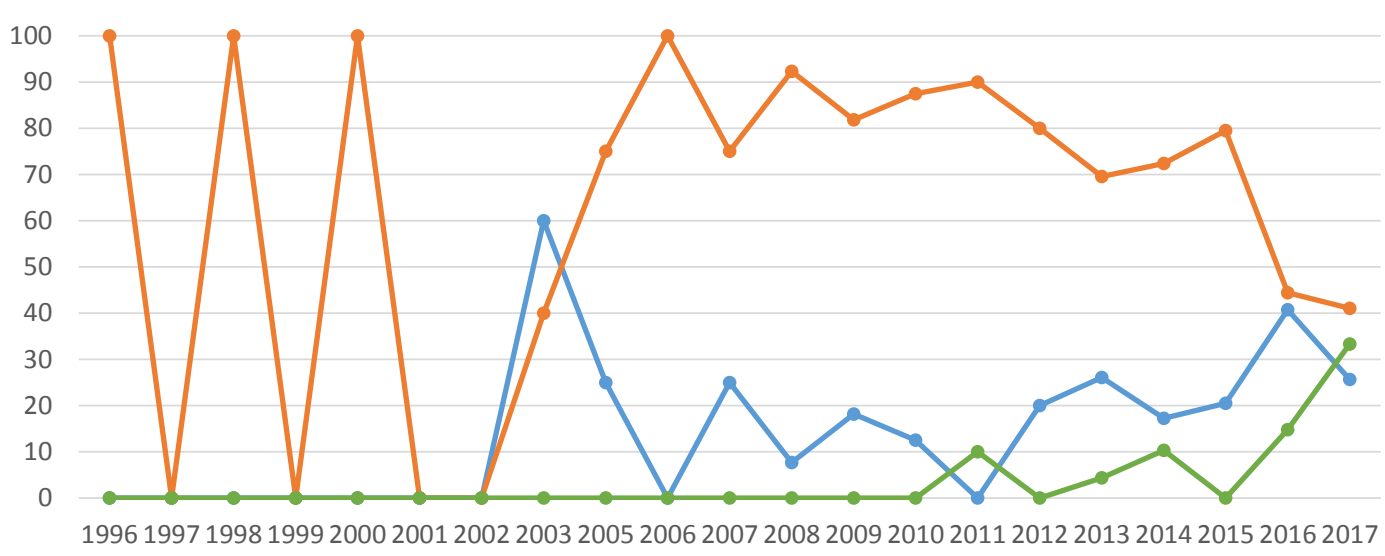

(a) By life cycle phase.

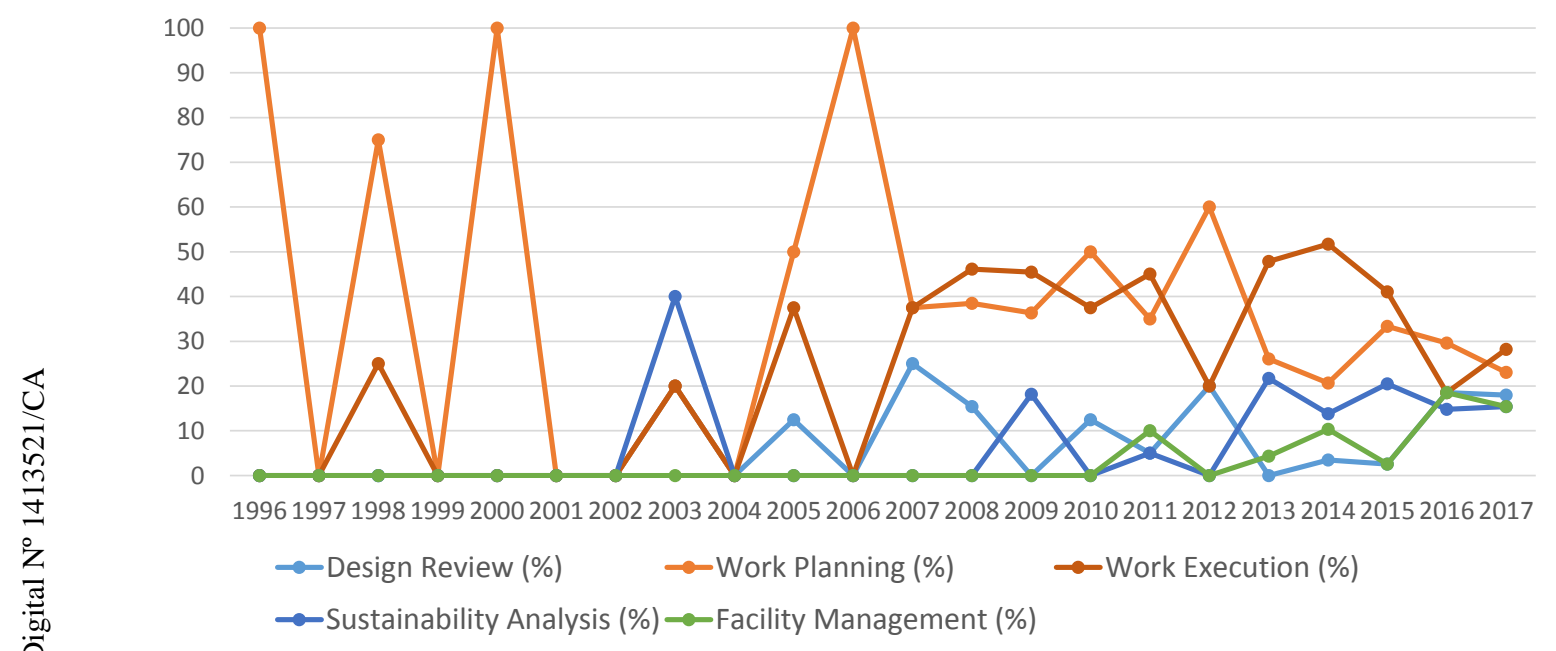

(b) By use case.

Figure 3.5: Percentage of total number of visualization applications in BIM over the years.

\subsection{3}

Summary of Findings

According to the preceding analysis, Building Information Modeling has been largely focused on construction planning and execution $(70 \%$ of all articles). Other applications tend towards the design phase (21\%), with an equal interest in "Design Review" and "Sustainability Analysis" themes. Only a few research focus on facility operations (9\%), with main applications in "Energy Analysis", "Thermal Analysis" and "Maintenance Management".

A minority of works proposed anticipating analysis in earlier life cycle phases (e.g. "Facility Management" during design). There are also many use cases in "Work Execution" that remain yet unexplored by current visualizations. Moreover, future research could adapt work planning and execution visualizations, traditionally used in construction, towards "Facility Management" applications. 
Until 2012, BIM was mainly used for construction with a few exceptions in design. Only from 2007 onward that BIM saw major use in "Work Execution". From 2012 to 2017, works in "Sustainability Analysis" and "Facility Management" have been steadily growing in number (from $4 \%$ to $33 \%$ of all works in each year). In the upcoming years, research interests should reach an equilibrium, with BIM applications spread equally across all use cases and all life cycle phases.

Within each use case theme, we can identify the following main application areas of visualization:

- Design Review: Clash Detection

- Work Planning: Task Scheduling

- Work Execution: Progress Tracking

- Sustainability Analysis: Energy Analysis

- Facility Management: Maintenance Management

\section{5}

\section{Critical Analysis of Visualization Techniques}

We present a detailed analysis of the visualizations employed by the 5 main BIM use cases from the previous section: Clash Detection, Task Scheduling, Progress Tracking, Energy Analysis, and Maintenance Management. From the 140 reviewed articles, 70 are concerned with one or more of these application areas. We have identified 25 different types of visualizations employed by these research (see Figure 3.6). The majority of techniques (19) are based on the more traditional Chart view. Lists and tables present information mainly using text. More visual schemes include graphs, plots, and diagrams. These indicate relationships among $\mathrm{CAD}$ components, plot quantitative metadata or illustrate temporal information.

Only 6 techniques are used within 2D CAD and/or 3D CAD views. Two of these employ visual effects to call the user's attention: Annotation and Component Highlight. Typically, the former overlays 2D geometries and text while the latter changes original geometries' color and/or transparency Channels. Highlight and Visibility Animations also change visual attributes of CAD objects but to convey time information. The remaining 2 visualizations enrich the 3D CAD model with additional geometries: Physical Entities or Spatial Regions. These usually indicate the locations and affected areas of heavy equipment, temporary structures, and other field work in general.

In the next subsections, we analyze in detail whether each visualization meets the requirements for each use case. We make use of Alluvial/Sankey 


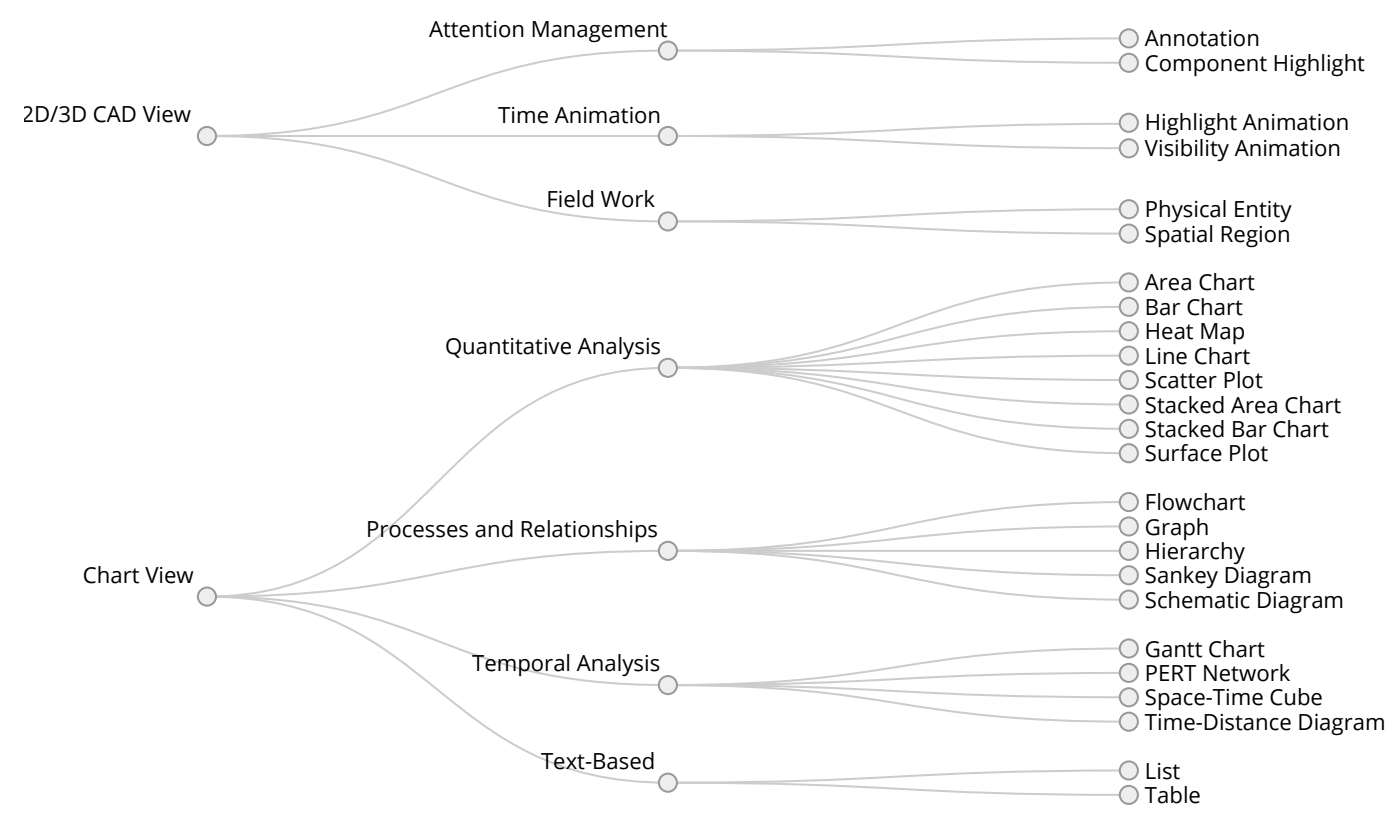

Figure 3.6: Visualization techniques (right) applied to the main BIM use cases. Similar techniques are organized by common themes (middle) within each view type (left).

diagrams to understand the relationships between different characteristics of each technique [Lupton \& Allwood, 2017; Rosvall \& Bergstrom, 2010]. This representation enables us to make evident which Views, Marks, and Channels are more frequently used. We control the color and width of each flow to match the visualization scheme and its amount of information. Items that convey the larger amount of information are sorted from top to bottom.

\subsection{1}

\section{Clash Detection}

Designing a facility with 3D CAD models enables automated checking of physical inconsistencies. These erros can cause severe delays and rework during construction, also increasing overall project costs. A recurring design problem is when two or more 3D components physically overlap one another. Usually this is a result of inconsistent 3D CAD models produced by different engineering teams. Building Information Modeling helps to avoid these issues by centralizing all designs in a single 3D CAD model.

Another type of clash may happen during construction, even if the designs have no physical overlap. Items such as ducts and ceilings may require installation of underpinnings, falsework, and similar components in the job site. Depending on the planned construction sequence, these temporary structures may occupy the physical space of another permanent facility component. This 
can also lead to delays and rework during assembly.

Analytical systems should help engineers locate these physical overlaps using some kind of visual feedback over the 3D CAD model [Li et al., 2009]. In addition, the experts need to identify which components are involved, their degree of inconsistency, and corresponding engineering specifications. Comments and suggestions could also be associated with the problem to increase collaboration among different teams.

\subsubsection{1}

\section{Visualizations}

Figure 3.7 describes how current BIM applications visualize information related to "Clash Detection". The second and third columns indicate major use of the 3D CAD model through Annotations, followed by a Hierarchy Chart view and Tables. Other techniques in the $3 \mathrm{D}$ CAD view include Component Highlights and Spatial Regions. We have observed that all works using Chart views have coordinated and linked them with the 3D view. Furthermore, applications tend to use Hierarchies and Tables to present context-sensitive information associated with the 3D CAD model (Figure 3.8d).

The Annotation visualization consists of overlay 2D geometries whose color and shape together indicate the type of design inconsistency (Figure 3.8a). These are often supplemented by texts with distance values, component IDs, and technical information. These Marks and Channels have been successfully employed to review and annotate other kinds of 3D scenes in VIS research [Burger et al., 2008; Cipriano \& Gleicher, 2008; Loughlin \& Hughes, 1994; Madsen et al., 2016]. In addition, glyphs of varying sizes are used to indicate distance between components. Glyphs are a widely-employed abstract representation capable of encoding diverse data within a 3D scene [Borgo et al., 2013; De Oliveira \& Levkowitz, 2003; Fuchs et al., 2017; Ward, 2002].

The Hierarchy visualization uses a combination of text, icon and line Marks (Figure 3.8b). Texts contain component IDs and engineering specifications. Icon shapes are used to display the types of problems while its colors represent their degree of inconsistency. Sufficiently different shapes can adequately display nominal data [Boriah et al., 2008]. On the other hand, displaying a continuous data type with colors requires adequate quantization of possible values [Few, 2009; Levkowitz, 1991; Silva et al., 2011; Tufte, 1983]. Overall, these visualizations follow traditional approaches of representing hierarchies [Burch et al., 2011; Graham \& Kennedy, 2010; Holten, 2006].

Works that use Component Highlights change the color, outline stipple, and/or transparency of original geometries to indicate the same information: 


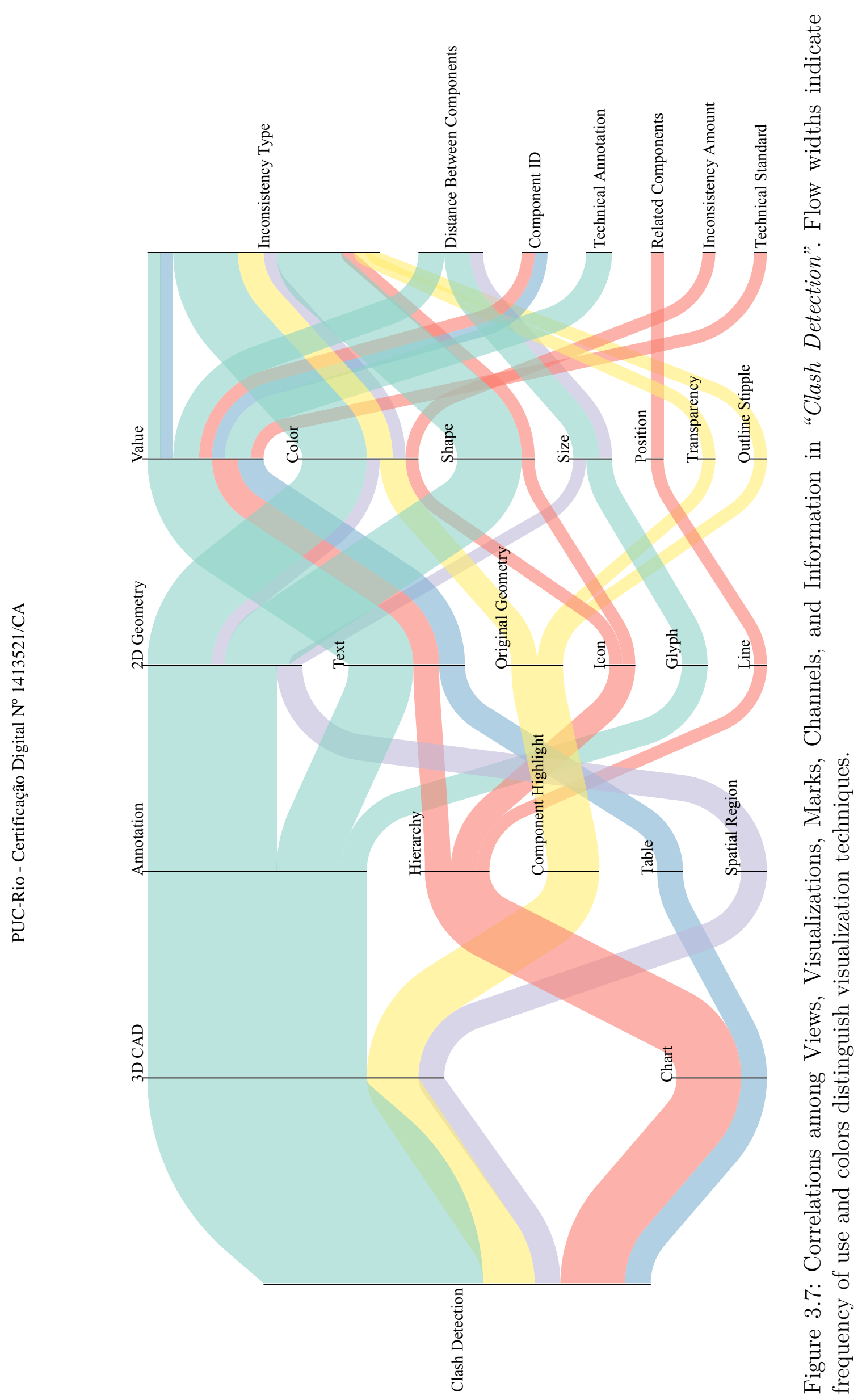




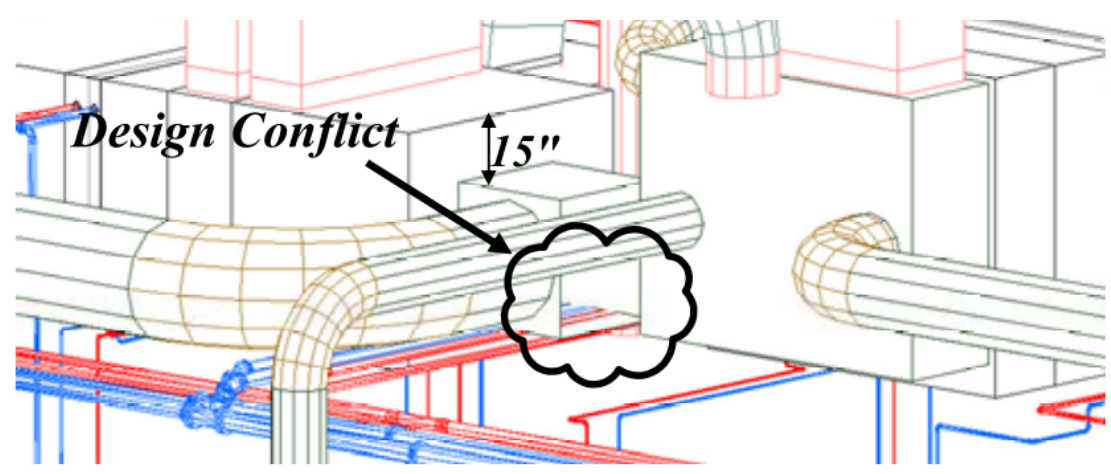

(a) Annotation [Staub-French \& Khanzode, 2007].

\begin{tabular}{|c|c|}
\hline D Clash Detection & \\
\hline G- Requisiti minimi & \\
\hline$-\square$ Tutti i modelli richiesti sono disponibili & \\
\hline$-\square$ Rappresentazione BIM dei progetti (Arch, Struct, MEP) nella stessa versione progettuale & \\
\hline L I modelli sono localizzati nel corretto sistema di coordinate cartesiane & \\
\hline (4) Intersezioni tra componenti architettonici & $\Delta$ \\
\hline (1)- Intersezioni tra componenti strutturali & ok \\
\hline (4) Intersezioni in modelli MEP & (4) $4 \Delta x$ \\
\hline G Clash detection - Merged BIM (II modello completo) & \\
\hline$\oplus-\mathbb{M}$ Modello strutturale vs Modello architettonico & (4) (4) \& $\times$ \\
\hline (4) Modello MEP vs Modello architettonico & \\
\hline$Ð \mathbb{0}$ Modello MEP vs Modello strutturale & (4) (6) \\
\hline
\end{tabular}

(b) Hierarchy [Ciribini et al., 2016].
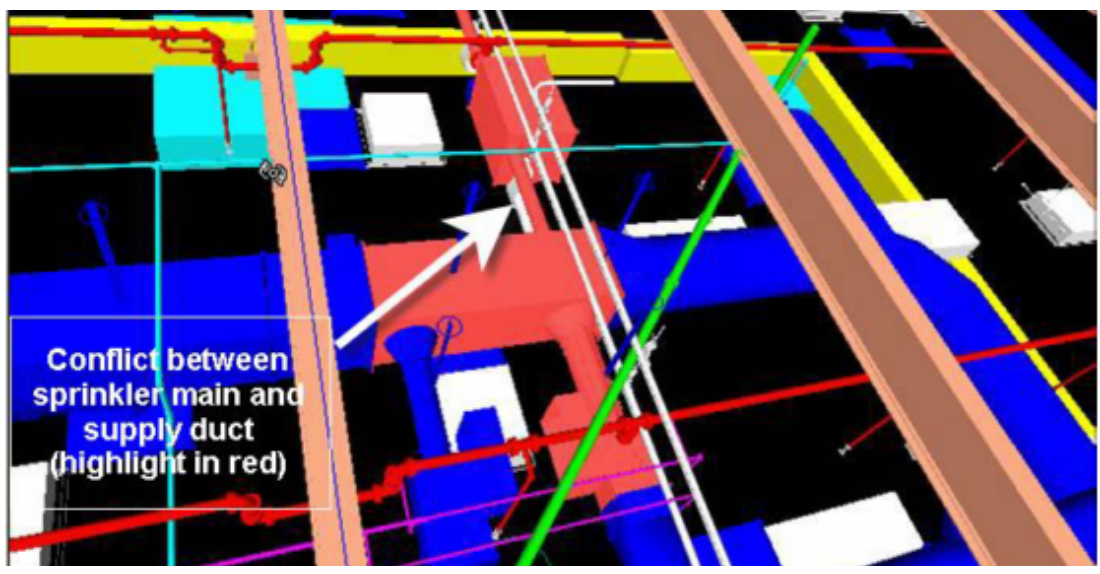

(c) Component Highlight [Khanzode et al., 2008].

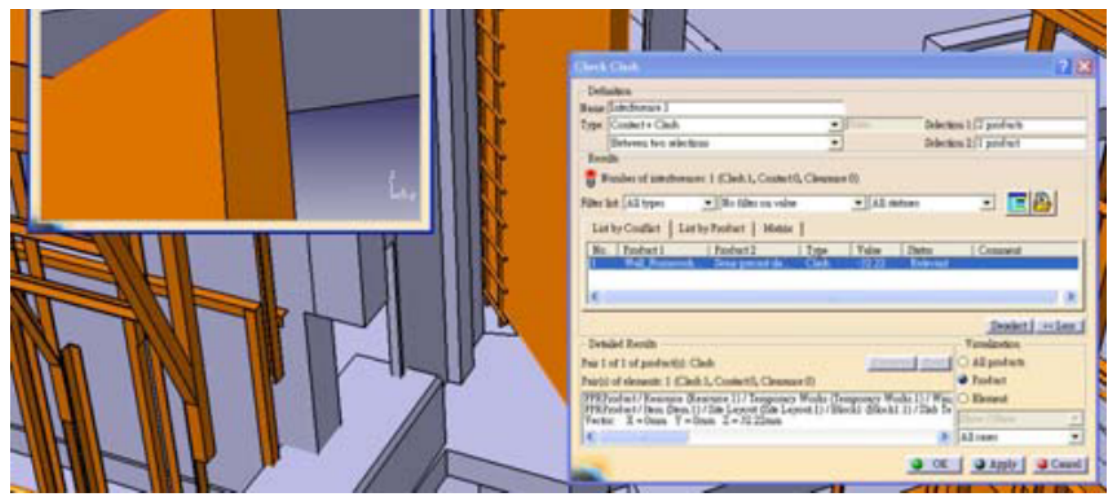

(d) Table [Kong, 2010].

Figure 3.8: Examples of the top 4 visualizations in "Clash Detection". 
Table 3.1: Overview of visualization applications in "Clash Detection". Rows are ordered by frequency of use.

\begin{tabular}{|c|c|c|c|}
\hline Visualization & View & Information Types & Reviewed Work \\
\hline Annotation & 3D CAD & $\begin{array}{l}\text { Scope (spatial, technical), } \\
\text { Quality (inconsistency) }\end{array}$ & $\begin{array}{l}\text { Abd \& Khamees [2017], Ciribini et al. } \\
\text { [2016], Khanzode et al. [2008], Staub-French } \\
\text { \& Khanzode [2007], Trebbe et al. [2015], } \\
\text { and Xie et al. [2017] }\end{array}$ \\
\hline Hierarchy & Chart & $\begin{array}{l}\text { Scope (item, technical), } \\
\text { Quality (inconsistency) }\end{array}$ & Ciribini et al. [2016] and Kong [2010] \\
\hline Component Highlight & 3D CAD & Quality (inconsistency) & $\begin{array}{l}\text { Ciribini et al. [2016], Lin et al. [2017], and } \\
\text { Vries \& Harink [2007] }\end{array}$ \\
\hline Spatial Region & 3D CAD & $\begin{array}{l}\text { Scope (spatial), Quality } \\
\text { (inconsistency) }\end{array}$ & Ciribini et al. [2016] \\
\hline Table & Chart & $\begin{array}{l}\text { Scope (item), Quality } \\
\text { (inconsistency) }\end{array}$ & Kong [2010] \\
\hline
\end{tabular}

inconsistency type. Geometry outlines have been used extensively to differentiate nearby geometries [Cole \& Finkelstein, 2010; Isenberg et al., 2003]. Although colors can accurately indicate this categorical data [Wang et al., 2008; Weiskopf, 2004], they may not adequately emphasize a 3D CAD geometry against other colored components (see Figure 3.8c). Likewise, transparency seems inappropriate for these requirements. The faded geometry blends with background objects and makes it harder for the user to distinguish shapes and sizes [Bartram et al., 2011; Tory \& Moller, 2004].

Table 3.1 summarizes the visualizations employed in "Clash Detection". Overall, we have observed some limitations in the surveyed techniques. First, the majority of implementations required Annotations to be manually inserted by the user. To improve accuracy and productivity, the visual analysis systems should be able to automate this process using information contained in the 3D CAD model. Moreover, the Annotation images shown in the articles not always made clear which 3D components were in physical overlap. The software should have also applied Component Highlights to better distinguish geometries of interest. Finally, some clashes involved items surrounded by many other 3D components. However, there were no mechanisms implemented to reduce visual clutter and/or overcome occlusion. This forces engineers to spend too much time navigating around the scene to accurately identify and analyze clashes. Magic lenses [Tominski et al., 2017] and geometry simplifications [Semmo et al., 2012] are examples of visualization techniques that can efficiently deal with these issues in 3D CAD models. 


\section{5 .2}

\section{Task Scheduling}

As demonstrated in Subsection 3.4.2, virtual construction planning has always been the major use case of Building Information Modeling. The basic idea is to associate metadata from construction tasks to 3D CAD components and spatial regions. This enables 4D (space+time) visualizations that can indicate the sequence of activities and their locations in the job site. Combining temporal with spatial information allows engineers to avoid many scheduling problems, such as inconsistent assembly ordering and workspace conflicts. This environment also facilitates communication and understanding of work plans among designers, planners, and field workers. The "Task Scheduling" use case encompasses only the analysis of temporal information associated with construction plans. Truly reliable "Work Planning" must involve many other use cases that will not be the focus of this current study (see Subsection 3.3.2).

A construction schedule can contain thousands of activities with varying start/finish dates, durations, and predecessor/successor relationships. In addition, tasks may involve from zero to many 3D CAD components or entire spatial regions. Critical path analysis can be used to identify high-risk tasks that must complete on time to preserve overall project deadlines. Visualization systems must handle all these concerns and at the same time make evident the planned assembly sequencing to avoid any mistakes in the field.

\subsubsection{1 \\ Visualizations}

Figure 3.9 indicates a large variety of visualization methods used for "Task Scheduling". Slightly more information is displayed in Chart views than 3D CAD views, with only a few exceptions using a 2D CAD view. Interestingly, the third column ranks visualizations from Chart and 3D CAD views in alternated fashion. Main techniques include: Gantt Chart, Visibility Animation, Table, and Annotation. This indicates a fairly balanced approach in using these two media for the current use case.

Perhaps not surprisingly, Gantt Charts are the most popular visualizations to analyze temporal information (Figure 3.10a). Other not so common displays include PERT networks [Malcolm et al., 1959; Pearlman, 1960] and Time-Distance diagrams (described in the next section). 


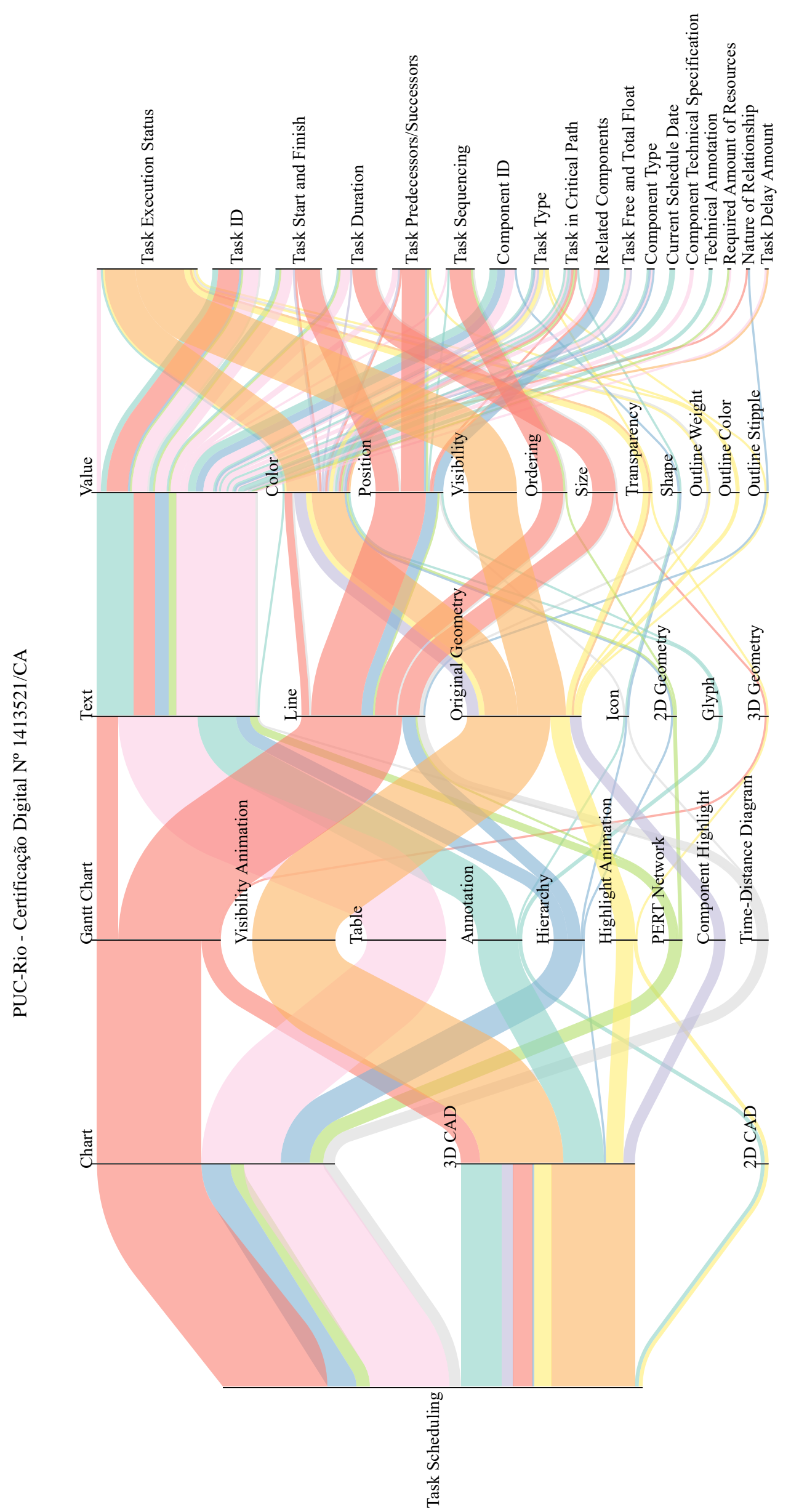

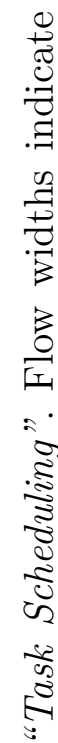




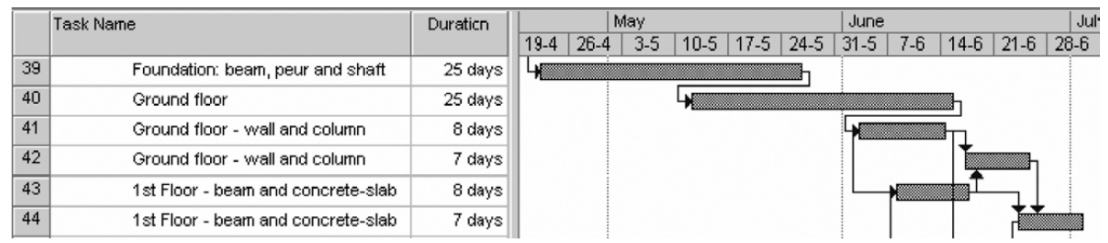

(a) Gantt Chart [Vries \& Harink, 2007].

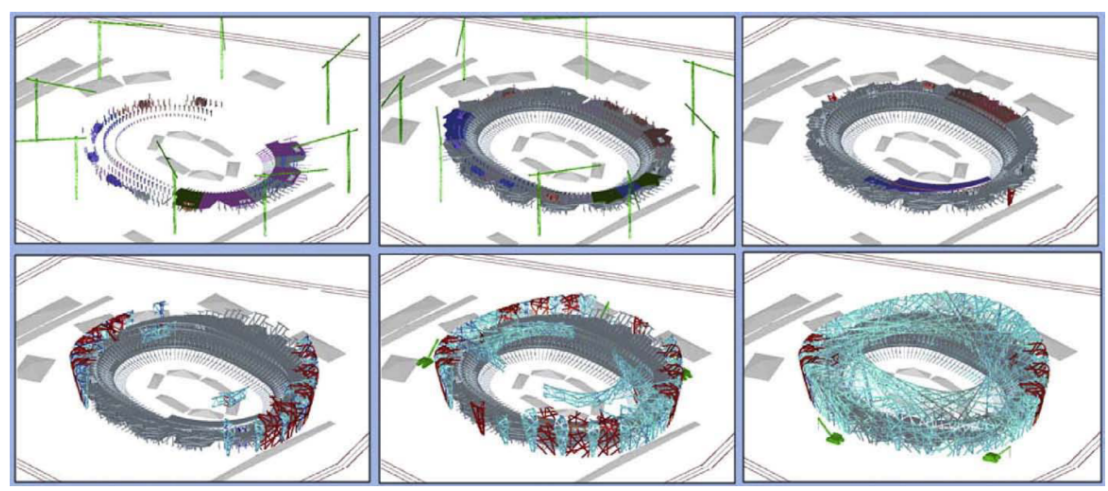

(b) Visibility Animation [Hu \& Zhang, 2011].

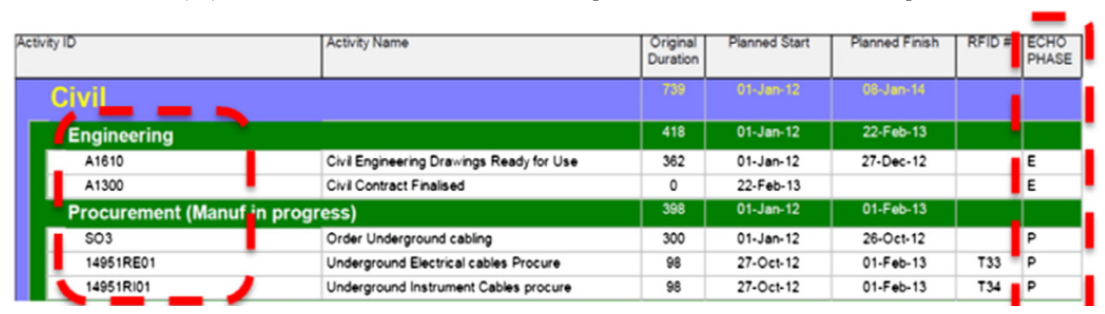

(c) Table [Zhou et al., 2015].

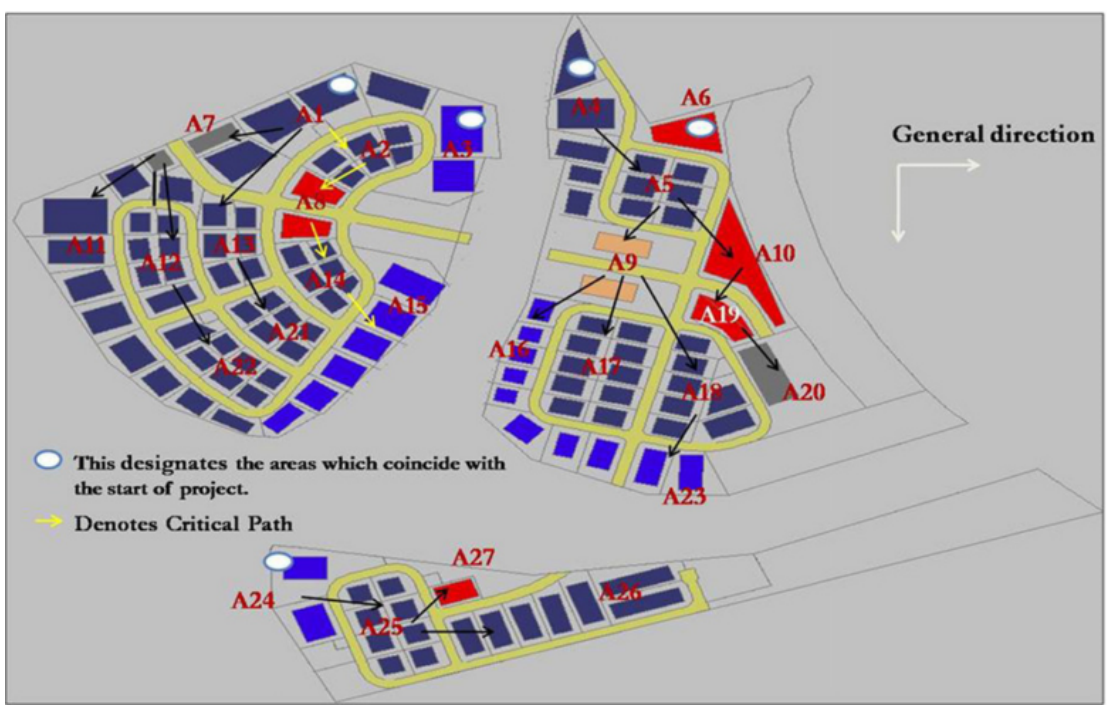

(d) Annotation [Kim et al., 2015].

Figure 3.10: Examples of the top 4 visualizations in "Task Scheduling". 
Gantt charts have been widely used since early $20^{\text {th }}$ century [Clark et al., 1922; Wilson, 2003]. These graphs plot time using the horizontal spatial dimension. Each task is represented by a Line Mark (horizontal bar) with varying positions, sizes (lengths), and colors. Positions indicate start/finish dates while lengths represent durations. Likewise, color scales are used to distinguish nominal and ordinal data: task types, criticality, and execution status. Moreover, thin connecting lines between tasks indicate predecessor/successor relationships, creating an intuitive graph-like view [Collins \& Carpendale, 2007; Herman et al., 2000; Shiravi et al., 2012].

Another common approach is to combine space and time information into 4D animations over the 3D CAD model. Most research change the visibility Channel of original 3D geometries to display their construction evolution (Figure 3.10b). In this scheme, facility components not yet built remain invisible. As simulation time progresses, geometries suddenly turn visible to indicate their construction has commenced. Color Channel adequately distinguishes between ongoing activities and already finished ones (ordinal information). However, this discrete animation makes it impossible to overview the entire schedule. At any given moment, parts of the 3D model that correspond to future tasks remain hidden. Moreover, no Mark/Channel is used to display activity duration. The user must infer this information from the length of time that corresponding 3D objects are colored as "in-progress". Similarly, predecessor/successor relationships are not directly obvious and must be derived by the visual sequence of appearing geometries.

Both qualitative analysis and practical user studies have long criticized this spatio-temporal visualization. A cognitive experiment with AEC professionals concluded that Visibility Animations interfere with the user's perception of task durations, sequencing and inter-dependencies [Chang et al., 2009]. Another research investigated how changes to the 3D objects' colors and contour lines could instead convey task durations and relationships [Benjaoran \& Bhokha, 2009]. More recently, interviews with construction experts identified many shortcomings in traditional 4D visualizations [Castronovo et al., 2014].

A not very common alternative is Highlight Animation. It changes varying Channels associated with original 3D geometries: color, transparency, outline color, stipple, and weight. These display categorical information such as task types, execution status, and predecessor/successor relationships. Quantitative information such as task start/finish and durations are indicated by auxiliary Tables or must be deduced from when the 3D geometries change in appearance. This visualization ends up sharing many of the limitations of the aforementioned Visibility Animation. 
Table 3.2: Overview of visualization applications in "Task Scheduling". Rows are ordered by frequency of use.

\begin{tabular}{|c|c|c|c|}
\hline Visualization & View & Information Types & Reviewed Work \\
\hline Gantt Chart & Chart, 3D CAD & $\begin{array}{l}\text { Scope (item), Schedule } \\
\text { (task) }\end{array}$ & $\begin{array}{l}\text { Candelario Garrido et al. [2017], Ciribini et al. } \\
\text { [2016], Elbeltagi \& Dawood [2011], Kang et al. } \\
\text { [2013], Kang et al. [2010], Koo \& Fischer } \\
\text { [2000], McKinney \& Fischer [1998], Tanyer \& } \\
\text { Aouad [2005], Tauscher \& Scherer [2015], Vries } \\
\text { \& Harink [2007], and Zhou et al. [2012a] }\end{array}$ \\
\hline Visibility Animation & $3 \mathrm{D} \mathrm{CAD}$ & Schedule (task) & $\begin{array}{l}\text { Abdelhameed [2012], Bansal [2017], Candelaric } \\
\text { Garrido et al. [2017], Ciribini et al. [2016], } \\
\text { Gelisen \& Griffis [2014], Hu \& Zhang [2011], } \\
\text { Kang et al. [2013], Kang et al. [2010], Kim } \\
\text { et al. [2011], Kim et al. [2005], Koo \& Fischer } \\
\text { [2000], Lin et al. [2017], Mahalingam et al. } \\
\text { [2010], McKinney \& Fischer [1998], Moon } \\
\text { et al. [2015], Russell et al. [2009], Staub-French } \\
\text { \& Khanzode [2007], Staub-French et al. [2008], } \\
\text { Tanyer \& Aouad [2005], Tauscher \& Scherer } \\
\text { [2015], Tsai et al. [2014], Xie et al. [2017], Zhou } \\
\text { et al. [2012a, 2014], and Zhou et al. [2015] }\end{array}$ \\
\hline Table & Chart & $\begin{array}{l}\text { Scope (item, technical), } \\
\text { Schedule (task), } \\
\text { Resource (quantity) }\end{array}$ & $\begin{array}{l}\text { Benjaoran \& Bhokha [2009], Kang et al. } \\
\text { [2013], Kim et al. [2013c], Kim et al. [2005], } \\
\text { McKinney \& Fischer [1998], Tsai et al. [2014], } \\
\text { and Zhou et al. [2015] }\end{array}$ \\
\hline Annotation & $2 \mathrm{D} / 3 \mathrm{D} \mathrm{CAD}$ & $\begin{array}{l}\text { Scope (item, technical), } \\
\text { Schedule (task) }\end{array}$ & $\begin{array}{l}\text { Gelisen \& Griffis [2014], Kim et al. [2015], Koo } \\
\text { \& Fischer [2000], Mahalingam et al. [2010], } \\
\text { and McKinney \& Fischer [1998] }\end{array}$ \\
\hline Hierarchy & Chart & $\begin{array}{l}\text { Scope (item), Schedule } \\
\text { (task) }\end{array}$ & $\begin{array}{l}\text { Kang et al. [2013], Kang et al. [2010], Kim } \\
\text { et al. [2013c], Koo \& Fischer [2000], and } \\
\text { McKinney \& Fischer [1998] }\end{array}$ \\
\hline Highlight Animation & $2 \mathrm{D} / 3 \mathrm{D} \mathrm{CAD}$ & Schedule (task) & $\begin{array}{l}\text { Benjaoran \& Bhokha [2009], Kam et al. [2003] } \\
\text { Kim et al. [2015], and Zhang et al. [2015] }\end{array}$ \\
\hline PERT Network & Chart & $\begin{array}{l}\text { Schedule (task), } \\
\text { Resource (quantity) }\end{array}$ & Kim et al. [2013c] \\
\hline Time-Distance Diagram & Chart & Schedule (task) & Staub-French et al. [2008] \\
\hline
\end{tabular}

Like the previous use case, Annotations are a fairly common mechanism to present additional information within either the 2D or 3D CAD views. In "Task Scheduling", overlay texts and icons indicate task IDs, types, and sequencing (Figure 3.10d). Tables and Hierarchies also have similar roles as the previous use case. Tables are typically linked with the 3D CAD view to present context-sensitive metadata (Figure 3.10c). Hierarchies indicate parent/child relationships among the facility's components. We refer to the previous subsection for a more detailed analysis of these techniques.

Table 3.2 summarizes the visualizations employed in "Task Scheduling". Overall, this use case presents interesting challenges of combining categorical and quantitative information with the 3D CAD model. One popular approach is the use of coordinated multiple views [Keefe et al., 2009; Wang Baldonado et al., 2000]. Another frequent approach is to display additional visual effects within the 3D CAD view. In this case, the commonly employed Visibility Animation suffers from severe perceptual issues. Continuous animations should be preferred, since they maintain the user's focus and visual memory. 


\subsection{3}

\section{Progress Tracking}

Project managers need to closely accompany construction execution to make sure all activities follow the defined schedule. Any deviations or delays must be quickly identified so that alternative plans can be devised and put into motion. Moreover, at any given moment, hundreds of activities may be ongoing at the same time on the field. Main challenges include tracking all these information, combining it with the 3D CAD model, and calling attention to problems and delays. Traditionally, project management uses the same methods and tools for planning and controlling the execution of activities. Many schedule visualization and analysis systems have the ability to track task delays and schedule deviations to enrich their visualizations.

\subsubsection{1}

\section{Visualizations}

It was expected that Figure 3.11 would show similar visualization techniques as the previous use case. Although Chart and 3D CAD views are still predominant, we observe many differences in the ranking of visualizations in the third column. Tables are now the most prominent mechanism of conveying information, closely followed by Gantt Charts, Highlight, and then Visibility Animations. Compared to "Task Scheduling", we see an increase in the use of Highlight Animations and Time-Distance Diagrams for the current use case.

The use of Tables hasn't changed: they convey mostly textual information related to task ID, execution status, progress, delay, start/finish, and others (Figure 3.12a). Meanwhile, Gantt Charts have the ability to display all these information with appropriate Marks and Channels (Figure 3.12b). It has been long established that visualization brings many benefits to understanding data properties [Keim, 2002; Ware, 2004]. The question is then: why isn't this traditional visualization being used more than tabular views? We present two hypothesis: lack of user familiarity and limitations in BIM-related Gantt views. First, construction managers may not be accustomed to advanced progress tracking and schedule comparison tools in commercial planning software. Second, Gantt visualizations within BIM analysis systems may not contain sophisticated analytical tools, being used merely as basic linked views. Future research could enrich these environments with advanced analytical features, as has already been suggested by Tory et al. [2013]. 


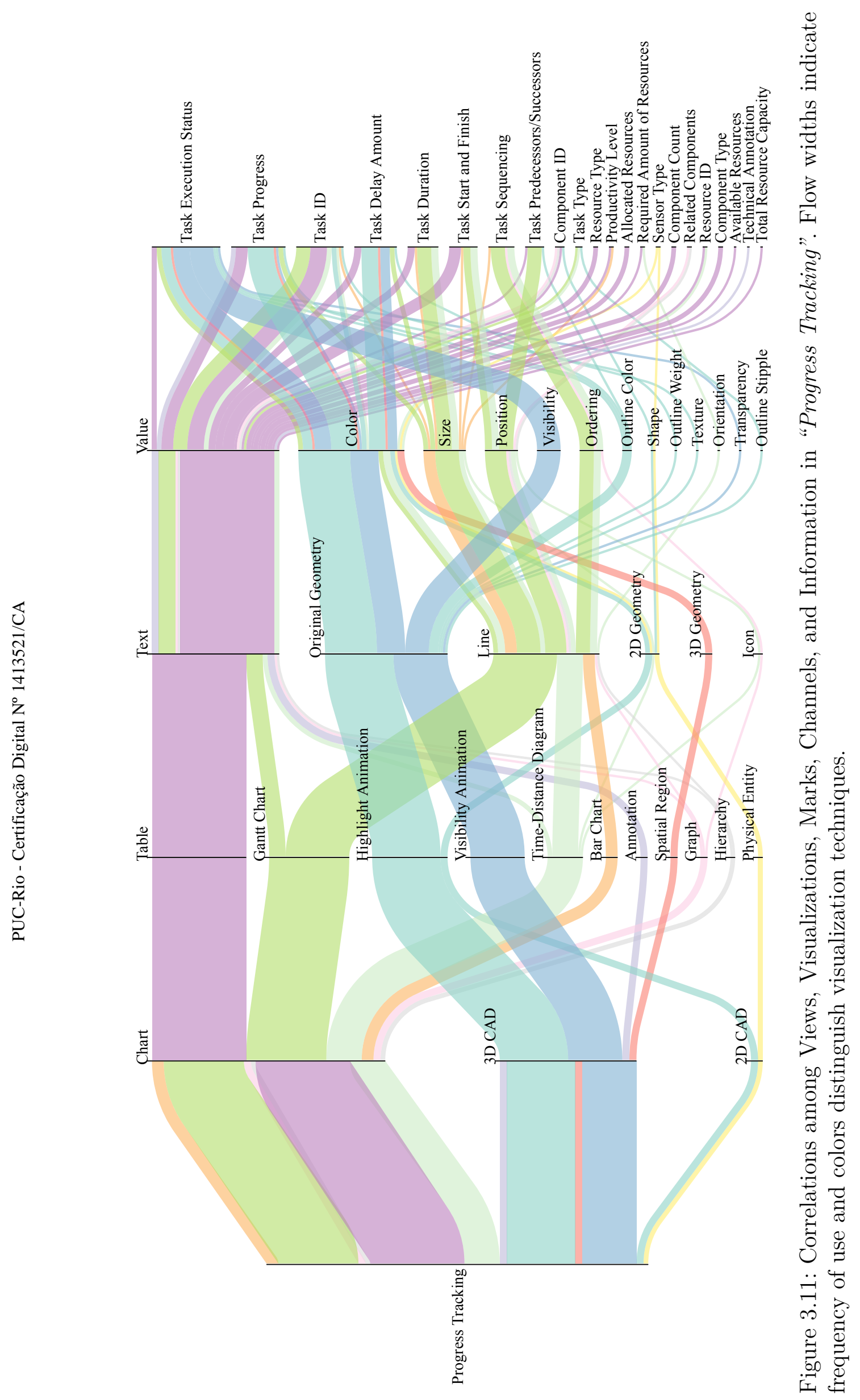




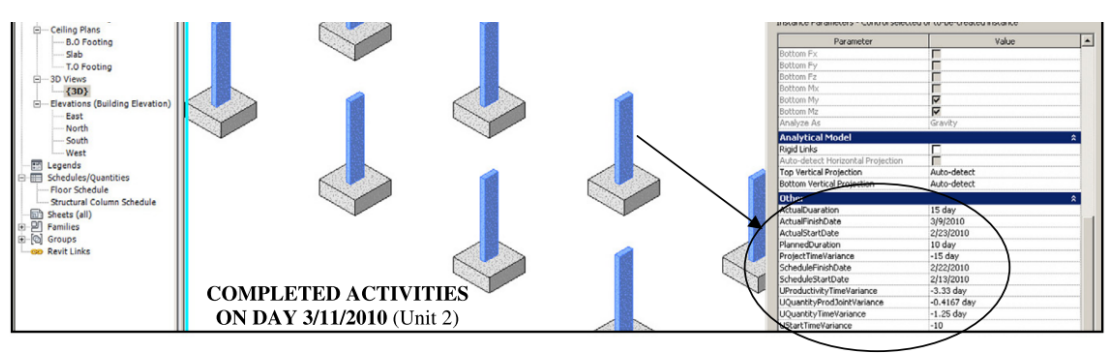

(a) Table [Elbeltagi \& Dawood, 2011].

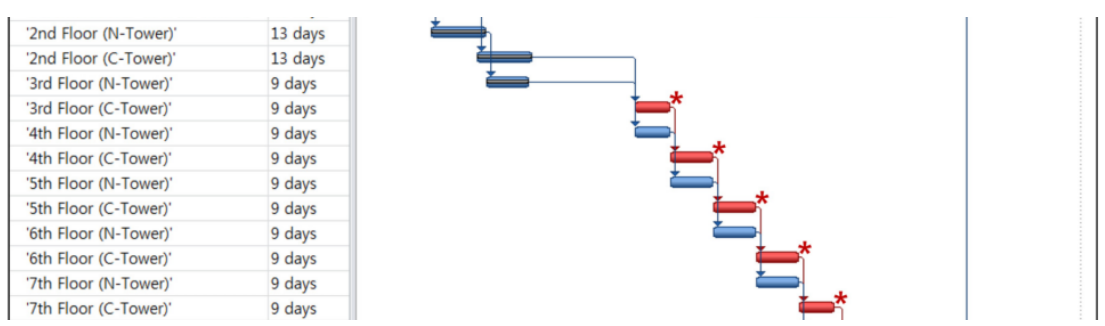

(b) Gantt Chart [Son et al., 2017].

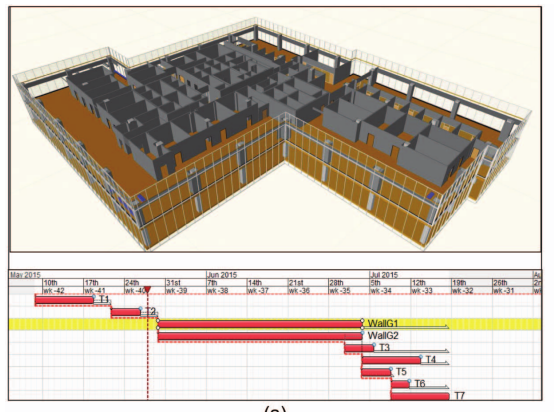

(a)

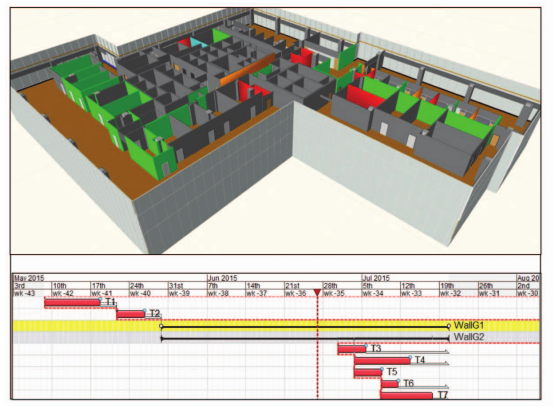

(c)

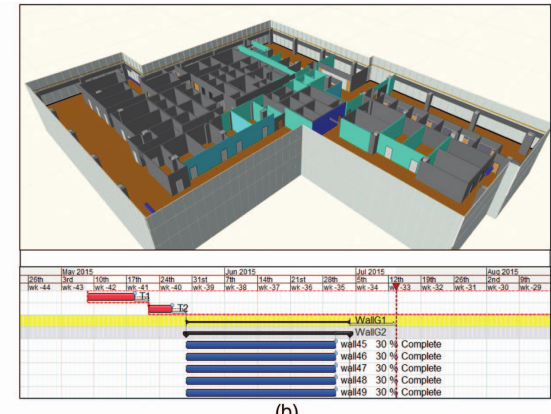

(b)

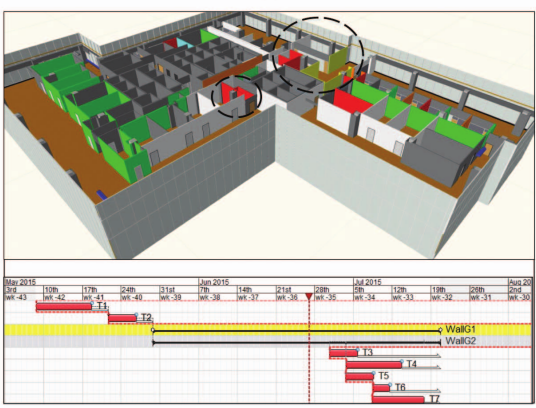

(d)

(c) Highlight Animation [Hamledari et al., 2017].
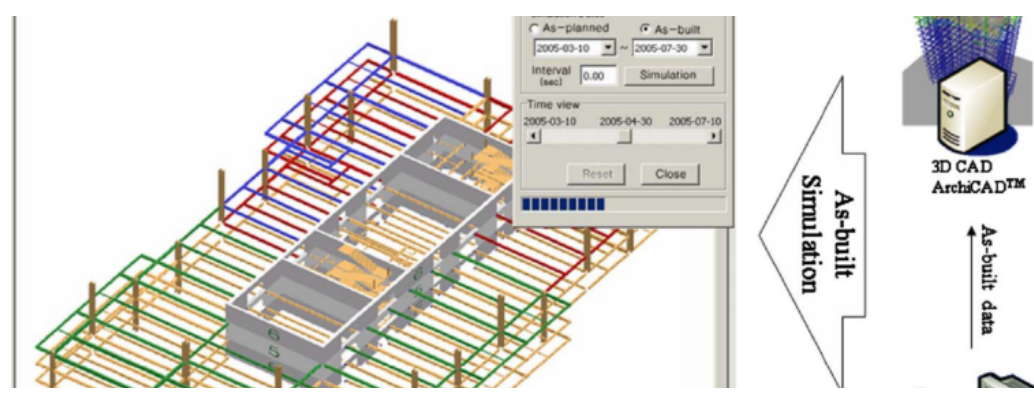

(d) Visibility Animation [Chin et al., 2008].

Figure 3.12: Examples of the top 4 visualizations in "Progress Tracking". 


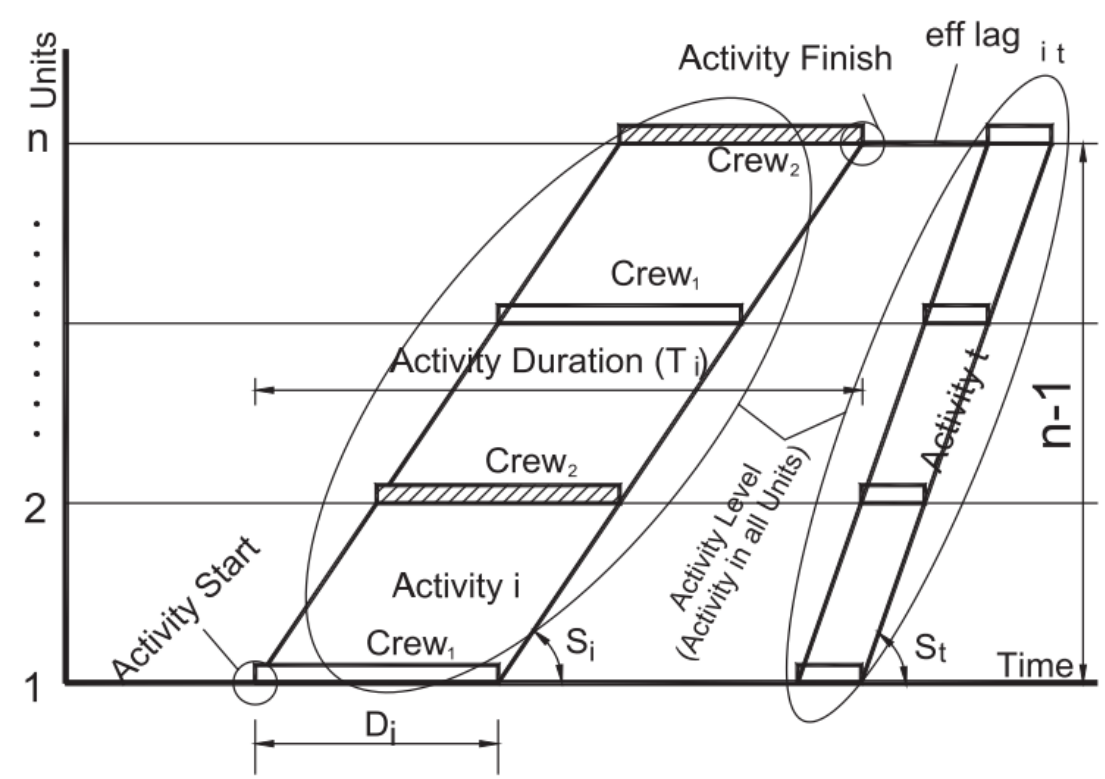

Figure 3.13: Example of Time-Distance Diagram for tracking progress of construction works [Elbeltagi \& Dawood, 2011].

Figure 3.13 displays another Chart-based visualization: Time-Distance Diagrams, also known as Line-of-Balance diagrams [Arditi et al., 2002; Pierce, n.d.]. This visualization is typically used to control longitudinal construction works such as pipelines, rails, roads, etc. They employ similar Marks and Channels as Gantt Charts (line positions, sizes, and colors) to convey similar information (task start/finish and durations). However, a Time-Distance Diagram uses one spatial axis to represent time and the other to indicate real physical distance. This allows using other Marks such as 2D geometries and Channels like shapes and orientations. These visual effects can indicate the occupied area of each task, the direction of progress, and even the progress rate. In essence, Time-Distance Diagrams are a powerful schematic-like visualization for tracking simultaneous activities on the construction site.

Regarding the 3D CAD view, most information is visualized using either Highlight (Figure 3.12c) or Visibility Animations (Figure 3.12d). Compared to the "Task Scheduling" use case, Highlights are more frequently used. This could be explained by the need to call the user's attention to 3D components associated with delayed tasks. Indeed, colors are the main Channel used to indicate task progress and delay amount. Unfortunately, this creates a very confusing visualization. The color Channel of original 3D geometries now convey both categorical information (task type and execution status) and quantitative information (task progress and delay amount). A few approaches failed to circumvent this issue by using other similar Channels such as outline color, stipple, and weight. Meanwhile, Visibility animations share the same limitations already described in the previous subsection. 
Table 3.3: Overview of visualization applications in "Progress Tracking". Rows are ordered by frequency of use.

\begin{tabular}{|c|c|c|c|}
\hline Visualization & View & Information Types & Reviewed Work \\
\hline Table & Chart & $\begin{array}{l}\text { Scope (quantity, item), } \\
\text { Schedule (metric, task), } \\
\text { Resource (ID, quantity) }\end{array}$ & $\begin{array}{l}\text { Benjaoran \& Bhokha [2009], Chin et al. } \\
\text { [2008], Elbeltagi \& Dawood [2011], Hu \& } \\
\text { Zhang [2011], Kim et al. [2013a], Park et al. } \\
\text { [2017], Russell et al. [2009], Tserng et al. } \\
\text { [2014], and Turkan et al. [2014] }\end{array}$ \\
\hline Gantt Chart & Chart & Schedule (task) & $\begin{array}{l}\text { Braun et al. [2015], Hamledari et al. [2017], } \\
\text { Han et al. [2015], Han \& Golparvar-Fard } \\
\text { [2017], Kim et al. [2013b], and Son et al. } \\
{[2017]}\end{array}$ \\
\hline Highlight Animation & $2 \mathrm{D} / 3 \mathrm{D} \mathrm{CAD}$ & $\begin{array}{l}\text { Scope (item), Schedule } \\
\text { (task) }\end{array}$ & $\begin{array}{l}\text { Benjaoran \& Bhokha [2009], Bosché et al. } \\
\text { [2014], Braun et al. [2015], Chen \& Luo } \\
\text { [2014], Hamledari et al. [2017], Han et al. } \\
\text { [2015], Han \& Golparvar-Fard [2015], Park } \\
\text { et al. [2017], Russell et al. [2009], Tauscher } \\
\text { \& Scherer [2015], Tserng et al. [2014], } \\
\text { Turkan et al. [2014], Wang et al. [2014], and } \\
\text { Zhou et al. [2015] }\end{array}$ \\
\hline Visibility Animation & 3D CAD & Schedule (task) & $\begin{array}{l}\text { Björnfot \& Jongeling [2007], Candelario } \\
\text { Garrido et al. [2017], Chin et al. [2008], } \\
\text { Elbeltagi \& Dawood [2011], Golparvar-Fard } \\
\text { et al. [2011], Han \& Golparvar-Fard [2017], } \\
\text { Kim et al. [2013a,b], Mahalingam et al. } \\
\text { [2010], and Son et al. [2017] }\end{array}$ \\
\hline Time-Distance Diagram & Chart & $\begin{array}{l}\text { Schedule (task), Resource } \\
\text { (ID, quantity) }\end{array}$ & $\begin{array}{l}\text { Björnfot \& Jongeling [2007], Elbeltagi \& } \\
\text { Dawood [2011], and Russell et al. [2009] }\end{array}$ \\
\hline Bar Chart & Chart & Schedule (metric, task) & Chin et al. [2008] and Russell et al. [2009] \\
\hline Graph & Chart & $\begin{array}{l}\text { Scope (item), Schedule } \\
\text { (task) }\end{array}$ & Braun et al. [2015] \\
\hline Spatial Region & 3D CAD & Schedule (task) & Park et al. [2017] \\
\hline Annotation & $3 \mathrm{D}$ CAD & $\begin{array}{l}\text { Scope (technical), Schedule } \\
\text { (task) }\end{array}$ & $\begin{array}{l}\text { Hamledari et al. [2017], Han \& } \\
\text { Golparvar-Fard [2015], and Mahalingam } \\
\text { et al. [2010] }\end{array}$ \\
\hline Physical Entity & 2D CAD & Facility (sensor) & Chin et al. [2008] \\
\hline Hierarchy & Chart & Scope (item) & Russell et al. [2009] \\
\hline
\end{tabular}

Instead of using these discrete animations, coordinated multiple views could combine the 3D CAD model with Gantt Charts or Time-Distance Diagrams. Both have had great success in improving management of schedule execution. For example, linking and brushing could help construction managers locate critical tasks in the 3D view [Boton et al., 2011; Buja et al., 1991; Yi et al., 2007].

Table 3.3 summarizes the visualizations employed in "Progress Tracking". As noted in Subsection 3.4.1, these approaches lack from additional analysis that could be provided by other use cases in the "Work Execution" theme. We call attention to this important research gap so that future work in BIM visualization can try to explore the latent synergies between these many use cases. 


\subsection{4 \\ Energy Analysis}

Today's governments face environmental pressure from several factors: global warming studies, increasing costs of fossil fuels, elevated pollution in large metropolis, among others. This general public concern combined with ever stricter regulations is forcing construction companies to improve their practice. As described in Subsection 3.4.2, the last 5 years have shown a growing trend in sustainable building design using BIM. Also known as Green Building, this practice promotes environmentally responsible and resourceefficient processes throughout a building's life-cycle [Zuo \& Zhao, 2014].

A major concern is the efficient use of energy resources throughout design, construction and, mainly, operation. Governments around the world have created certificates systems to promote and award efficient buildings [PérezLombard et al., 2009]. An example is the Leadership in Energy and Environmental Design (LEED) rating system in the US [Azhar et al., 2011]. Another benefit of energy-efficient design is the resulting cost savings during operation phase [Council, 2008]. This scenario has sparked the interest in the combined use of BIM with energy performance simulation systems [Crawley et al., 2008].

Several factors can influence a building's energy use, for example: physical characteristics of materials, size and placement of windows, and layout of airconditioning equipment. Building Information Modeling can aggregate all these information within its detailed 3D CAD model. This virtual representation is then used for diverse physical simulations to analyze heat propagation, wind flows, ambient lighting, among others. These studies can be performed still in design stage to improve building materials and equipment layout prior to construction. During operation phase, the simulations can help understanding actual consumption and guide efficiency-focused renovation plans.

\subsubsection{1}

\section{Visualizations}

Figure 3.14 shows that the overwhelming majority of "Energy Analysis" information is displayed using a Chart view. The second most frequent view is $2 \mathrm{D}$ CAD, followed by the $3 \mathrm{D}$ CAD view in last place. This is very different from previously analyzed use cases, where 3D CAD and Chart views shared the highest ranks. As described in this section, we suppose this is mainly due to the specific nature of energy-related information. 
ป

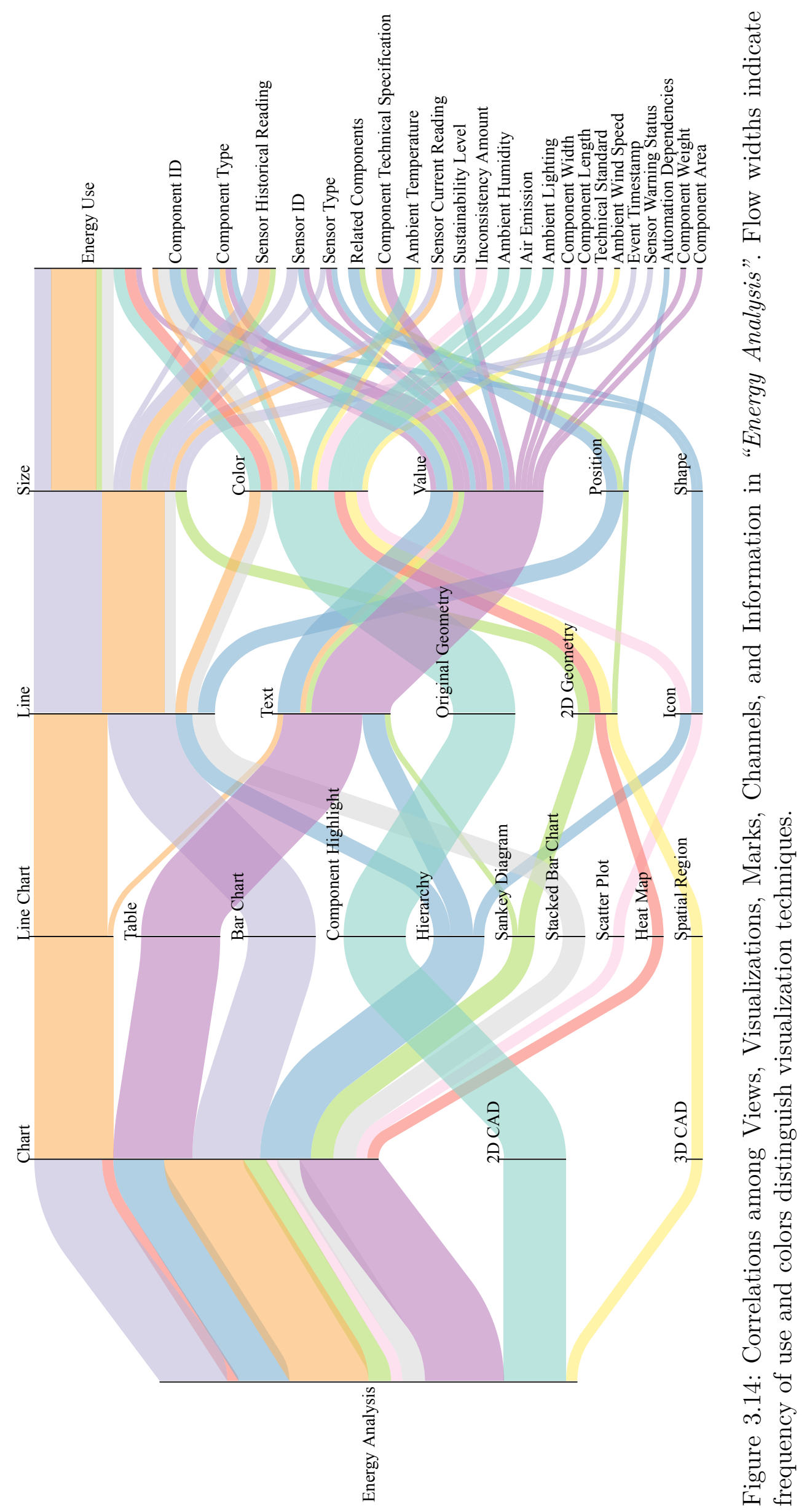



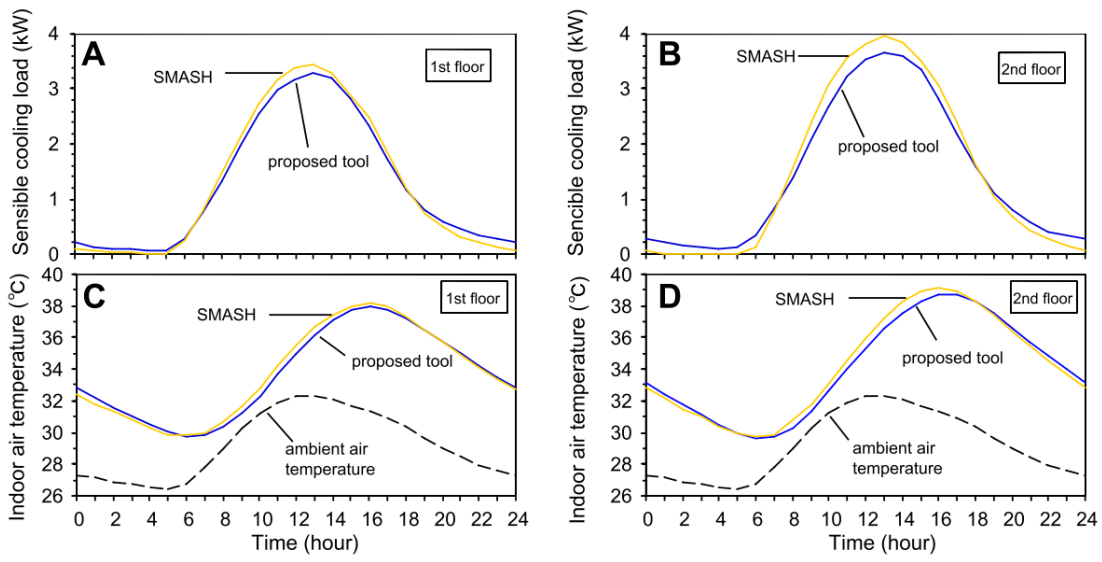

(a) Line Chart [He et al., 2009].

\begin{tabular}{|c|c|c|c|c|}
\hline Index number & Analytical construction & $\begin{array}{l}\text { Visual lighting } \\
\text { transmittance }\end{array}$ & $\begin{array}{l}\text { Solar heat gain } \\
\text { coefficient }\end{array}$ & $\begin{array}{l}\text { Thermal resistance- } \\
R\left(\mathrm{hft}^{\circ} \mathrm{F}\right) / \mathrm{BTU}\end{array}$ \\
\hline 0 & $1 / 8$ in Pilkington single glazing & 0.9 & 0.86 & 0.8466 \\
\hline 1 & 1/4 in Pilkington single glazing & 0.9 & 0.86 & 0.8473 \\
\hline 2 & $3 / 8$ in Pilkington single glazing & 0.88 & 0.81 & 0.8478 \\
\hline 3 & $1 / 2$ in Pilkington single glazing & 0.88 & 0.81 & \\
\hline 4 & Double glazing - $1 / 4$ in thick-bluegreen/low-E $(\mathrm{e}=0.05)$ & 0.45 & 0.27 & 2.8573 \\
\hline 5 & Double glazing - $1 / 4$ in thick - clear/low-E $(e=0.1)$ & 0.45 & 0.39 & 2.8573 \\
\hline 6 & $\begin{array}{l}\text { Double glazing }-1 / 4 \text { in thick }- \text { clear/low- } \mathrm{E}(\mathrm{e}=0.2) \\
\text { Deuble gatang }\end{array}$ & 0.45 & 0.45 & 2.8573 \\
\hline 8 & 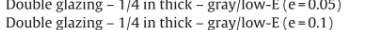 & $\begin{array}{l}0.35 \\
037\end{array}$ & 0.24 & 2.8573 \\
\hline 9 & $\begin{array}{l}\text { Double glazing }-1 / 4 \text { in thick }- \text { grayyllow- }(e=0.1) \\
\text { Double glazing }-1 / 4 \text { in thick }- \text { gray/low- } E(e=0.2)\end{array}$ & 0.37 & $\begin{array}{l}0.34 \\
0.39\end{array}$ & 2.8573 \\
\hline 10 & Double glazing $-1 / 4$ in thick - green/low- $(\mathrm{e}-0.05)$ & 0.6 & 0.31 & 28573 \\
\hline & Double glazing - $1 / 4$ in thick - green/low-E $(\mathrm{e}=0.1)$ & 0.61 & 0.36 & 28573 \\
\hline & Double glazing $-1 / 4$ in thick - green/low- $\mathrm{E}(\mathrm{e}=0.2)$ & 0.61 & 0.41 & 2.8573 \\
\hline 13 & Double glazing $-1 / 4$ in thick - low-E/clear $(e=0.05)$ & 0.7 & 0.3 & 2.8573 \\
\hline 14 & Double glazing - $1 / 8$ in thick - clear $/$ low-E $(e=0.1)$ & 0.57 & 0.48 & 2.8573 \\
\hline 15 & Double glazing - $1 / 8$ in thick - clear/low-E $(e=0.2)$ & 0.58 & 0.57 & 2.8573 \\
\hline 16 & Double glazing $-1 / 8$ in thick - low-E/clear $(e=0.05)$ & 0.72 & 0.41 & 2.8573 \\
\hline 17 & Single glazing SC -0.2 & 0.08 & 0.19 & 0.8473 \\
\hline 18 & Single glazing $\mathrm{SC}=0.4$ & 0.3 & 0.39 & 0.8473 \\
\hline 19 & $\begin{array}{l}\text { Single glazing } S \mathrm{C}=0.6 \\
\text { Sing }\end{array}$ & 0.76 & 0.6 & 1.1803 \\
\hline & & & & 1.1803 \\
\hline
\end{tabular}

(b) Table [Rahmani Asl et al., 2015].

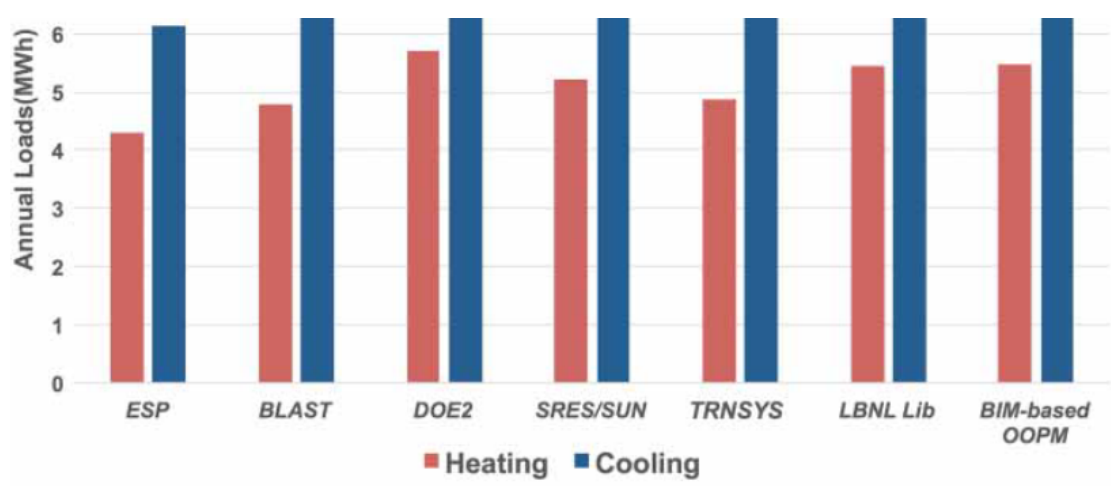

(c) Bar Chart [Jeong et al., 2016].
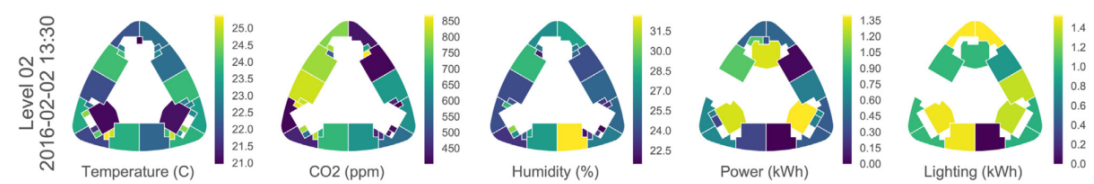

(d) Component Highlight [Gerrish et al., 2017].

Figure 3.15: Examples of the top 4 visualizations in "Energy Analysis". 
The top visualization technique, Line Chart, plots curves to indicate simulated energy use or actual sensor readings over time (Figure 3.15a). Typically, the color Channel distinguishes the curves of different sensors or building components. Displaying the variation of continuous data as a time series is a well-known and intuitive visualization technique [Hochheiser \& Shneiderman, 2004; Javed et al., 2010]. The predominance of quantitative information also leads to the high use of Bar Charts (Figure 3.15c). These are also a widely-established mechanism to display and compare different numeric values [Talbot et al., 2014; Wehrend \& Lewis, 1990]. Many other kinds of charts are used for these same purposes: Sankey Diagrams, Stacked Bar Charts, Heat Maps, and Scatter Plots.

Looking at the right of Figure 3.14, we see a great diversity of categorical and quantitative and information. Note how the Table visualization relates to almost all of them: it is very easy to simply present all these data in tabular form (Figure 3.15b). This has the negative side-effect of overwhelming the user with too much information.

Only a few research combine Charts with 2D/3D spatial views. Typically, a 2D CAD view accompanies numeric plots to present Component Highlights (Figure 3.15d). Curiously, this view is preferred to the 3D CAD representation. We observed typical applications concerned with individual floors of a building. In this case, a 2D representation made it easier to color-code different rooms in order to display ambient measurements and energy use.

Table 3.4 summarizes the visualizations employed in "Energy Analysis". We can conclude that this use case brings a rather unique set of visualization challenges. The main information is quantitative in nature and understanding their change over time is one of the main user tasks. This is probably the principal reason why Chart views are so popular: many established techniques already meet these demands. Linked 2D CAD views are then only employed to provide associated geometry highlights. Nevertheless, displaying quantitative information within a $2 \mathrm{D} / 3 \mathrm{D} \mathrm{CAD}$ view could facilitate understanding of root causes affecting building energy performance. Therefore, we suggest future work to evaluate the possible benefits of scientific visualization techniques within Building Information Models [Brodlie et al., 2012; Haber \& McNabb, 1990]. 
Table 3.4: Overview of visualization applications in "Energy Analysis". Rows are ordered by frequency of use.

\begin{tabular}{llll}
\hline Visualization & View & Information Types & Reviewed Work \\
\hline \multirow{2}{*}{ Line Chart } & & Scope (item, technical), & Abdelalim et al. [2017], Gerrish et al. \\
& Chart & [2017], He et al. [2009], Jeong et al. [2016], \\
& & Fustainability (use), & Kim et al. [2015], Oti et al. [2016], and \\
& & Shalabi \& Turkan [2017]
\end{tabular}

\subsection{5}

\section{Maintenance Management}

One of the main activities during "Operation" is maintaining a facility's physical integrity. Structures suffer continuous degradation from exposure to elements. Depending on climate conditions, different materials may corrode or fracture more easily. Hydraulic, mechanical and electronic systems lose efficiency and tend to malfunction over time.

It is the responsibility of the facility manager to keep track of current health and remaining lifespan of its building. These professionals employ several different maintenance management strategies [Garg \& Deshmukh, 2006]. Each has varying task and data requirements, as well as different implementation costs.

Reactive maintenance is the simplest form, where components are used until the point of failure. It keeps routine maintenance costs low, but can severely increase operational costs in the long run. Preventive maintenance 
is the most common: periodic interventions are planned to keep components functioning. With the increasing adoption of building automation systems, it is now possible to monitor the health of critical equipment in real time. This enables Predictive maintenance schemes, where computer models and algorithms can predict failures based on observed behavior. Another similar strategy is Proactive maintenance, which focuses on improved operation to minimize the root causes of wear and tear.

\subsubsection{1}

\section{Visualizations}

Figure 3.16 describes how Building Information Modeling is being used for these various maintenance strategies. Information are visualized mainly with 3D CAD and Chart views, with a few exceptions using the 2D CAD view. This distribution is very similar to the ones observed in previous use cases, except for "Energy Analysis".

Within the 3D CAD view, the main visualization technique is Annotation (Figure 3.17a). It conveys three major types of information: maintenancerelated problems, sensor-related readings, and component-related specifications. These data are typically displayed using texts over the 3D components. Regrettably, BIM applications tend to display too much textual information in this manner, overwhelming the user's perception. Only a minority of information is visualized with other Marks and Channels such as icons and glyphs of varying shapes and colors. The former can be adequately used to convey categorical information, while the latter can also be employed for quantitative data. Future BIM research should look into using more of these visual effects to lower cognitive load in complex scenarios. For more details on Annotation and glyph-based visualization, see our analysis in Subsection 3.5.1.

As with previous use cases, Chart views concentrate mainly on Tables (Figure 3.17b). BIM applications seem to employ these whenever many different kinds of information need to be inspected at the same time. Researchers typically combine these with Component Highlights within 2D or 3D CAD views (Figure 3.17c). These provide spatial context for each information while also promoting richer visual analysis of data properties and relationships.

Schematic Diagrams are a form of Chart view that is used solely in "Maintenance Management" (Figure 3.17d). This visualization combines several Marks and Channels to display a graph-like structure of facility components. Texts and icons convey sensor ID and type, lines show automation dependencies, and glyphs indicate problem-related information. 


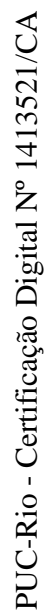

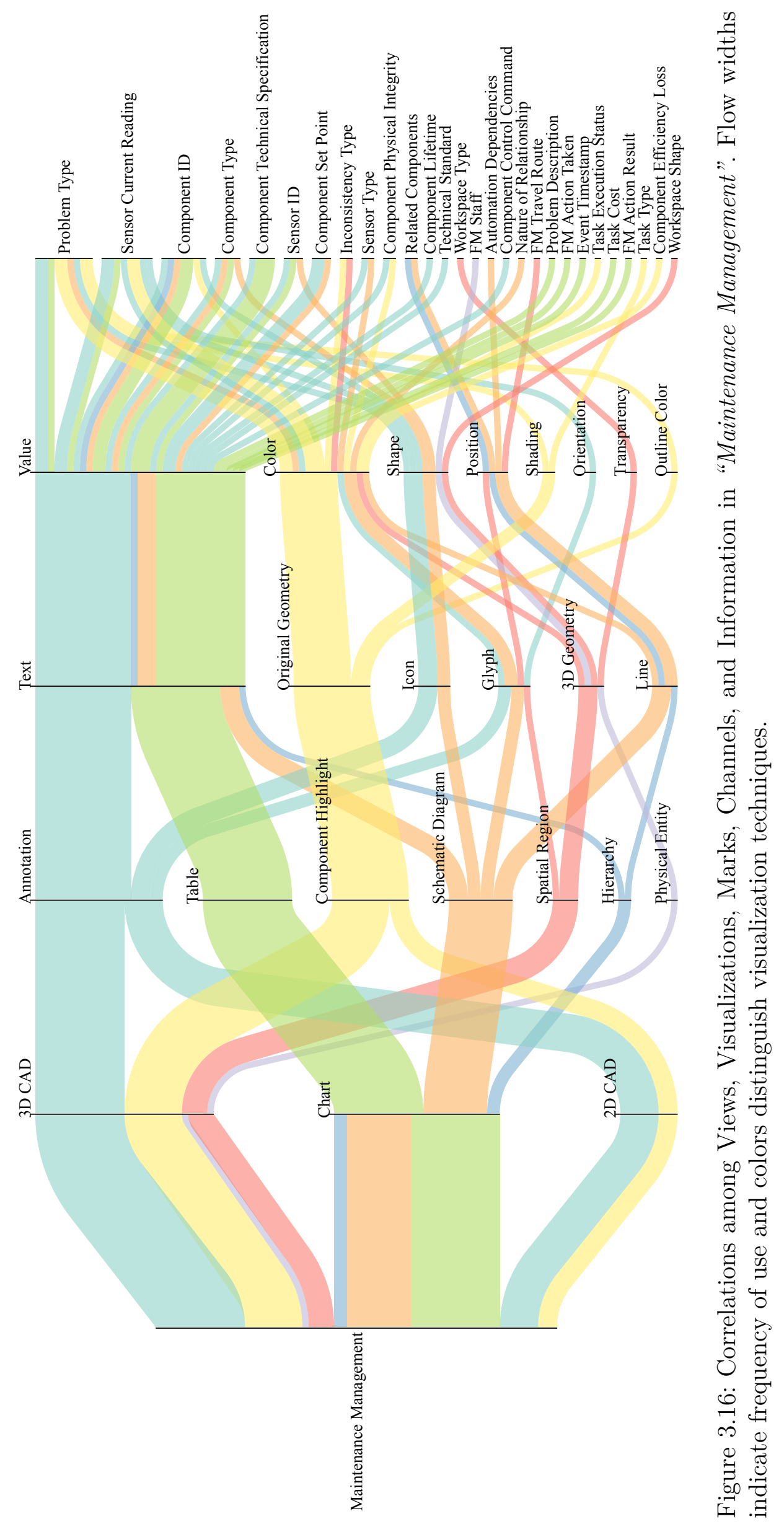




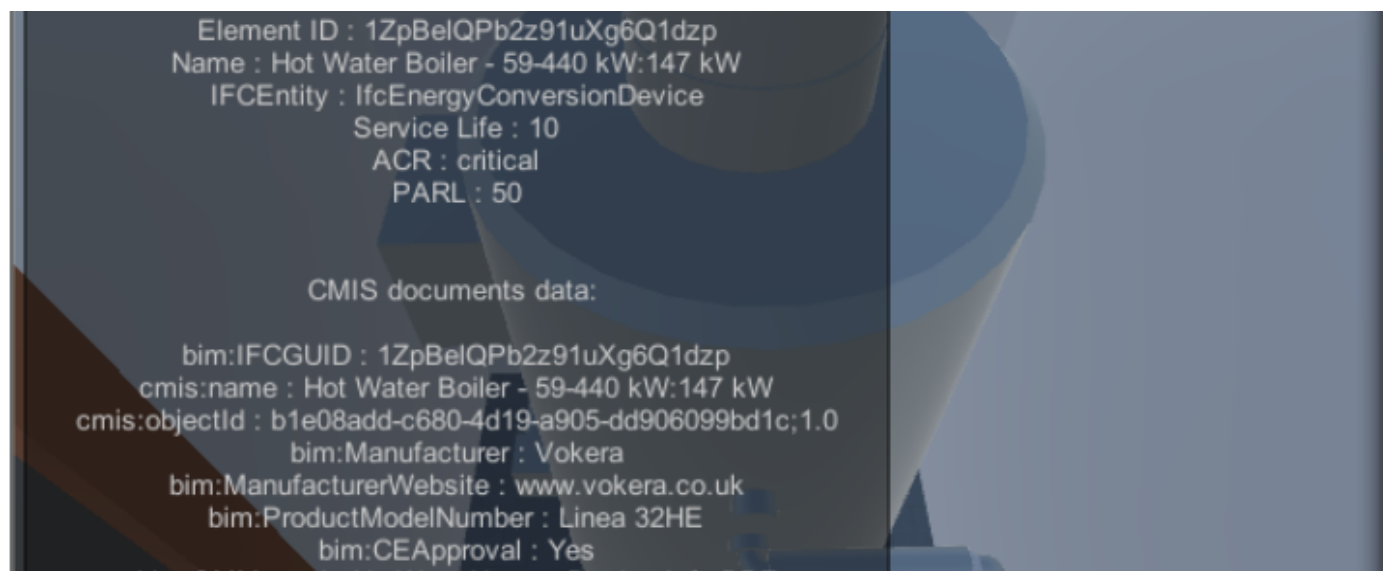

(a) Annotation [Patacas et al., 2016].

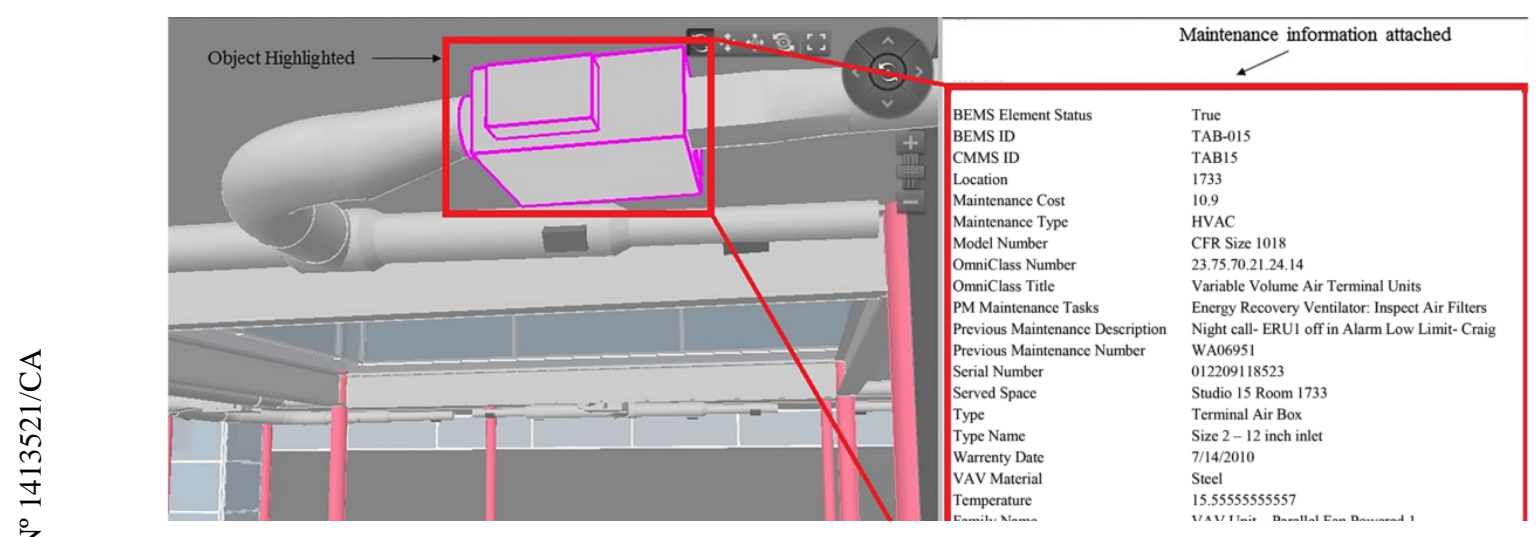

(b) Table [Shalabi \& Turkan, 2017].
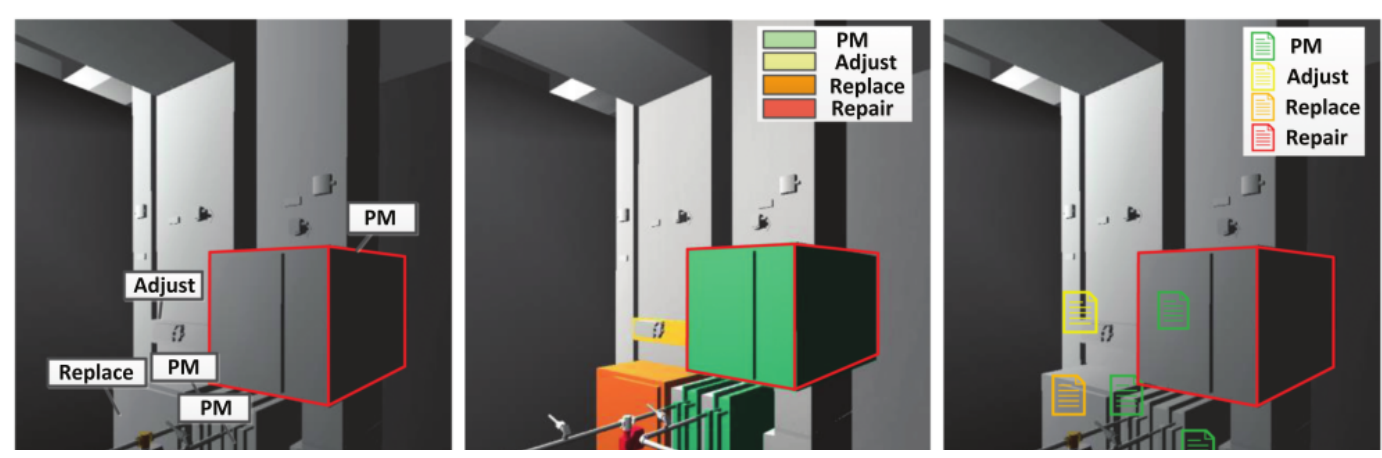

(c) Component Highlight [Yang \& Ergan, 2016].

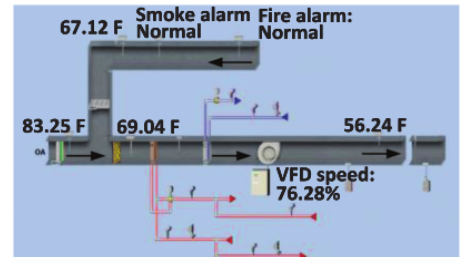

Option 3A

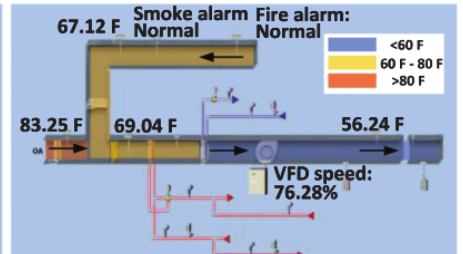

Option 3B

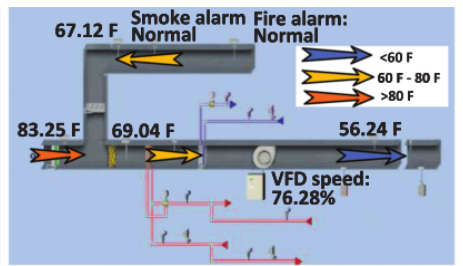

Option 3C

(d) Schematic Diagram [Yang \& Ergan, 2016].

Figure 3.17: Examples of the top 4 visualizations in "Maintenance Management". 
Identifying problems, tracking their root causes and estimating their consequences are all activities that require a deep understanding of logical relationships among facility components. Schematic Diagrams can convey these kinds of information in a direct and intuitive manner [Kim et al., 2010]. Moreover, facility managers are already familiar with these representations from supervisory systems [Boyer, 2009]. If physically locating a particular component is necessary, they can be linked to 3D CAD view for a more integrated analysis.

Figure 3.16 also indicates a few maintenance-related applications during "Design" phases. These research used Spatial Region and Physical Entity visualizations within the 3D CAD model. The first adds semi-transparent 3D geometries to indicate maintenance accessibility areas. The second adds 3D representations of field workers to evaluate the designed maintenance routes. Both strategies enrich the 3D CAD model to evaluate overall maintainability of installations. This brings the critical view of the facility manager to designers, who can then improve facility layout to avoid later maintenance issues, improving whole-life costs.

Table 3.5 summarizes the visualizations employed in "Maintenance Management". In conclusion, we have found these techniques to be quite similar to "Clash Detection". Both use Annotations and Component Highlights over the 3D CAD model to call attention to issues related to facility components. At the same time, "Maintenance Management" employs unique views such as Schematic Diagrams to improve understanding of causes and effects of problems. The current use case is also similar to "Energy Analysis": both need to investigate quantitative measurements from sensors. However, BIM applications for maintenance simply show these information as text within Tables or Annotations. We refer to our analysis in the previous use case for recommendations on how to improve this paradigm. As mentioned in Subsection 3.4.1, future work could also adapt schedule analysis tools to bring the benefits of virtual construction planning to virtual maintenance planning. 
Table 3.5: Overview of visualization applications in "Maintenance Management". Rows are ordered by frequency of use.

\begin{tabular}{|c|c|c|c|}
\hline Visualization & View & Information Types & Reviewed Work \\
\hline Annotation & 2D/3D CAD & $\begin{array}{l}\text { Scope (item, technical), } \\
\text { Facility (degradation, } \\
\text { problem, sensor) }\end{array}$ & $\begin{array}{l}\text { Patacas et al. [2016] and Yang \& Ergan } \\
\text { [2016] }\end{array}$ \\
\hline Table & Chart & $\begin{array}{l}\text { Scope (item, technical), } \\
\text { Facility (problem, sensor, } \\
\text { work log) }\end{array}$ & $\begin{array}{l}\text { Hallberg \& Tarandi [2011], Shalabi \& } \\
\text { Turkan [2017], and Wang et al. [2013a] }\end{array}$ \\
\hline Component Highlight & $2 \mathrm{D} / 3 \mathrm{D} \mathrm{CAD}$ & $\begin{array}{l}\text { Scope (item), Facility } \\
\text { (degradation, problem, } \\
\text { sensor), Schedule (task), } \\
\text { Quality (inconsistency) }\end{array}$ & $\begin{array}{l}\text { Hallberg \& Tarandi [2011], Liu \& Issa } \\
\text { [2014], Shalabi \& Turkan [2017], Williams } \\
\text { et al. [2014], and Yang \& Ergan [2016] }\end{array}$ \\
\hline Schematic Diagram & Chart & $\begin{array}{l}\text { Scope (item), Facility } \\
\text { (sensor, problem) }\end{array}$ & Yang \& Ergan [2016] \\
\hline Spatial Region & 3D CAD & $\begin{array}{l}\text { Schedule (task), Quality } \\
\text { (inconsistency), Facility } \\
\text { (work log) }\end{array}$ & Liu \& Issa [2014] and Wang et al. [2013b] \\
\hline Hierarchy & Chart & Scope (item) & Hallberg \& Tarandi [2011] \\
\hline Physical Entity & 3D CAD & Facility (work log) & Wang et al. [2013b] \\
\hline
\end{tabular}

\subsection{6}

\section{Summary of Findings}

Figure 3.18 displays a general overview of the preceding analysis. We have identified Chart and 3D CAD views as the most common means of visualizing information in the analyzed BIM use cases. Recurring Chart visualizations include Tables, Gantt, Hierarchies, Time-Distance, Bar, and Line. Schedule information was effectively visualized using Gantt Charts and Time-Distance Diagrams. Hierarchies was adequately used as linked views to provide contextsensitive information. Line and Bar Charts were also associated with a 2D/3D view to display quantitative data. We found that the abundance of Tables can overwhelm the user with too much textual information. Instead, BIM applications should always strive to display facility data visually, preferably using $2 \mathrm{D}$ or $3 \mathrm{D}$ CAD views.

Within the 3D CAD view, the majority of BIM information was presented with Visibility Animation, Annotations, Highlight Animation, and Component Highlight. Annotations and Component Highlights were adequately used to call attention to problems and design inconsistencies. However, Visibility and Highlight Animations should be avoided for not making evident important schedule issues. These techniques make it harder to understand task durations, sequencing, and spatio-temporal simultaneity. We observed that some analysis were hampered by too much visual clutter and occlusion, yet almost no research tackled these issues. 


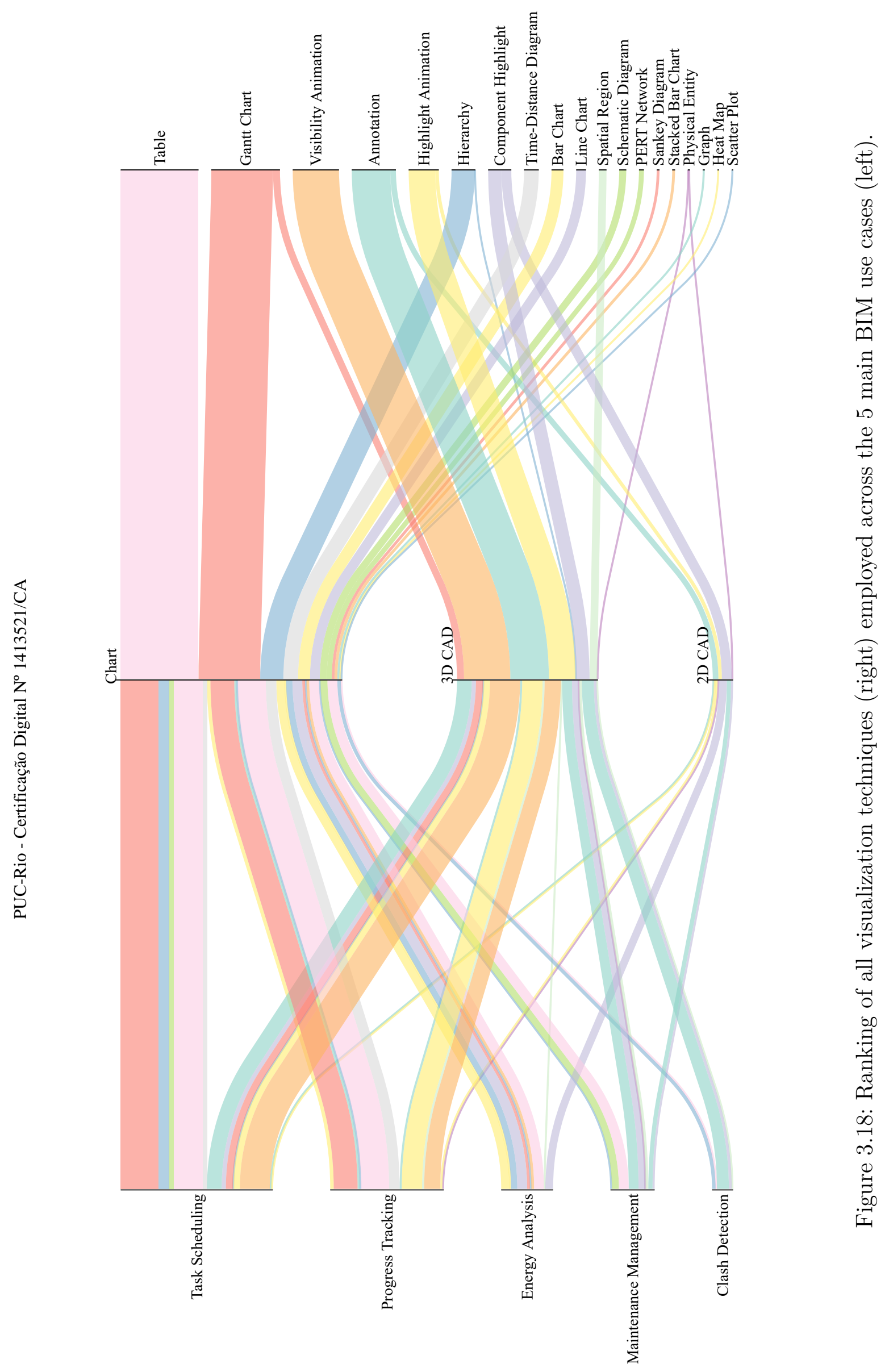


We also identified possible visualization improvements related to specific use cases. For example, "Clash Detection" and "Maintenance Management" techniques could automatically call attention to problems and inconsistencies. In addition, Task Scheduling and Progress Tracking could employ contextpreserving continuous animations. Moreover, Energy Analysis could benefit from scientific visualizations of physical simulations and sensor data within the 3D CAD model. Finally, Maintenance Management could explore alreadydeveloped schedule visualizations to enable virtual maintenance planning.

\section{6 Proposed Design Guidelines}

In Table 3.6, we suggest overall design principles for future research in Building Information Modeling. Each guideline focuses on specific issues observed in the preceding literature review. These recommendations were motivated by best practices from the visualization community.

Prefer graphical displays over text. Tables are a popular means of presenting various types of information in BIM. However, too much textual information can overwhelm the user, impairing his understanding and judgement. Researchers have long acknowledged the benefits of presenting information graphically [Borkin et al., 2013; Gibson, 1950; Tufte, 1983; Ware, 2004]. These studies have shown that human perception can process visual information faster and more accurately than other means. Adequate visualizations can bring forth important characteristics of the underlying dataset and help the user conduct his analysis [Bertini et al., 2011; Few, 2009; Keim, 2002; Keim et al., 2006; Yi et al., 2007]. For these reasons, future BIM research should refrain from tables if the information could otherwise be presented graphically.

Employ 2D/3D CAD views whenever possible. Building Information Modeling promotes the use of 3D CAD models as a central database of facility and project-related information. This integrated environment becomes a natural platform for engineers and project managers to conduct their analysis. Many use cases require the identification and correlation of information with building components and spatial regions. For example, accurate and reliable work planning need to consider spatio-temporal simultaneity to avoid workspace conflicts in the job site. Overall, 2D/3D CAD views can help the users in browsing for relevant data, understanding causes of problems, and evaluating their effects on surrounding physical areas [Cockburn \& McKenzie, 2002; Haining, 2003; Huk, 2006; Kraak \& Ormeling, 2013]. Therefore, BIM systems should always employ the virtual CAD model either to directly display information or to provide spatial highlights from other linked views. 
Make better use of coordinated multiple views. Only about half of previous work that make use of Charts also displays information within a spatial view, such as the 3D CAD model. Furthermore, many research do not take advantage of linking and brushing between these views. Visualization literature has already demonstrated the benefits of coordinating multiple views [Boton et al., 2012, 2011; Fredrikson et al., 2003; Keefe et al., 2009; Kehrer \& Hauser, 2013; North \& Shneiderman, 2000; Roberts, 2007; Wang Baldonado et al., 2000]. This scheme takes advantage of specialized visualizations to highlight different aspects of the same underlying dataset. We recommend future research in BIM to better exploit these interactions to improve analysis throughout a facility's life cycle.

Call attention to features of interest. Large-scale construction projects involve lots of information associated with complex 3D CAD models. Existing BIM software still require the user to manually browse through these datasets in search of relevant attributes and/or inconsistencies. Future solutions should evolve into expert systems that could intelligently aid engineers [Durkin \& Durkin, 1998; Liao, 2005]. In this scenario, visualization would play a major role in automatically calling attention to features of interest during exploratory analysis [Lamberti \& Wallace, 1990; Mackinlay et al., 2007]. For example, focus+context techniques could highlight important 3D geometries while preserving their spatial relationships [Bjork et al., 1999; Bjork \& Redstrom, 2000; Ellis \& Dix, 2007; Qu et al., 2009; Shneiderman, 1996].

Reduce visual clutter and occlusion in $3 \mathrm{D}$ CAD views. In complex 3D CAD models, it is often difficult to distinguish individual components and judge spatial relationships. The visualization community has already developed many techniques that could help overcome these issues. Feature distinction can be improved by outlines [Cole \& Finkelstein, 2010; Isenberg et al., 2003], tone mapping [Drago et al., 2003; Krawczyk et al., 2005; Reinhard et al., 2002], and luminance enhancement [Kleffner \& Ramachandran, 1992; Luft et al., 2006; Tai \& Inanici, 2012]. Richer illumination models can also improve perception: ambient occlusion [Shanmugam \& Arikan, 2007; Tarini et al., 2006] and real-time shadows [Barroso \& Celes, 2007; Govindaraju et al., 2003; Wyman et al., 2015]. To reduce visual clutter, visualizations can aggregate uninteresting details [Chang et al., 2007; Elmqvist \& Fekete, 2010] or replace them with simpler abstract representations [Glander \& Döllner, 2009; Semmo et al., 2012]. Magic lenses can filter unwanted details in areas of interest [Kruger et al., 2006; Tominski et al., 2017; Trapp et al., 2008]. Similar techniques can also overcome 3D occlusion issues [Elmqvist \& Tsigas, 2008]. 
Use continuous animations to preserve context. Since early days, Building Information Modeling has been applied to virtual construction planning. In this use case, $4 \mathrm{D}$ visualizations have been developed to illustrate construction sequences within 3D CAD models. Traditional implementations, however, rely on discrete Visibility animations that fail to make evident important planning characteristics. It is impossible to overview the entire schedule since parts of the 3D model that correspond to future tasks remain hidden. Moreover, activity durations must be inferred from the length of time that corresponding geometries are colored as "in-progress". Similarly, predecessor/successor relationships are not directly obvious and must be derived by the visual sequence of appearing geometries. Visualization research have suggested that animations should be implemented as continuous visual transformations [Heer \& Robertson, 2007; Robertson et al., 2008]. This scheme helps the user keep track of state transitions and brings his attention towards objects of interest in the scene [Bartram \& Ware, 2002; Healey \& Enns, 2012].

Take advantage of scientific visualization. Physical simulations play an important part in Building Information Modeling. Finite-element methods (FEM) evaluate mechanical and structural characteristics of a facility. Computational-fluid dynamics (CFD) predict the flow of air to understand cooling/heat propagation. Additionally, modern facilities are equipped with sensors that provide real-time measurements of ambient temperature and energy consumption, among others. These large amounts of quantitative data are all associated with 3D CAD geometries and/or spatial regions. Scientific visualization research have already developed several techniques to analyze these kinds of datasets [Brodlie et al., 2012; Nielson et al., 1997; Wong \& Bergeron, 1994]. Meanwhile, many BIM applications still rely on tables, charts, and plots for such analysis. Future solutions could make better use of the suggested visualizations to improve facility design and operation.

Choose adequate color schemes depending on data types. Colors can be a powerful mechanism to call the user's attention to geometries of interest. Studies on human perception have determined that colors are useful in either labeling categories or mapping quantitative data [Few, 2009; Silva et al., 2011; Tufte, 1983; Ware, 2004]. We have observed that some BIM applications mix these, displaying both qualitative and quantitative information with the same color scheme. One example are Highlight Animations that encode task execution status together with task delay amounts. Future work should take care in choosing an adequate color scheme and applying it for separate data types [Bergman et al., 1995; Harrower \& Brewer, 2003; Healey, 1996; Zhou \& Hansen, 2016]. 
Table 3.6: Proposed design guidelines based on the visualization issues observed in current BIM applications.

\begin{tabular}{|c|c|c|}
\hline Issue & Guideline & Related Work \\
\hline $\begin{array}{l}\text { Abundance of textual } \\
\text { displays }\end{array}$ & $\begin{array}{l}\text { Prefer graphical } \\
\text { displays over text }\end{array}$ & $\begin{array}{l}\text { Bertini et al. [2011], Borkin et al. [2013], } \\
\text { Few [2009], Gibson [1950], Keim [2002], } \\
\text { Keim et al. [2006], Tufte [1983], Ware } \\
\text { [2004], and Yi et al. [2007] }\end{array}$ \\
\hline $\begin{array}{l}\text { Lack of spatial } \\
\text { context }\end{array}$ & $\begin{array}{l}\text { Employ } 2 \mathrm{D} / 3 \mathrm{D} \text { CAD } \\
\text { views whenever } \\
\text { possible }\end{array}$ & $\begin{array}{l}\text { Cockburn \& McKenzie [2002], Haining } \\
\text { [2003], Huk [2006], and Kraak \& Ormeling } \\
{[2013]}\end{array}$ \\
\hline $\begin{array}{l}\text { Unrelated abstract } \\
\text { and spatial views }\end{array}$ & $\begin{array}{l}\text { Make better use of } \\
\text { coordinated multiple } \\
\text { views }\end{array}$ & $\begin{array}{l}\text { Boton et al. [2012, 2011], Fredrikson et al. } \\
\text { [2003], Keefe et al. [2009], Kehrer \& Hauser } \\
\text { [2013], North \& Shneiderman [2000], } \\
\text { Roberts [2007], and Wang Baldonado et al. } \\
\text { [2000] }\end{array}$ \\
\hline $\begin{array}{l}\text { Laborious exploratory } \\
\text { analysis }\end{array}$ & $\begin{array}{l}\text { Call attention to } \\
\text { features of interest }\end{array}$ & $\begin{array}{l}\text { Bjork et al. [1999], Bjork \& Redstrom } \\
\text { [2000], Durkin \& Durkin [1998], Ellis \& Dix } \\
\text { [2007], Lamberti \& Wallace [1990], Liao } \\
\text { [2005], Mackinlay et al. [2007], Qu et al. } \\
\text { [2009], and Shneiderman [1996] }\end{array}$ \\
\hline $\begin{array}{l}\text { Complex 3D CAD } \\
\text { models }\end{array}$ & $\begin{array}{l}\text { Reduce visual clutter } \\
\text { and occlusion in } 3 \mathrm{D} \\
\text { CAD views }\end{array}$ & $\begin{array}{l}\text { Barroso \& Celes [2007], Chang et al. [2007], } \\
\text { Cole \& Finkelstein [2010], Drago et al. } \\
\text { [2003], Elmqvist \& Fekete [2010], Elmqvist } \\
\text { \& Tsigas [2008], Glander \& Döllner [2009], } \\
\text { Govindaraju et al. [2003], Isenberg et al. } \\
\text { [2003], Kleffner \& Ramachandran [1992], } \\
\text { Krawczyk et al. [2005], Kruger et al. [2006], } \\
\text { Luft et al. [2006], Reinhard et al. [2002], } \\
\text { Semmo et al. [2012], Shanmugam \& Arikan } \\
\text { [2007], Tai \& Inanici [2012], Tarini et al. } \\
\text { [2006], Tominski et al. [2017], Trapp et al. } \\
\text { [2008], and Wyman et al. [2015] }\end{array}$ \\
\hline $\begin{array}{l}\text { Animations as } \\
\text { discrete snapshots }\end{array}$ & $\begin{array}{l}\text { Use continuous } \\
\text { animations to } \\
\text { preserve context }\end{array}$ & $\begin{array}{l}\text { Bartram \& Ware [2002], Healey \& Enns } \\
\text { [2012], Heer \& Robertson [2007], and } \\
\text { Robertson et al. [2008] }\end{array}$ \\
\hline $\begin{array}{l}\text { No spatial display of } \\
\text { physical simulations }\end{array}$ & $\begin{array}{l}\text { Take advantage of } \\
\text { scientific visualization }\end{array}$ & $\begin{array}{l}\text { Brodlie et al. [2012], Nielson et al. [1997], } \\
\text { and Wong \& Bergeron [1994] }\end{array}$ \\
\hline $\begin{array}{l}\text { Inadequate color } \\
\text { coding within } 2 \mathrm{D} / 3 \mathrm{D} \\
\text { views }\end{array}$ & $\begin{array}{l}\text { Choose adequate } \\
\text { color schemes } \\
\text { depending on data } \\
\text { types }\end{array}$ & $\begin{array}{l}\text { Bergman et al. [1995], Few [2009], Harrower } \\
\text { \& Brewer [2003], Healey [1996], Silva et al. } \\
\text { [2011], Tufte [1983], Ware [2004], and Zhou } \\
\text { \& Hansen [2016] }\end{array}$ \\
\hline
\end{tabular}




\section{4}

\section{CasCADe Visualization System}

Throughout the years, different visualization techniques have been applied to improve analysis and decision making over BIM models [Ding et al., 2014]. These virtual designs can be enhanced with $4 \mathrm{D}$ visualizations $(3 D+$ time) for virtual construction planning. Engineers can easily identify, analyze and communicate problems regarding spatio-temporal aspects of construction processes. More accurate and reliable plans consequently reduce waste and improve productivity.

Despite all these potential benefits, BIM-based 4D visualization systems are yet to be widely adopted in real-world AEC projects [Howell \& Batcheler, 2003; Miettinen \& Paavola, 2014]. This can be traced back to limitations in the analytical features provided by existing solutions [Heesom \& Mahdjoubi, 2004]. They typically follow the same principal logic: a discrete Visibility Animation where 3D objects appear over time according to their construction sequence [Mahalingam et al., 2010]. This limits the visual analysis to individual snapshots of the entire construction plan. Additionally, task durations and inter-dependencies are not evident and must be inferred from the animation sequence. Typical scheduling problems such as spatio-temporal simultaneity are also not immediately apparent.

This chapter presents CasCADe, a novel 4D visualization system that aims to improve upon these previous approaches. We first present a list of the main design requirements for 4D construction schedule analysis based on the consultation of experienced AEC professionals. Motivated by the shortcomings in previous research, we present our second contribution: the design of CasCADe's visualization framework. Its core concept is to map time information as a spatial dimension to create an effect of cascading equipment in a 3D exploded view (Figure 4.1). This unique environment brings several advantages over existing approaches. A general overview of the entire construction plan is now always available: at any moment, it is possible to glance upwards or downwards to identify future or past activities. Moreover, relative $3 \mathrm{D}$ positioning intuitively indicate tasks that occur simultaneously and physically near each other. We also describe several analytical tools developed to highlight spatio-temporal issues in the construction schedule. 


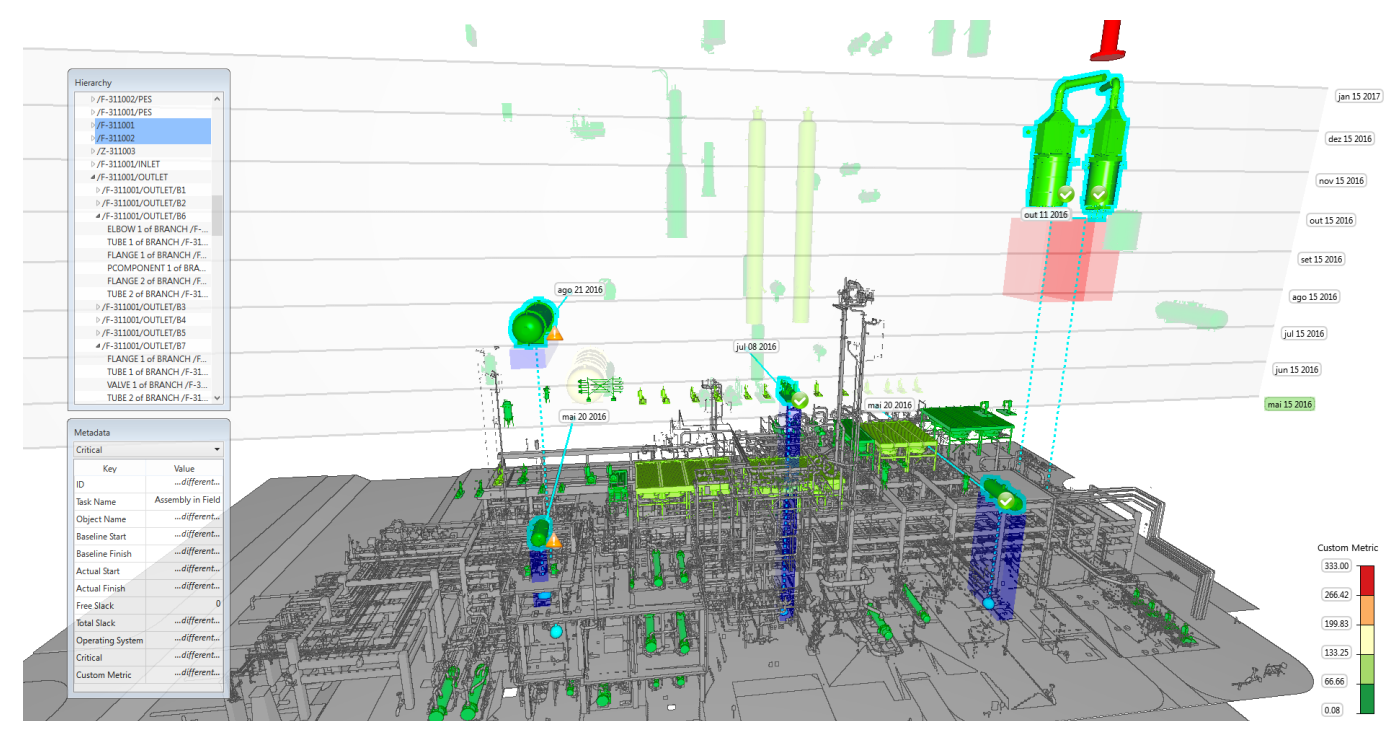

Figure 4.1: CasCADe's unique 4D visualization combines the intuitive task sequencing from PERT/Gantt charts with the spatial awareness conveyed by 3D CAD models to bring forth problems and inconsistencies in engineering construction schedules.

CasCADe was collaboratively designed and evaluated by AEC professionals using the real-world construction schedule of an Oil \& Gas process plant. We describe how it helped the experts identify and understand several issues in this large-scale engineering project. The results of this study motivated the oil company to improve its work processes for future enterprises. We believe the proposed framework opens-up new opportunities for visualization research in the AEC industry.

\section{1}

\section{Related Work}

Collier \& Fischer [1995] conducted one of the earliest research on 4D CAD visualization in the AEC industry. The article implemented the already described Visibility Animation: 3D objects appear over time to indicate their fabrication and assembly sequence (see Subsection 3.5.2). Many research followed this approach to facilitate the generation of construction schedules [Adjei-Kumi \& Retik, 1997; Fischer \& Aalami, 1996] and link them with 3D models [Aouad, 1999; McKinney et al., 1998, 1996]. The following subsections highlight other visualization schemes closely related to CasCADe's approach.

\subsection{1}

\section{Work Space, Site Utilization and Safety}

4D CAD visualizations support planning construction site layout and occupancy. Physical areas can be automatically identified from schedule data [Ak- 
inci et al., 2002] to manage spatial conflicts on the job site [Guo, 2002; Liapi, 2003] and to highlight safety risks during construction works [Zhou et al., 2012b]. Semi-transparent volumes and color maps are the most common visualizations techniques to classify these regions of space in 3D CAD models.

\subsection{2}

\section{Coordinated Multiple Views}

To facilitate analysis of diverse construction information, coordinated multiple views are associated with the $4 \mathrm{D}$ CAD model to display contextsensitive data for resource allocation [Chau et al., 2004; Jongeling \& Olofsson, 2007] and cost management [Tanyer \& Aouad, 2005]. Examples include hierarchies, line-of-balance diagrams, data tables and time series plots, as well as frameworks to arrange multiple views according to the needs of different users [Boton et al., 2013; Boton et al., 2011; Froese, 2010; Kubicki et al., 2007].

\subsection{3}

\section{Abstract Graphical Overlays}

Lean construction methods focus on visual management to improve collaboration between multi-disciplinary teams [Arayici et al., 2011]. Following these principles, 4D CAD visualizations have been enhanced with symbolic representations as abstract graphic overlays to convey work flow, resource demand, and construction status [Sacks et al., 2009] or to call attention to highrisk activities [Hartmann et al., 2012]. Similar works explored user annotations to highlight construction issues within the 3D CAD model [McKinney et al., 1998].

\subsection{4}

\section{Exploded Views}

Previous researches have demonstrated the usefulness of exploded views to convey spatio-temporal relationships between components of interest. Applications range from visually exploring volumetric datasets [Bruckner \& Groller, 2006], examining equipment assemblies [Li et al., 2008], and navigating through architectural models [Niederauer et al., 2003]. Other works have also explored this concept for assembly planning of complex mechanical parts [Da Xu et al., 2012; Driskill \& Cohen, 1995]. 


\subsection{5}

\section{Space-Time Cube}

Time-geographical studies have proposed a 4D visualization technique named the space-time cube. It allows for spatio-temporal analysis of events on maps [Kristensson et al., 2009; Miller, 2005] and other applications in general [Bach et al., 2014]. A typical use case is to trace 4D event trajectories as lines [Gatalsky et al., 2004] or stacked color-mapped bands [Tominski et al., 2012]. Another goal is to identify clustering patterns through heat maps and 3D plots [Kwan \& Lee, 2004], or proportional symbols and volumetric rendering [Nakaya \& Yano, 2010].

\subsection{6}

\section{Limitations of Previous Approaches}

As already noted in Subsection 3.5.2, Visibility Animations bring several limitations to virtual construction planning:

- Schedule overview is not practical since at any given time parts of the 3D model that correspond to future tasks remain hidden;

- Activity duration is not apparent and must be derived by the length of time that corresponding 3D objects remain "in-progress";

- Predecessor and successor relationships are not directly presented and must be inferred by the sequence of appearing geometries;

- Spatio-temporal simultaneity is not evident, making it difficult to avoid workspace conflicts in the construction site;

Unlike these traditional animations, CasCADe explores the concept of mapping time as a spatial dimension. Previous researches have studied this approach in exploded views and the space-time cube. CasCADe differs from these by focusing on the detailed analysis of individual events at fixed locations over extended periods of time. Instead of looking for overall trends and patterns, its analytical functions are designed to make evident fine-grained characteristics and relationships, such as event durations, inter-dependencies, and spatio-temporal overlaps.

\section{2}

\section{Designing CasCADe}

This section describes CasCADe's development methodology and identifies the main requirements for $4 \mathrm{D}$ construction schedule analysis. 


\subsection{1}

\section{User-Centered Methodology}

CasCADe's development followed a user-centered design methodology: domain experts were involved from the beginning in requirements analysis, throughout implementation and testing [Sedlmair et al., 2012]. This research is part of an ongoing partnership with a major oil company, whose professionals work closely with academic researchers using real-world datasets. Three collaborators were involved: (1) Schedule specialist with 15 years of experience (industrial engineer); (2) Field inspector with 9 years of experience (civil engineer); (3) Piping and equipment specialist with 11 years of experience (mechanical engineer). They participated in regular review sessions in an iterative design and implementation process. These meetings were fundamental to better understand user tasks and collect design suggestions through informal interviews. This feedback guided the concurrent development of CasCADe's visualization framework and analytical functions.

\subsection{2}

\section{Task and Data Requirements}

Engineering construction schedules contain diverse types of planning information. Some are numerical quantities, such as work durations, which can be displayed using color mapping. Others define categories, like assemblies that belong to the critical path. These can be made evident by highlighting their corresponding physical entity. In addition, schedule data can be related to different kinds of physical support, i.e. individual geometries or spatial regions. These requirements were classified by task and data type to help select appropriate visualization techniques [Keim, 2002].

Table 4.1 specifies the main design requirements for analyzing construction schedules with $4 \mathrm{D}$ visualizations. The first two use cases consist in acquiring a general understanding of the construction plan and determining which activities need to be further inspected. The AEC professionals typically spend more time in use cases 3-5, where they carefully examine prioritized assemblies and validate their constructability. Note that this order matches the visualinformation seeking mantra of overview first, zoom and filter, then details on demand [Shneiderman, 1996]. Section 4.4 further explains these user tasks and relates them to the analytical features implemented in CasCADe. This non-exhaustive list presents only the fundamental requirements found in past literature, as supplemented by the three interviewed AEC professionals. 


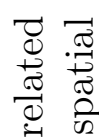

흥

突包

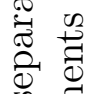

की

ర్

$\bigcup_{0}^{\infty} 0$

营

\&:

氖.]

$\stackrel{\circ}{\circ}$

धृ

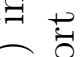

(ㅇํㅇ

水解

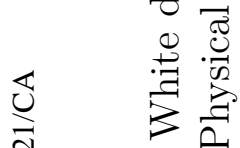

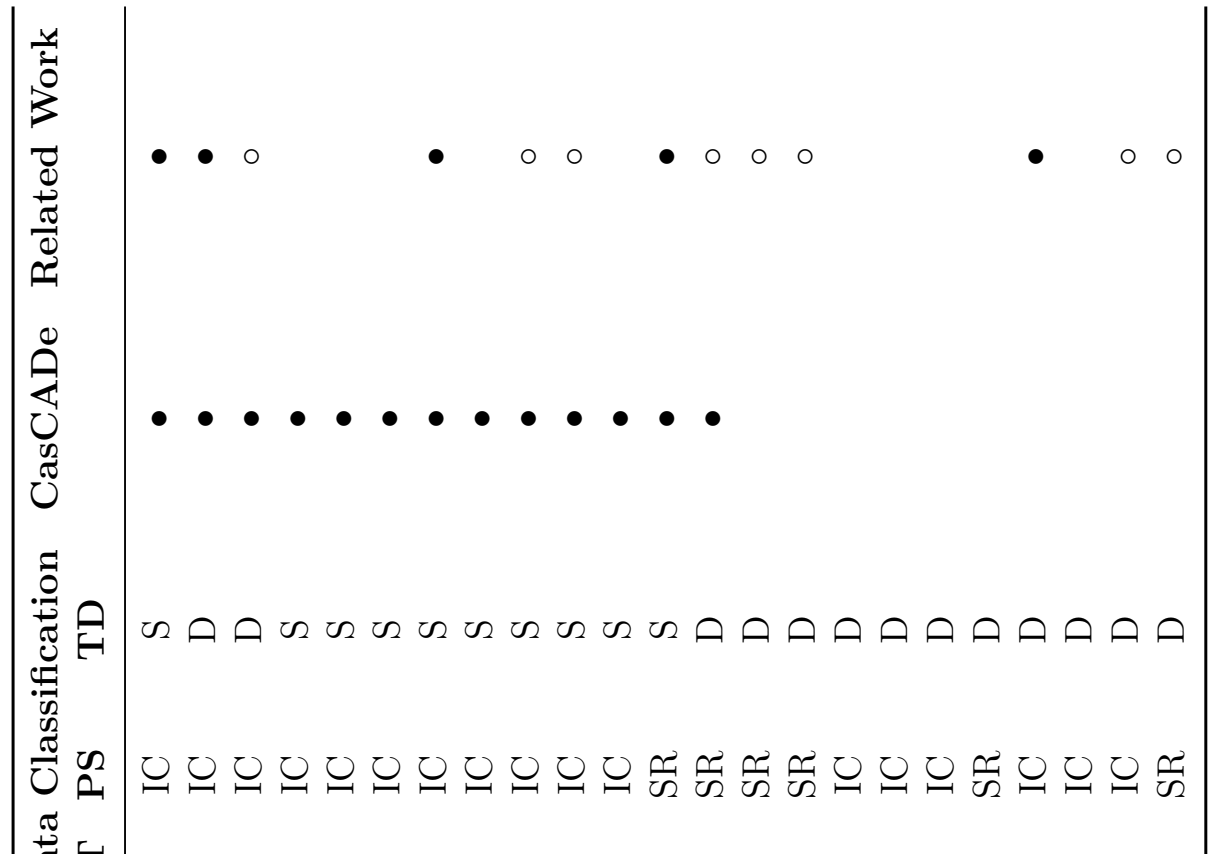

$\dot{\mathscr{D}} \dot{\vec{\vartheta}}$

过

응.유

范

荡

ชิ

궁

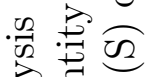

氶

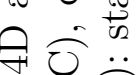

을

范

:

छ्व

苛茵

क्षे है

है

$\ddot{\theta} \underset{\tilde{\sigma}}{\ddot{\theta}}$

$\forall \stackrel{\square}{2}$

ค๊

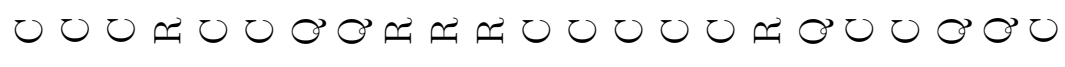

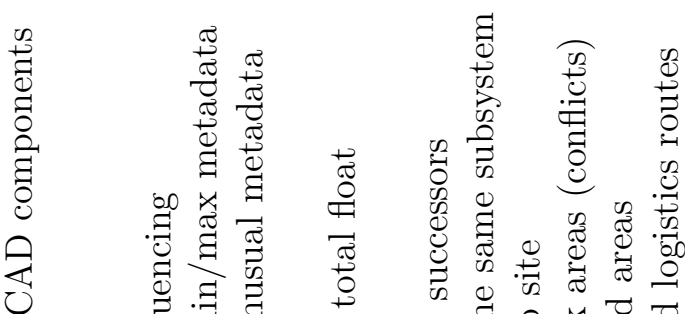

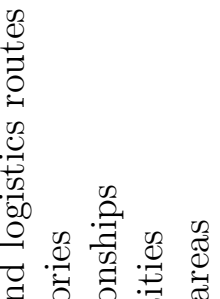

.

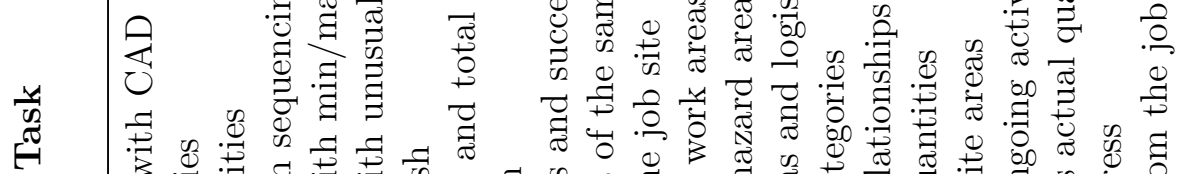

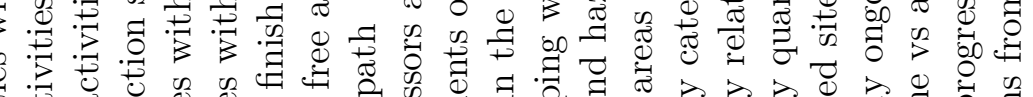

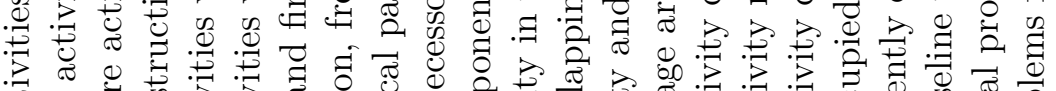

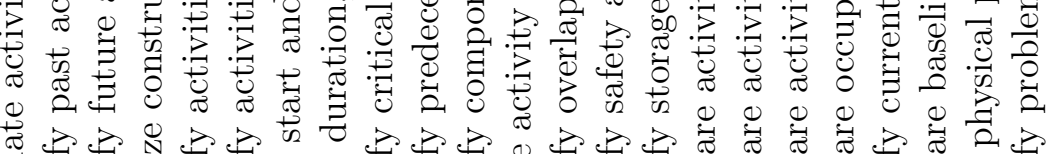

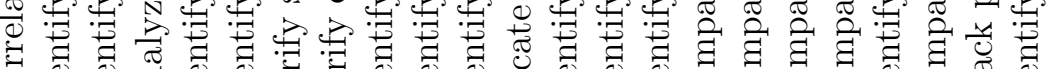

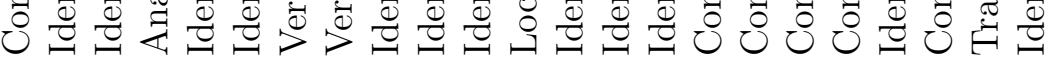
ఈ

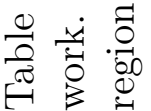


The last two columns compare the requirements met by CasCADe's visualization with traditional approaches from related work. Note that existing solutions only partially satisfy use cases 1, 4, 5, and 7. Moreover, several requirements are only satisfied by separate individual systems, as indicated by the elevated number of white dots ( $\operatorname{circ}$ ). No single solution provides a wide array of analysis functions. These two observations lead to the conclusion that previous research focused more on broadening the scope of application of $4 \mathrm{D}$ visualizations than on improving elementary schedule analysis capabilities.

Unlike these approaches, CasCADe was designed to tackle the more fundamental use cases 1 through 5 . These mainly determine whether a construction schedule will be feasible in practice. CasCADe's goal is to provide a single feature-rich information visualization in two ways: (i) by supporting a wider variety of user tasks in the same $4 \mathrm{D}$ environment; and (ii) by providing more than one visual technique to simultaneously display temporal information (e.g. graphical overlays and color-coding). This strategy facilitates metadata correlation and promotes a broader understanding of the underlying plans.

\section{3}

\section{Proposed Visualization Framework}

This section describes the main concepts behind CasCADe's visualization framework.

\subsection{1 \\ Background Concepts}

Traditional approaches to construction planning focus only on temporal aspects through Gantt charts and PERT network diagrams. These 2D views do not capture the spatial aspects necessary to create a truly executable construction plan. Recent research proposed many enhancements to these environments: graphical overlays, links and highlights for relationships, and comparison between multiple schedules [Tory et al., 2013]. For future work, the authors suggested extending their approach to 3D CAD models.

Parallel to this, studies on BIM have demonstrated many benefits in integrating and presenting non-spatial information within 3D CAD models [Koo \& Fischer, 2000; Nielsen \& Erdogan, 2004; Staub-French \& Khanzode, 2007]. These systems improve communication and collaboration between specialist teams [Bouchlaghem et al., 2005; Mahalingam et al., 2010]. This is likely because the 3D environment explores the domain expert's cognitive memory to identify components of interest and relate them with surroundings [Gibson, 1950; Healey \& Enns, 2012; Kleffner \& Ramachandran, 1992]. 
(a)

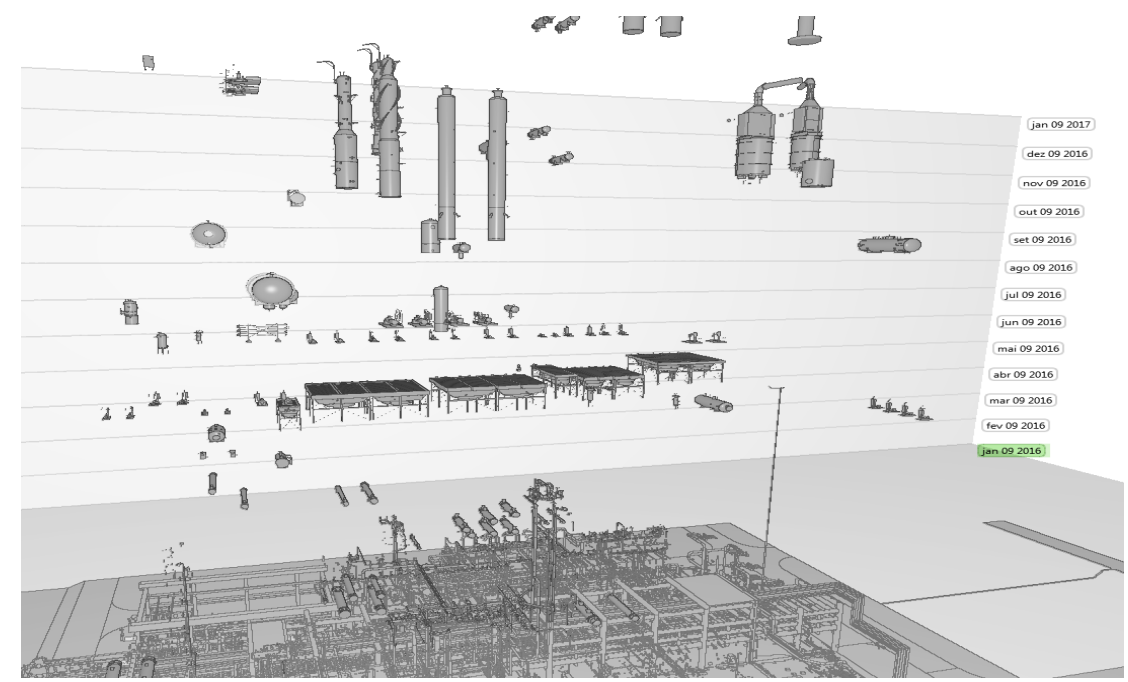

(b)
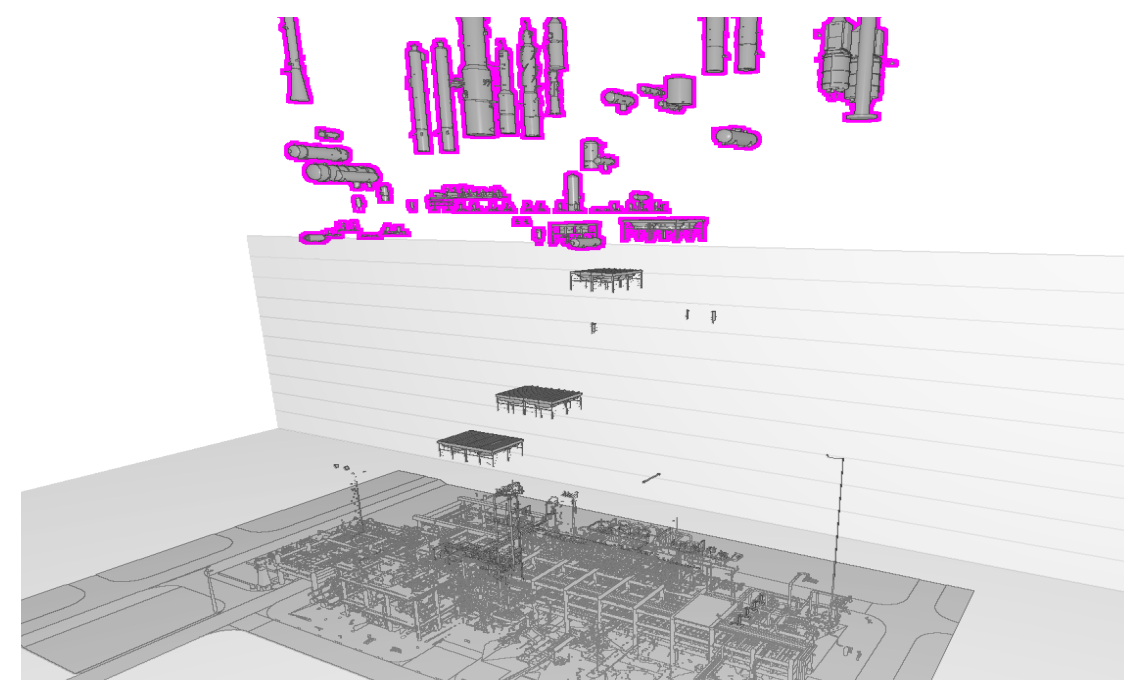

Figure 4.2: The proposed cascading visualization enables an overview of the entire schedule (a) and highlights future construction works (b).

\subsection{2}

\section{Cascading Visualization}

CasCADe introduces a $4 \mathrm{D}$ visualization framework that uniquely combines the main features of $2 \mathrm{D}$ and $3 \mathrm{D}$ environments. Its main principle is to use one of the 3D CAD model's spatial coordinates to present time, similar to PERT/Gantt charts. Geometries are translated vertically along the z-axis according to the finish dates of corresponding schedule tasks (Figure 4.2a). This way, the remaining $x$ and $y$ coordinates preserve crucial information about each activity's location at the job site.

All geometries, regardless of their original elevations in the $3 \mathrm{D} \mathrm{CAD}$ model, are mapped along the z-axis using the same frame of reference: a horizontal plane, located at the bottom of the vertical time axis, which represents the "current reference date". This avoids any ambiguity when visually relating nearby geometries in the $4 \mathrm{D}$ environment. The final $z$ coordinate of each object 
is computed using the following equations:

$$
\begin{aligned}
& Z_{\text {obj }}=Z_{\text {plane }}+\frac{\left(\text { FinishDate }_{\text {task }}-\text { CurrDate }\right)}{\left(\text { LastDate }_{\text {plot }}-\text { CurrDate }\right)} * \text { Size }_{\text {plot }} \\
& \text { LastDate }_{\text {plot }}=\text { CurrDate }+ \text { Count }_{\text {Interval }} * \text { Days }_{\text {Interval }}
\end{aligned}
$$

These equations perform a linear mapping of the task's finish date $\left(\right.$ FinishDate $\left._{\text {task }}\right)$ against the currently available time range (LastDate plot $_{-}$ CurrDate). If the fractional term is greater than 1.0, the task lies above the vertical time axis (Figure 4.2b). The user can change the current date (CurrDate) and adjust the plot area to handle any time scale: days, weeks, months or years (Days Interval); how much far ahead in time to examine $\left(\right.$ Count $\left._{\text {Interval }}\right)$; and the vertical size in scene units $\left(\right.$ Size $\left._{\text {plot }}\right)$. The plot can also be translated vertically $\left(Z_{\text {plane }}\right)$, away from the scene's visual clutter.

The choice of axis to plot time should reflect the main characteristics of the underlying 3D CAD model. For an Oil \& Gas plant, the horizontal plane still preserve crucial positioning information to illustrate assembly locations. Depending on the type and physical layout of the facility, the visualization could use other axis combinations to plot time while preserving spatial locations. Similar to traditional exploded views, multiple cascading reference frames could be used simultaneously to illustrate assembly sequencing of complex parts.

\section{4}

\section{Analytical Features of the CasCADe System}

Table 4.2 enumerates the analytical functions implemented within CasCADe's visualization framework. Different use cases and tasks from Subsection 4.2.2 guided the design of each set of tools, as well as recommendations from previous research [Castronovo et al., 2014]. The following subsections describe which problem-solving tasks are facilitated by these functionalities and compares them with related techniques from the literature.

\subsection{1}

\section{Overview Schedule}

The AEC professionals typically begin schedule review sessions by crosschecking recently completed activities and verifying the remaining construction sequence. The 3D perspective camera in the proposed visualization framework can introduce difficulties in visually correlating geometries in time and space [Shneiderman, 2003]. To prevent this, the system provides projection aids to identify task finish dates (Figure 4.5a) and locations on the job site (Figure 4.5b). 


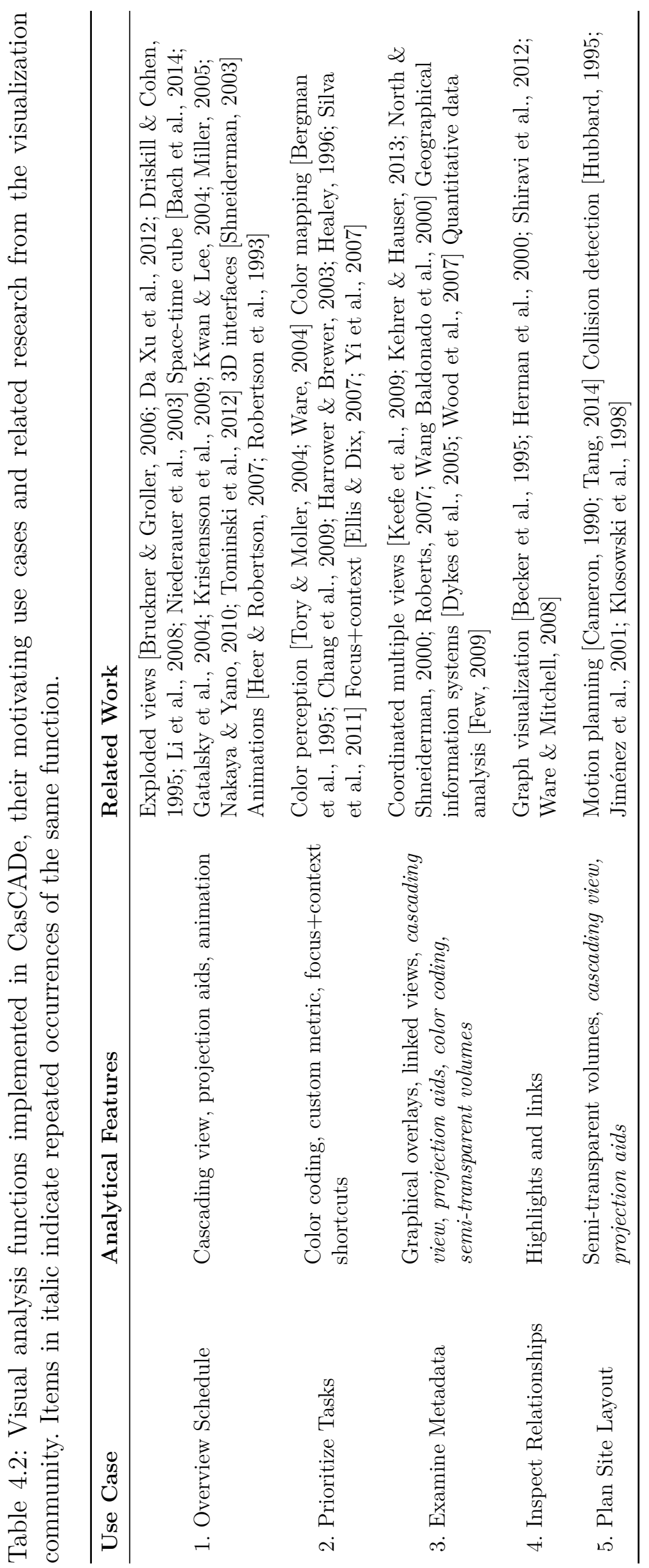


Previous work suggested animations can be used to attract attention, engage the user and provide a narrative context that facilitate learning [Heer \& Robertson, 2007; Robertson et al., 1993]. Following these precepts, CasCADe implements an animation to enhance perception of time evolution and task sequencing (Figure 4.3). As simulation progresses, the system translates downwards schedule-related objects, one step closer to the horizontal reference plane. Geometries that cross this boundary are automatically positioned at their target locations in the 3D CAD model.

\subsection{2}

\section{Prioritize Tasks}

Given the size and scope of a construction schedule, the engineering experts need to prioritize detailed activity analysis. This requires looking for discrepancies and anomalies in the temporal metadata associated to each 3D CAD component. CasCADe color-codes geometries to call the user's attention to these inconsistencies (Figure 4.4a). Colors are useful in labeling categories and mapping quantitative data [Tory \& Moller, 2004; Ware, 2004]. Researches have also shown the importance of choosing adequate mapping schemes [Bergman et al., 1995; Healey, 1996; Silva et al., 2011]. In CasCADe, the user is free to choose any schedule metadata to be presented using one of its many configurable palettes [Chang et al., 2009; Harrower \& Brewer, 2003].

The engineering collaborators requested the ability to create a customized metric associated with the color mapping. Their motivation was that individual attributes may not indicate certain kinds of inconsistencies. Therefore, CasCADe allows for a custom mathematical formula to be input in a text box using pre-defined symbols and constants. This unique functionality opens up the possibility of different kinds of analysis, such as: estimating probability of delays, leveling resources between simultaneous activities, comparing planned vs actual work execution, measuring costs vs productivity.

After selecting activities of interest, the user can activate focus + context shortcuts for more detailed inspection [Yi et al., 2007]. As shown in Figure 4.4b, focused geometries are highlighted with colored contours while context is provided by surrounding semi-transparent geometries. When color-coding is active, double-clicking on one of the legend's colors automatically focuses the camera on related geometries and sets the remainder of the scene as transparent. The user can also quickly toggle visibility of non-selected activities as a means to reduce visual clutter [Ellis \& Dix, 2007]. Note these effects are not possible in traditional Visibility/Highlight animations. 

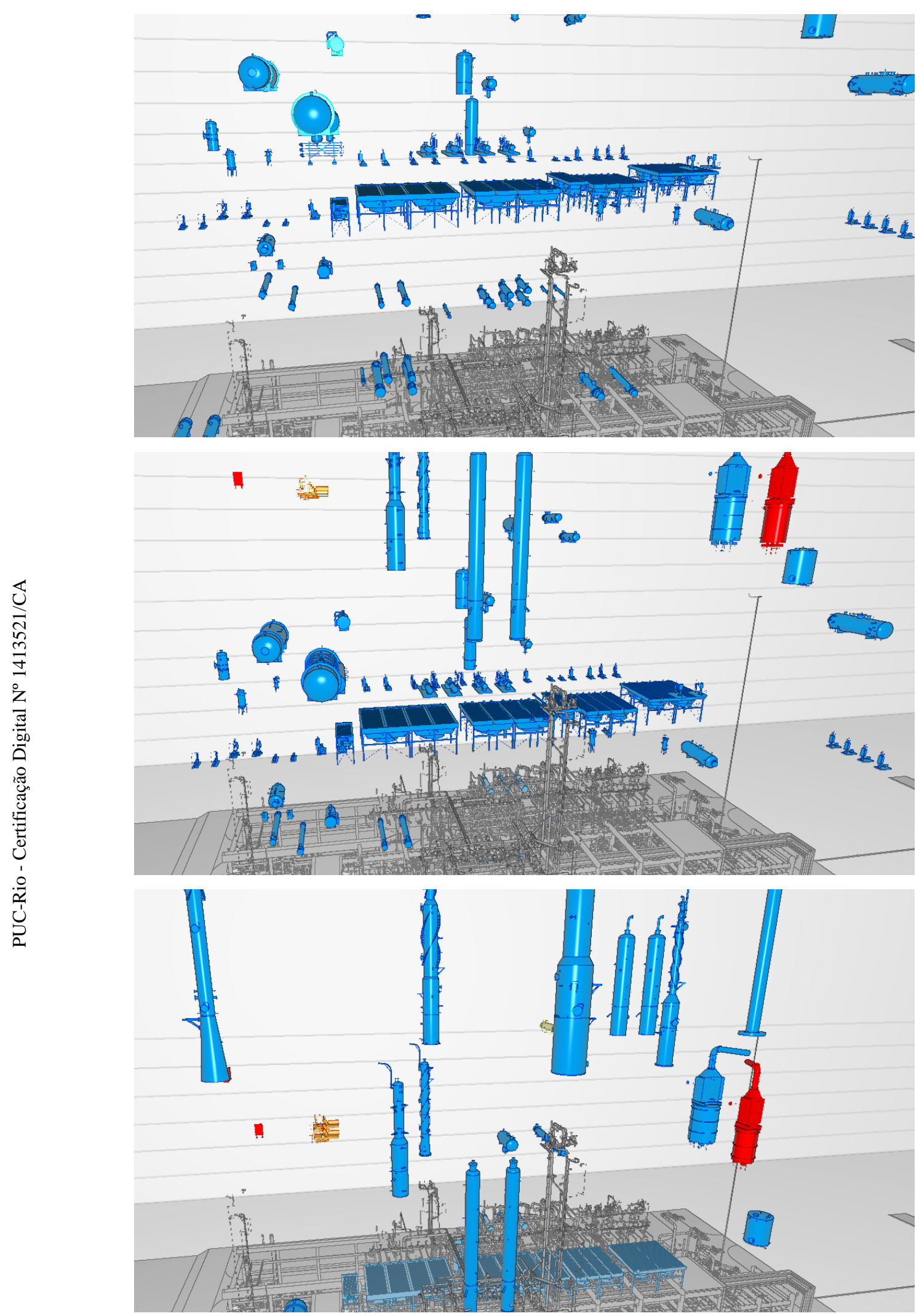

Figure 4.3: Sequential snapshots of CasCADe's 4D animation. 


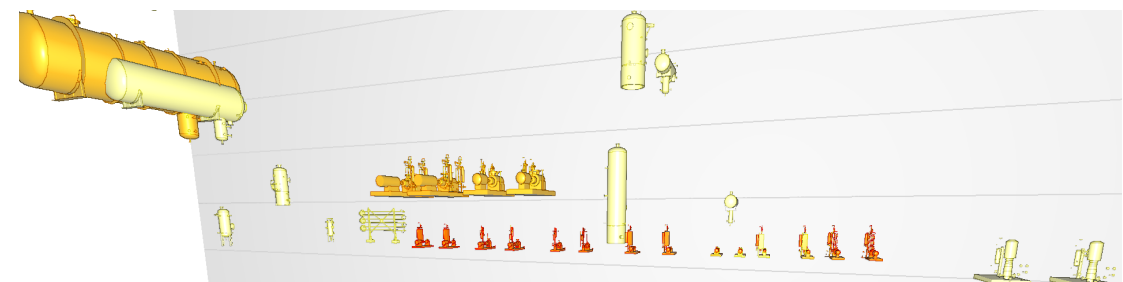

(a)

(b)
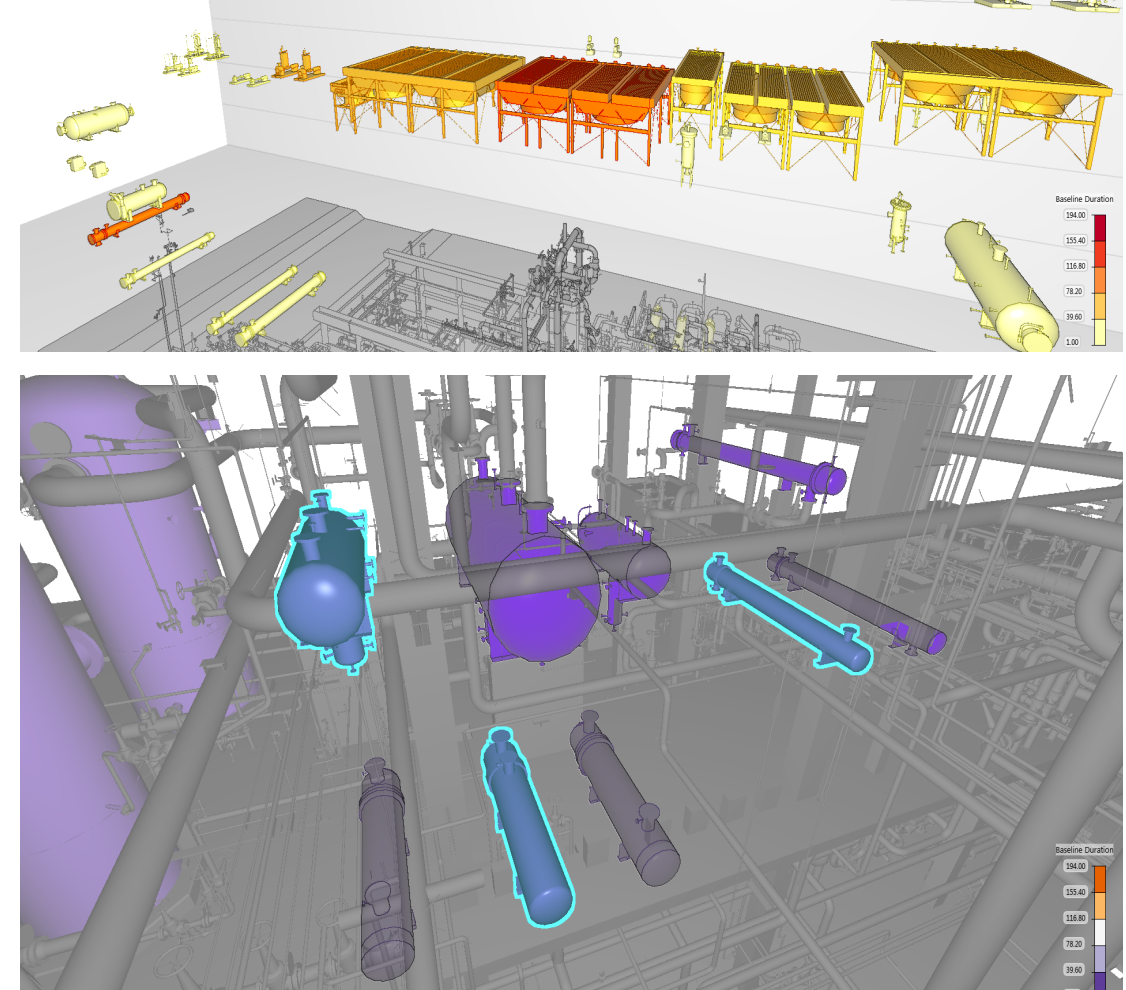

Figure 4.4: Techniques for identifying and focusing on activities of interest: (a) color-coding highlights schedule discrepancies; (b) focus+context shortcuts use transparency to bring forth occluded geometries.

\subsection{3}

\section{Examine Metadata}

During detailed analysis, the AEC professionals inspect quantitative data associated with each construction task. They look for inconsistencies on start and finish dates, durations and other attributes. Usually, problems are identified by cross-checking different fields over different activities. Therefore, the visualization must be able to simultaneously present diverse characteristics of the underlying schedule.

A typical approach in BIM has been to implement coordinated multiple views (Subsection 4.1.2). The visualization literature has studied this technique extensively with great success [Keefe et al., 2009; Kehrer \& Hauser, 2013; North \& Shneiderman, 2000; Roberts, 2007; Wang Baldonado et al., 2000]. It supports exploratory analysis through the simultaneous display of different aspects of the same underlying dataset. CasCADe takes a fundamentally opposite approach to achieve the same goal. As described in Section 4.3, the proposed 
framework combines multiple types of visualizations into a single $4 \mathrm{D}$ view. This simplifies the users' visual analysis tasks by focusing their attention on a single display where data correlations are immediately evident. This approach is similar to multi-layered visualizations in geographical information systems (GIS) [Dykes et al., 2005; Wood et al., 2007].

Many of CasCADe's analytical functions can be activated simultaneously to present different metadata over the 3D CAD model [Few, 2009]. The cascading view and visual projection aids make evident finish dates and task sequencing. Additional linked views display the product hierarchy and schedule metadata in tabular form. These attributes can also be shown directly over each 3D geometry using texts, numbers and symbols. On top of that, different temporal information can determine the geometries' color-coding. Finally, semi-transparent volumes indicate activity durations, similar to 3D bar charts.

\subsection{4}

\section{Inspect Relationships}

Construction schedules inherently contain many kinds of relationships between activities, e.g., predecessors/successors that indicate hard dependencies between construction works. Another example is the critical path: activities that cannot be delayed without impacting the final project deadline. A third type of correlation between activities is seldom explored: the physical and functional inter-connections between facility components. This information is crucial to determine the most effective assembly sequencing to anticipate testing of subsystems. Although these three examples are fundamental in a construction schedule, the majority of existing 4D CAD solutions fail to appropriately support their analysis (Subsection 4.1.6).

CasCADe fills this gap by graphically representing relationships between construction works. It preserves geometries from past and future activities always visible. The system draws colored highlights and links between 3D components according to different types of relationships: predecessors/successors, critical path or plant operating system (Figure 4.5c). This design explores the user's familiarity with traditional 2D time visualizations, e.g. Gantt charts and PERT networks. Other researches have also explored this representation to display both 2D and 3D graphs [Becker et al., 1995; Herman et al., 2000; Shiravi et al., 2012; Ware \& Mitchell, 2008]. 
(a)

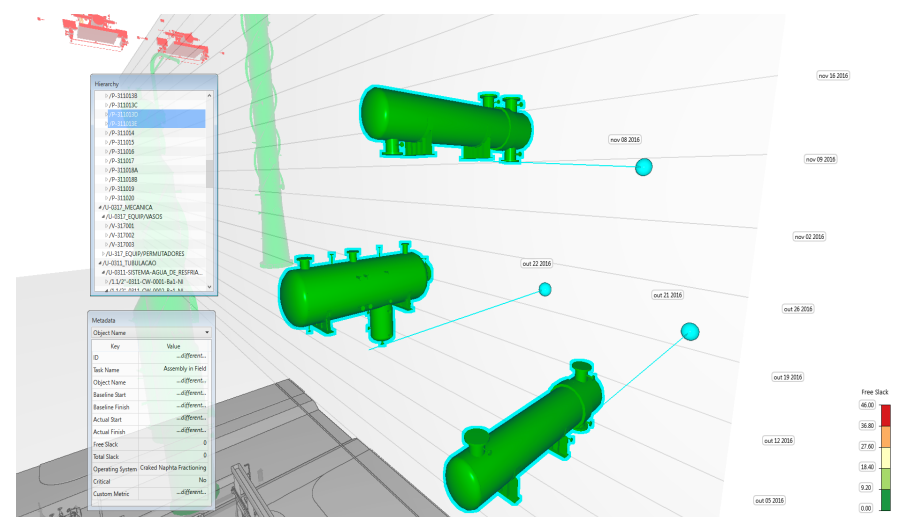

(b)

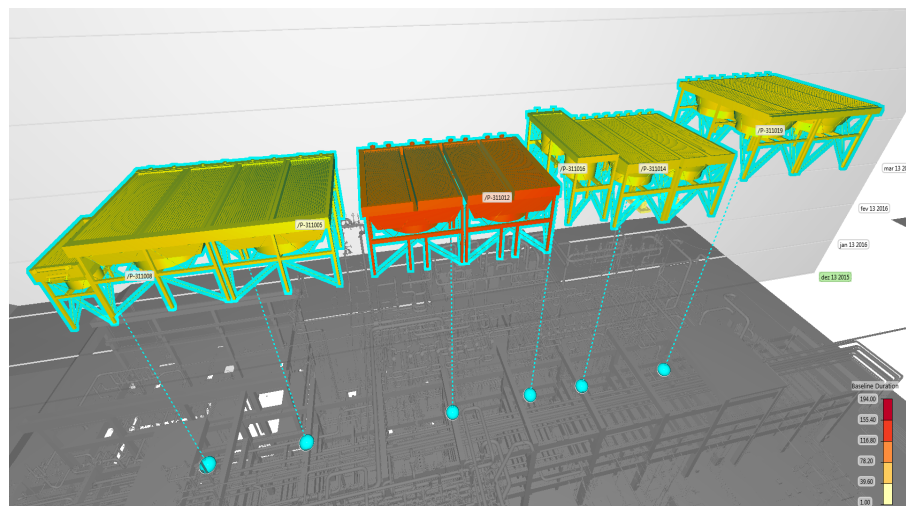

(c)

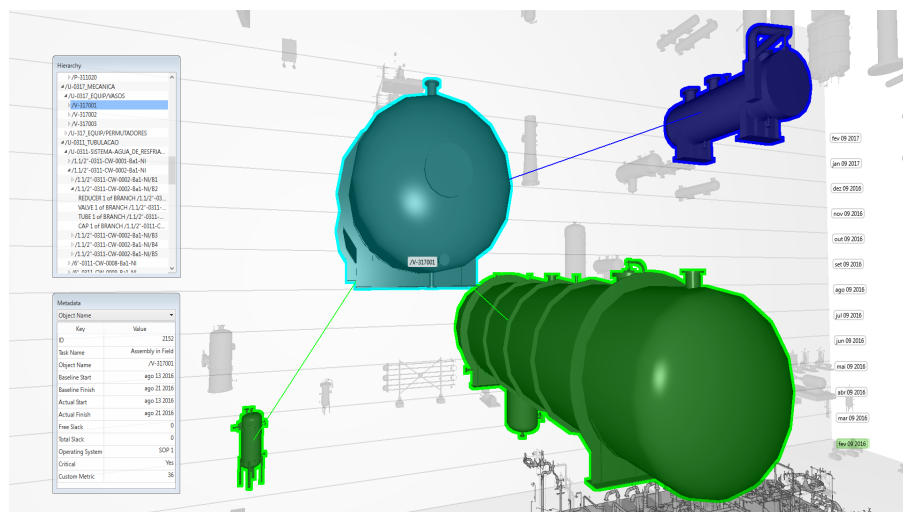

(d)

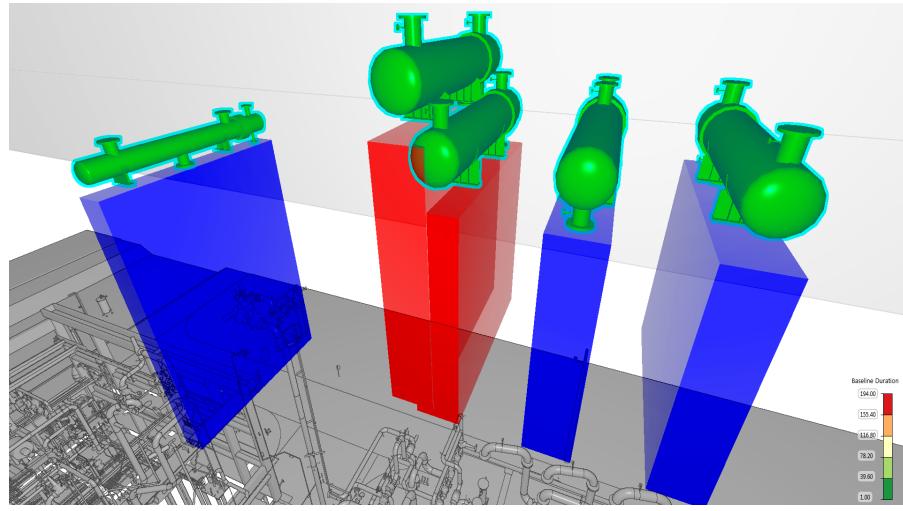

Figure 4.5: Examples of visual tools for detailed task analysis: (a) horizontal lines distinguish nearby finish dates; (b) overlay texts present contextual information and vertical lines display assembly locations; (c) linked views convey additional schedule information while green/blue highlights and links identify predecessor/successor relationships; (d) semi-transparent volumes indicate task durations, occupied areas and workspace conflicts (in red). 


\subsection{5 \\ Plan Site Layout}

A reliable and executable plan also needs to consider the handling of facility components at the job site. Physical areas need to be prepared and isolated in order to adequately and safely conduct programmed activities. For example, falsework may need to be installed to provide access to hard-to-each places, while heavy machinery may be required to move large components. In addition, pre-fabricated materials are often gathered in the area to reduce logistics delays. Consequently, the AEC collaborators emphasized the need to identify occupied work spaces and any spatio-temporal conflicts between simultaneous activities.

CasCADe uses semi-transparent volumes to indicate work areas, like previous BIM research (Subsection 4.1.1). However, the proposed visualization framework enables an enhanced visual representation of these areas over time. Each 3D workspace volume is stretched along the vertical time dimension $(z-$ axis), according to the activity's start and finish dates. The resulting " $4 \mathrm{D}$ envelope" conveys two important pieces of information: the space occupied by each activity and its duration in time. This functionality also enables the automatic identification of scheduling conflicts through 3D collision detection. Robotics research has long explored a similar approach to plan the motion of machines [Cameron, 1990; Tang, 2014]. Many real-time algorithms have been proposed to detect collisions in interactive graphics applications [Hubbard, 1995; Jiménez et al., 2001; Klosowski et al., 1998]. CasCADe implements a bounding-volume hierarchy to quickly identify overlapping workspace volumes and highlight them in red for the user (see Figure $4.5 \mathrm{~d}$ ).

\section{5 \\ Implementation}

CasCADe is a multi-platform Windows/Linux application developed in $\mathrm{C}++$ using GCC/MinGW. The user interface is implemented with the Qt framework and rendering uses OpenGL. The rendering pipeline takes advantage of geometry instancing to achieve sufficient performance for large 3D CAD scenes [Santos \& Celes Filho, 2014]. The graphics engine initially implemented the order-independent transparency (OIT) algorithm from [McGuire $\&$ Bavoil, 2013]. However, the users found it hard to distinguish between overlapping geometries. The depth complexity of 3D CAD models still presents a great challenge in maintaining visual quality with OIT techniques [Everitt, 2001; Wyman, 2016; Yang et al., 2010]. Moreover, the oil company discarded a solution based on ray tracing due to the costs in hardware necessary to render 
large-scale and dynamic 3D CAD scenes in real time [Wald et al., 2017, 2014].

\section{6}

\section{User Evaluation}

The collaborators evaluated CasCADe using the real-world construction plans of an existing Oil \& Gas process plant. Subcontractors defined the schedule, while the owner company supervised task planning and execution. The schedule contained 646 construction tasks, among which 127 corresponded to equipment assembly in the field. Throughout the design and implementation of CasCADe, the company conducted schedule review sessions to identify problems and inconsistencies in this construction plan [Isenberg et al., 2013].

(a)

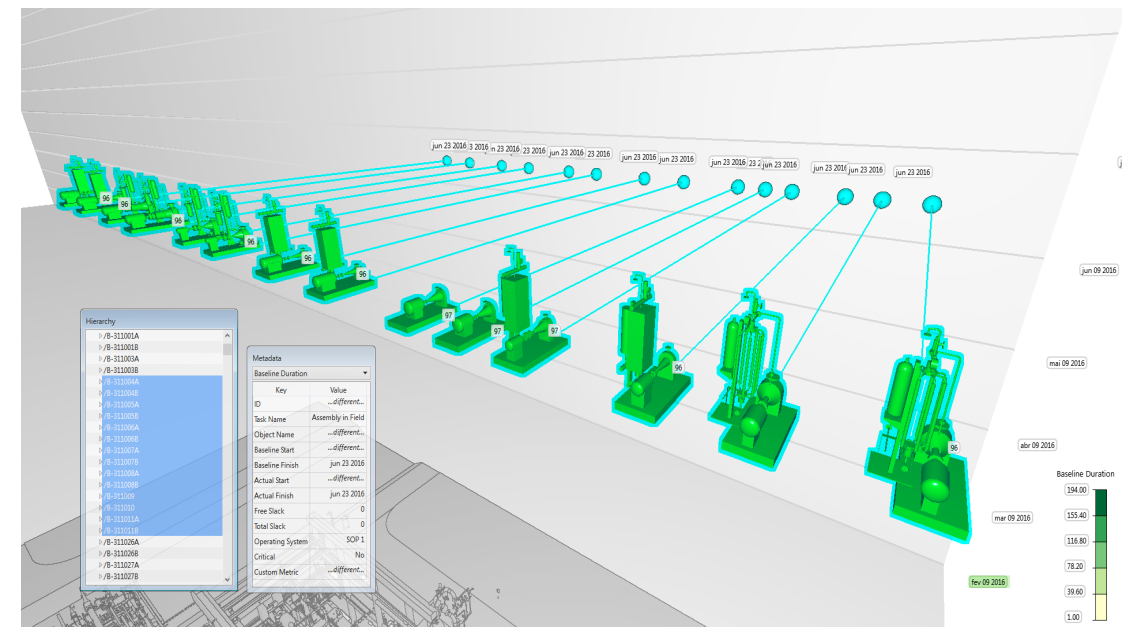

(b)

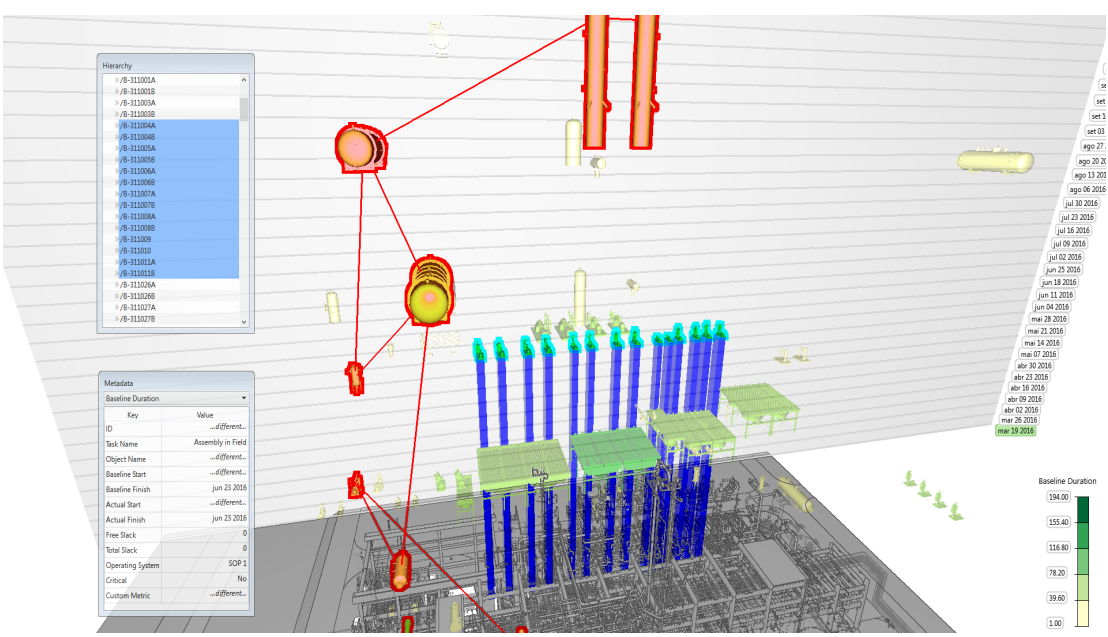

Figure 4.6: CasCADe made evident schedule uncertainties: (a) many parallel assemblies with unusually high durations; (b) these assemblies (blue bars) would compete for resources with the critical path (in red). 


\subsection{1}

\section{Schedule Uncertainties}

The first step was to review the overall construction schedule and its critical path. Figure 4.6a exemplifies how the developed visualizations were applied. The professionals repeatedly found cases where a large number of construction works with long durations were programmed to be executed in parallel. This high degree of uncertainty would create conflicts in resource allocation (e.g. materials and crew).

The $4 \mathrm{D}$ visualization also exposed another problem: the tasks did not belong to the critical path of the construction schedule (Figure 4.6b). It would be a great challenge to meet the simultaneous demands of both the critical path and those other assemblies. In these cases, a more sequential scheduling, considering the available work crews, could minimize temporal overlap and increase assembly productivity and reduce storage costs.

(a)

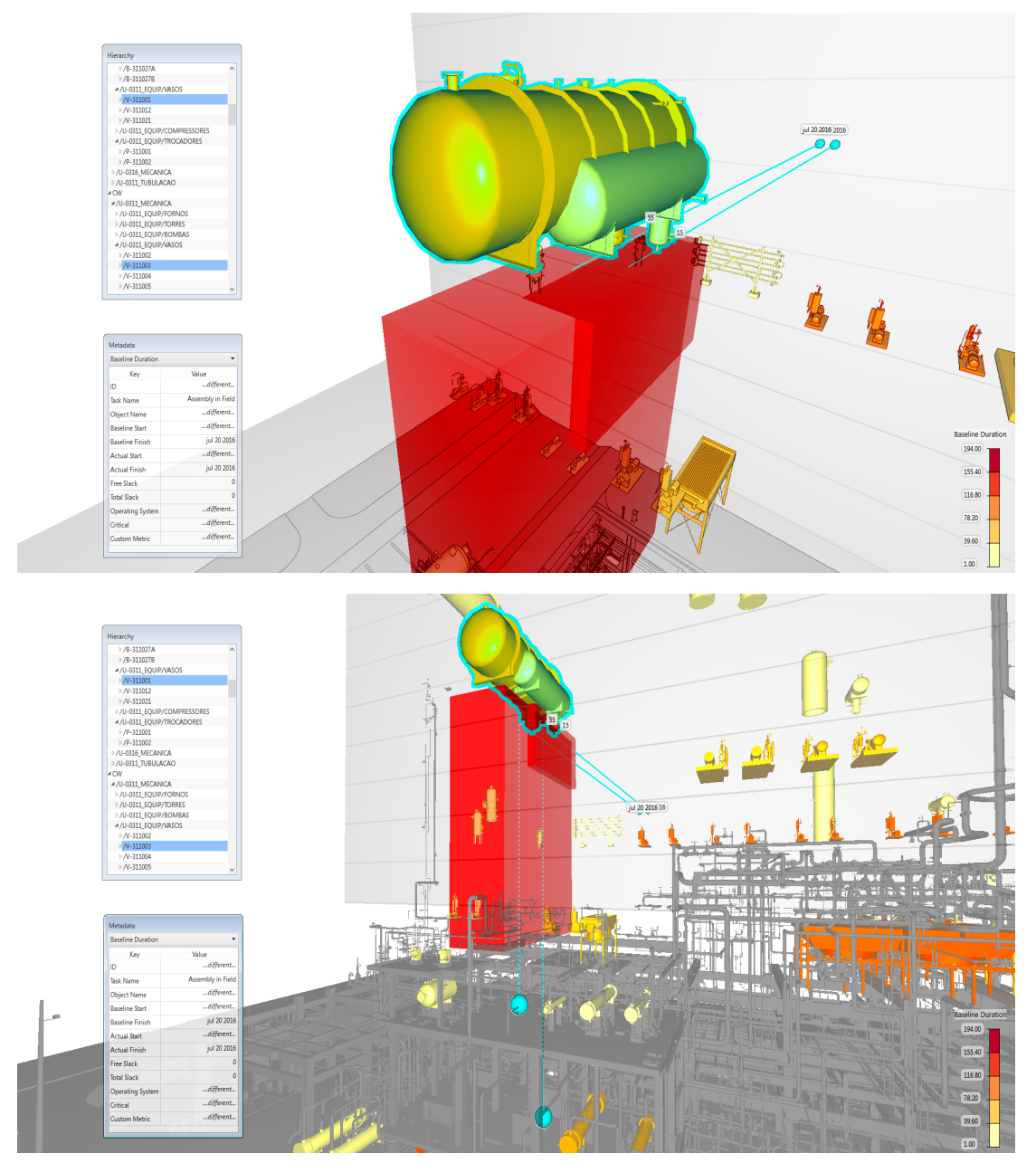

Figure 4.7: Example of workspace conflict found by the engineering collaborators: (a) simultaneous scheduling of two vessels is made evident by overlapping geometries and volumes (in red); (b) safety risks would prevent execution of these activities on floors above one another. 


\subsection{2}

\section{Workspace Conflicts}

During the review sessions, CasCADe helped the engineering collaborators to find several workspace conflicts in the equipment assembly plan. Figure 4.7 a presents one of the situations identified automatically by the software. In this particular case, one of the assemblies would start one month after the other and both would finish at the same time.

In this case, the projection aids proved to be useful in checking the final assembly location of each equipment. As indicated in Figure 4.7b, one of the geometries would be built on the floor above the other. The engineers noted that this would demand the isolation of the entire area for safety concerns. If this conflict was not observed prior to task execution, it could lead to highrisks for construction workers on the floor below. A new assembly sequence could avoid idle teams and unused materials that would be left in the job site.

\subsection{3}

\section{Custom Risk Metric}

During real-world construction works, subcontractors regularly adjust the schedule according to task progress and unforeseen problems. The owner company must oversee these changes to avoid any new inconsistencies in the construction plan. The collaborators used CasCADe's custom-metric feature to conduct a visually guided risk analysis. Their goal was to determine which assemblies had the higher probability vs impact of compromising the schedule. Special attention would then be dedicated to analyzing the constructability of these activities. The following equation presents the metric devised by the experts to identify critical construction works:

$$
\text { Priority }=\frac{\left(\text { Num }_{\text {pred }}+1\right) * \text { Duration }_{\text {base }} *\left(\text { Num }_{\text {suc }}+1\right)}{\text { Float }_{\text {free }} * \sqrt{\text { Float }_{\text {total }}}+1}
$$

In Equation 4-3, the dividend combines the delay probability of a particular task with its impact on the overall enterprise. The probability is given by two measures: number of predecessors $\left(\right.$ Num $\left._{\text {pred }}\right)$ and baseline

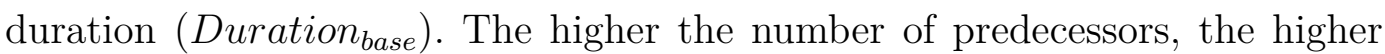
the chance of an assembly being delayed by a previous one. Similarly, large durations correspond to complex and/or uncertain activities that are more likely to face unforeseen problems. The impact is quantified by the number of successors of a given task $\left(\right.$ Num $\left._{\text {suc }}\right)$ : how many pending works would be negatively affected by any delays. 
The divisor mitigates the overall metric by the task's free float $\left(\right.$ Float $\left._{\text {free }}\right)$ and total float $\left(\right.$ Float $\left._{\text {total }}\right)$. The free float represents the amount of time that a task can be delayed without affecting any of its successors, whereas the total float indicates the maximum delay that would not affect the project's final deadline. Because of its impact on the overall schedule, the total float is given higher importance by a square root operation. Smaller float values correspond to lower error margins, thus increasing the overall risk metric.

Applying Equation 4-3 in the developed 4D visualization highlighted one heat exchanger in particular, as shown in red in Figure 4.8a. Compared to similar equipment throughout the plant, there is no justification for its excessively long assembly duration. This brought additional evidence of the lack of detail in the schedule devised by the subcontractors. Different assembly tasks corresponding to equipment of the same kind were planned to last anywhere from 9 up to 110 days. This level of variability and uncertainty would make it nearly impossible to accurately manage resources and logistics in the job site.

The metric also identified the construction of the plant's stack as a "highrisk" activity. It was properly scheduled to start assembly before its connecting furnaces, which were related as predecessors/successors in the construction plan. However, the 4D visualization indicated an overlap between the stack and furnace assemblies (see Figure 4.8b). In this situation, the furnaces would arrive at the construction site while the area was still restricted by the stack's construction works, resulting in delays and increased storage costs. Using the operating system highlight of our $4 \mathrm{D}$ visualization, it was possible to verify which other equipment could be impacted by this problem.

\section{7}

\section{User Feedback}

Throughout this research, the collaborating engineers provided valuable design guidelines and feedback. Afterwards, we conducted an interview with a series of open-ended questions on three themes: (1) What were the main benefits and limitations of the proposed 4D visualization? (2) Which analysis tools worked best and which needed improvement? (3) What other kinds of schedule revision tasks should be supported?

Overall, the experts demonstrated a high degree of satisfaction with CasCADe, often highlighting the intuitive perception of task sequencing and their locations on the job site. They also praised the ease to analyze diverse time information in the same view using different visual effects. One standout functionality was the focus+context navigation shortcuts, which quickly high- 
(a)

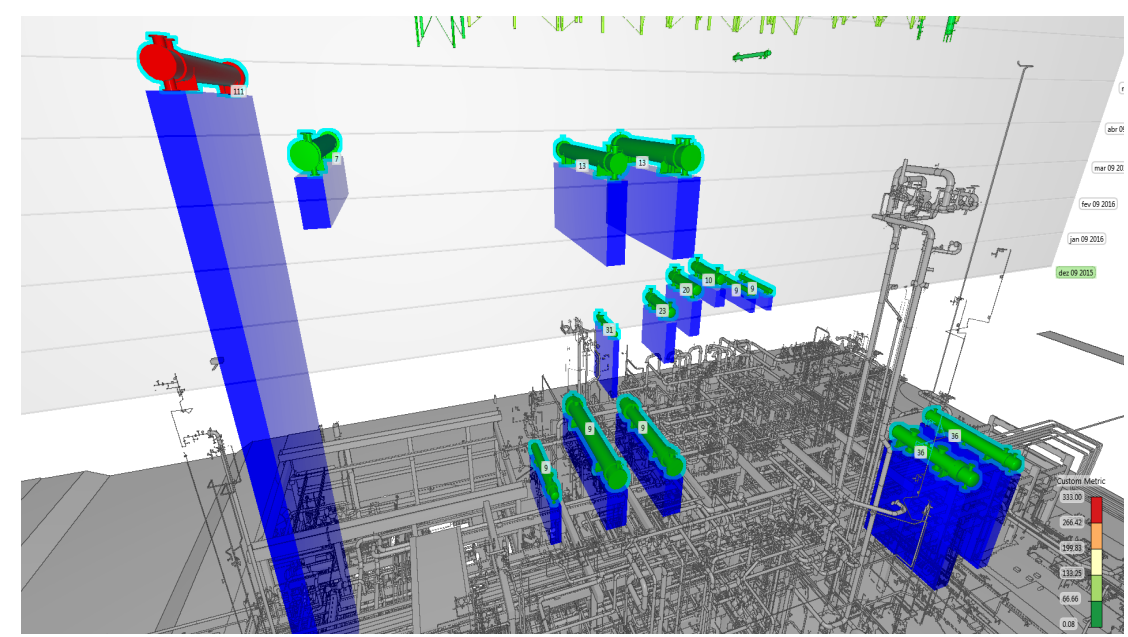

(b)

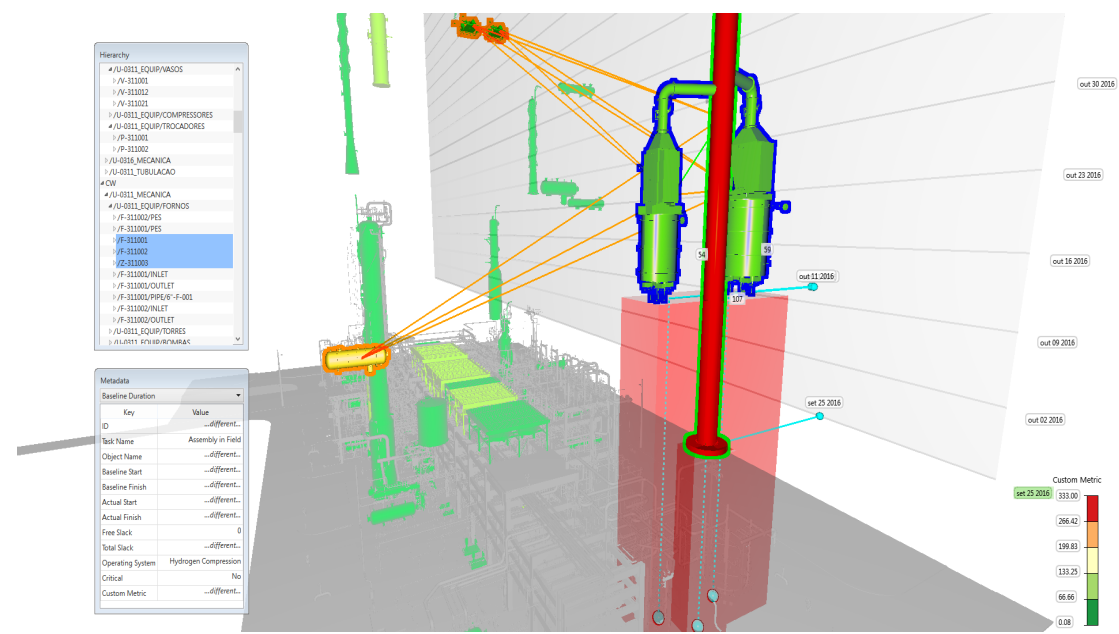

Figure 4.8: The collaborators used CasCADe's customized metric to colorcode high-priority activities: (a) heat exchanger in red with unusually long duration; (b) workspace conflict between the process plant's stack (red) and its two adjacent furnaces (green).

lighted and moved the camera towards geometries of interest. All participants deemed fundamental the ability to customize the visualization by toggling effects and editing the color-coding metric.

Some participants had difficulty in navigating through the 3D environment and requested additional camera shortcuts; for instance, for switching the point of view between plotted geometries and their final assembly locations. Another improvement would be to consolidate the many visualization options into predefined templates geared towards different kinds of analysis. For future work, the domain experts suggested the visualization of additional construction information such as workforce and materials, and the ability to compare two schedules in order to investigate alternative plans and follow work execution. 


\section{5}

\section{Future Research Directions}

Throughout this thesis, we have identified many opportunities for future work. This chapter compiles related topics into themes to guide both BIM and VIS practictioners in their next endeavours.

Exploring synergies among use cases. Some BIM use cases directly affect one other, creating the need for inter-dependent analysis. For instance, planned activity durations ("Task Scheduling") are heavily influenced by the size of their work crew ("Resource Management"), both of which will determine overall project costs ("Cost Management"). Future work could integrate these different task and data requirements within a more intelligent BIM visualization system. We have also found a relative lack of applications across "Work Execution" use cases. This is another opportunity for BIM and VIS pratictioners to explore latent synergies among related areas of application.

Extending use cases to other life cycle phases. Management strategies such as Integrated Project Delivery (IPD) highlight the cost-benefit of anticipating change to early project life cycle [Guide, 2007; Lu et al., 2015]. According to our review, several BIM-based analysis from "Work Planning" and "Facility Management" could also be performed in design phases. Future research could also investigate how to increase BIM adoption across the entire operation phase. In particular, we have identified an opportunity of reusing existing "Work Planning" and "Work Execution" solutions in later phases, such as: "Commissioning, As-Built and Handover", "Asset Management and Facility Maintenance", and "Decommissioning and Major Re-Programming". Finally, applications of "Sustainability Analysis" could be expanded to all life cycle phases. We suggest looking into the construction phase, where very few research have explored so far.

Evolving CasCADe's visualization framework. A more rigorous and systematic HCI methodology could evaluate the proposed visualization to identify possibilities for improvement. In addition, new order-independent transparency algorithms could robustly handle the high depth complexity of 3D CAD models (Section 4.5). These techniques could even automatically highlight features of interest, similar to rendering of volumetric datasets [Vi- 
ola et al., 2005]. Moreover, Subsection 4.2.2 suggests additional use cases that could be explored by future works. In particular, developing analytical features to compare construction schedules should bring interesting visualization challenges. Finally, future work could explore the applicability of the proposed spatio-temporal framework in other domains besides engineering/construction.

Improving current visualizations. Future research could follow one or more of the proposed design guidelines from Section 3.6. These could be implemented in existing BIM systems or developed in new visualization applications. We suggest conducting formal evaluations of the benefits of these changes, if possible with real-world case studies [Freitas et al., 2002; Plaisant \& Catherine, 2004; Sedlmair et al., 2012; Zuk et al., 2006].

Generalizing visualization frameworks. Some BIM use cases share similar task and data requirements. For example: "Site Layout Planning", "Logistics Planning" and "Space Management". The three are concerned with improving space utilization, either in the construction site or in the built facility. Future research could map these similarities and propose a single visualization framework to meet the demands of many use cases. Another example is the need to compare equivalent BIM datasets for alternative designs, alternative work plans, or alternative risk contingency plans [Andrienko et al., 2003]. This scenario should bring interesting visualization challenges in exploratory visual analysis [Cooper \& Podgorny, 1976; Gleicher et al., 2011].

Additional review analysis. Future studies could perform additional analysis of the results from our systematic literature review. One idea is to study the synergies among reviewed articles through graph visualizations. These could indicate which use cases area explored simultaneously in the same work. Another possibility would be to employ statistical methods to find hidden correlations between the 4 proposed classification taxonomies. Moreover, plotting the use of individual visualization techniques over time could highlight converging trends in BIM research.

Future literature reviews. The systematic method applied in the current review enables other researchers to reproduce our findings in the future. The authors could compare new results with our conclusions in order to assess the evolution of visualization in BIM. We also suggest comparing our analysis of current practice with new research in conceptual BIM frameworks. This could assess if emerging techniques are being directed to the right problems. Finally, the proposed classification framework can serve as a basis for other literature reviews across both BIM and/or VIS fields. 


\section{6 \\ Conclusions}

This thesis described the findings of a systematic literature review of information visualization in Building Information Modeling (BIM). The review summarized research results using a novel classification made of 4 taxonomies: Life Cycle Phases, Use Cases, Information and Data Types, and Visualizations. This framework enabled a critical analysis of visualization techniques employed in practical applications of BIM. Based on this study, we proposed a set of design guidelines for new and improved approaches.

Motivated by these observations, we presented another contribution: the design of an innovative $4 \mathrm{D}$ visualization system named CasCADe. The developed visualization framework maps time as a spatial dimension to create an effect of cascading geometries in a 3D exploded view. This creates an intuitive environment similar to PERT/Gantt charts where general overview, task sequencing, and spatio-temporal simultaneity are immediately evident. We also described how its analytical tools are assembled into an informationrich visualization for virtual construction planning.

Engineering collaborators used CasCADe to review the real-world construction plans of an Oil \& Gas process plant. The system brought forth uncertainties from the lack of predecessor/successor relationships and tasks with excessively long durations. Overall, CasCADe identified both large-scale issues related to task detailing and sequencing and small-scale ones pertaining to work-space conflicts and constructability. The results motivated the oil company to improve its work processes and to apply the solution on its next enterprise.

BIM research has shown many potential benefits of information visualization for managing large-scale engineering projects. Our work has aimed to improve the effectiveness of these techniques following best practices from VIS literature. We expect research interest in Building Information Modeling to continue to grow for many years to come. We hope this thesis contributes to its industry adoption while also raising awareness to interesting new challenges for the visualization community. Greater cooperation between BIM and VIS practitioners should lead to exciting new results in the future. 


\section{Bibliography}

ABD, A M; KHAMEES, A S. As built case studies for BIM as conflicts detection and documentation tool. English. Cogent Engineering 4.1 (2017). ISSN: 23311916 (ISSN). DOI: 10.1080/23311916.2017.1411865. ABDELALIM, A; O'BRIEN, W; SHI, Z. Data visualization and analysis of energy flow on a multi-zone building scale. English. Automation in Construction 84 (2017), pp. 258-273. ISSN: 09265805 (ISSN). DOI: $10.1016 / j$. autcon.2017.09.012.

ABDELHAMEED, W A. Virtual reality applications in project management scheduling. Computer-Aided Design and Applications 9.1 (2012), pp. 71-78. DOI: 10.3722/cadaps. 2012.71-78.

ABDUL KADIR, M R; LEE, W P; JAAFAR, M S; SAPUAN, S M; ALI, A A A. Factors affecting construction labour productivity for Malaysian residential projects. Structural Survey 23.1 (2005), pp. 42-54. DOI: 10.1108/02630800510586907.

ADETUNJI, I.; PRICE, A.; FLEMING, P.; KEMP, P. Sustainability and the UK construction industry - a review. Proceedings of the Institution of Civil Engineers - Engineering Sustainability 156.4 (2003), pp. 185-199. ISSN: 1478-4629. DOI: 10.1680/ensu.2003.156.4.185.

ADJEI-KUMI, THEOPHILUS; RETIK, ARKADY. A library-based 4D visualisation of construction processes. Information Visualization, 1997. Proceedings., 1997 IEEE Conference on. IEEE. 1997, pp. 315-321.

AIBINU, A A; ODEYINKA, H A. Construction delays and their causative factors in nigeria. Journal of Construction Engineering and Management 132.7 (2006), pp. 667-677. DOI: 10.1061/(ASCE) 07339364 (2006) 132:7 (667).

AIBINU, A.A; JAGBORO, G.O. The effects of construction delays on project delivery in Nigerian construction industry. International Journal of Project Management 20.8 (2002), pp. 593-599. ISSN: 02637863. DOI: $10.1016 / \mathrm{S} 0263-7863(02) 00028-5$.

AIBINU, A; VENKATESH, S. Status of BIM adoption and the BIM experience of cost consultants in Australia. Journal of Professional Issues in Engineering Education and Practice 140.3 (2014). DOI: 10 . 1061/(ASCE) EI.1943-5541.0000193. 
AKINCI, BURCU; FISCHEN, MARTIN; LEVITT, RAYMOND; CARLSON, ROBERT. Formalization and automation of time-space conflict analysis. Journal of Computing in Civil Engineering 16.2 (2002), pp. $124-134$.

ALINAITWE, H M; MWAKALI, J A; HANSSON, B. Factors affecting the productivity of building craftsmen - studies of Uganda. Journal of Civil Engineering and Management 13.3 (2007), pp. 169-176. DOI: $10.1080 / 13923730.2007 .9636434$.

ALNUAIMI, A S; TAHA, R A; AL MOHSIN, M; AL-HARTHI, A S. Causes, effects, benefits, and remedies of change orders on public construction projects in Oman. Journal of Construction Engineering and Management 136.5 (2010), pp. 615-622. DOI: 10.1061/(ASCE)C0.19437862.0000154.

ALZAHRANI, JAMAN I; EMSLEY, MARGARET W. The impact of contractors' attributes on construction project success: A post construction evaluation. International Journal of Project Management 31.2 (2013), pp. 313-322.

ANDI; MINATO, TAKAYUKI. Design documents quality in the Japanese construction industry: factors influencing and impacts on construction process. International Journal of Project Management 21.7 (2003), pp. 537-546. ISSN: 0263-7863. DOI: 10.1016/S0263$7863(02) 00083-2$.

ANDRIENKO, NATALIA; ANDRIENKO, GENNADY; GATALSKY, PETER. Tools for visual comparison of spatial development scenarios. Information Visualization, 2003. IV 2003. Proceedings. Seventh International Conference on. IEEE. 2003, pp. 237-244.

AOUAD, G. Trends in information visualisation in construction. English. IEEE International Conference on Information Visualization, IV 1999. Ed. by URSYN A.; BANISSI E.; SARFRAZ M.; TATHAM E.; KHOSROWSHAHI F. Vol. 1999-Janua. Research Centre for the Built and Human Environment, University of Salford, United Kingdom: Institute of Electrical and Electronics Engineers Inc., 1999, pp. 590-594. ISBN: 10939547 (ISSN); 0769502105 (ISBN). DOI: 10.1109/IV.1999.781617.

ARAYICI, Y; COATES, P; KOSKELA, L; KAGIOGLOU, M; USHER, C; O'REILLY, K. Technology adoption in the BIM implementation for lean architectural practice. Automation in Construction 20.2 (2011), pp. 189-195. DOI: 10.1016/j.autcon.2010.09.016. 
ARDITI, DAVID; TOKDEMIR, ONUR B; SUH, KANGSUK. Challenges in line-of-balance scheduling. Journal of construction engineering and management 128.6 (2002), pp. 545-556.

ASHLEY, D.B.; LURIE, C.S.; JASELSKIS, E.J. Determinants of construction project success. Project Management Journal 18.2 (1987), pp. 69 79. ISSN: 87569728. DOI: http://doi .org/10 . 1080/01446193. 2011. 611152.

ASSAF, SADI A.; AL-HEJJI, SADIQ. Causes of delay in large construction projects. International Journal of Project Management 24.4 (2006), pp. 349-357. ISSN: 0263-7863. DOI: 10.1016/J. I JPROMAN. 2005.11.010.

AZHAR, S. Building information modeling (BIM): Trends, benefits, risks, and challenges for the AEC industry. English. Leadership and Management in Engineering 11.3 (2011), pp. 241-252. ISSN: 15326748 (ISSN). DOI: 10.1061/(ASCE) LM. 1943-5630 .0000127.

AZHAR, SALMAN; CARLTON, WADE A; OLSEN, DARREN; AHMAD, IRTISHAD. Building information modeling for sustainable design and LEED®rating analysis. Automation in construction 20.2 (2011), pp. 217-224.

AZHAR, SALMAN; KHALFAN, MALIK; MAQSOOD, TAYYAB. Building information modelling (BIM): now and beyond. Construction Economics and Building 12.4 (2015), pp. 15-28. ISSN: 2204-9029. DOI: 10.5130/ajceb.v12i4.3032. arXiv: 9809069v1 [arXiv:gr-qc].

BACH, BENJAMIN; DRAGICEVIC, PIERRE; ARCHAMBAULT, DANIEL; HURTER, CHRISTOPHE; CARPENDALE, SHEELAGH. A review of temporal data visualizations based on space-time cube operations. Eurographics conference on visualization. 2014.

BANSAL, V K. Integrated CAD and GIS-Based Framework to Support Construction Planning: Case Study. Journal of Architectural Engineering 23.3 (2017). DOI: 10.1061/ (ASCE) AE. 1943-5568.0000262.

BARLISH, KRISTEN; SULLIVAN, KENNETH. How to measure the benefits of BIM - A case study approach. Automation in Construction 24 (2012), pp. 149-159. ISSN: 0926-5805. DOI: 10 .1016/J . AUTCON . 2012. 02.008 .

BARROSO, VITOR BARATA R B; CELES, WALDEMAR. Improved realtime shadow mapping for cad models. Computer Graphics and Image Processing, 2007. SIBGRAPI 2007. XX Brazilian Symposium on. IEEE. 2007, pp. 139-146.

BARTRAM, LYN; CHEUNG, BILLY; STONE, MAUREEN. The effect of colour and transparency on the perception of overlaid grids. 
IEEE Transactions on Visualization and Computer Graphics 17.12 (2011), pp. 1942-1948.

BARTRAM, LYN; WARE, COLIN. Filtering and brushing with motion. Information Visualization 1.1 (2002), pp. 66-79.

BASSIONI, H A; PRICE, A D F; HASSAN, T M. Performance measurement in construction. Journal of Management in Engineering 20.2 (2004), pp. 42-50. DOI: 10.1061/(ASCE) 0742-597X (2004) 20:2 (42).

BECERIK-GERBER, B; JAZIZADEH, F; LI, N; CALIS, G. Application areas and data requirements for BIM-enabled facilities management. Journal of Construction Engineering and Management 138.3 (2012), pp. 431-442. DOI: 10.1061/ (ASCE) C0.1943-7862.0000433.

BECERIK-GERBER, B; KENSEK, K. Building information modeling in architecture, engineering, and construction: Emerging research directions and trends. Journal of Professional Issues in Engineering Education and Practice 136.3 (2010), pp. 139-147. DOI: 10.1061/(ASCE) EI.1943-5541.0000023.

BECERIK-GERBER, BURCIN; RICE, SAMARA. The Perceived Value Of Building Information Modeling In The U.S. Building Industry. ITcon Journal of Information Technology in Construction (ITcon) 15.15 (2010), pp. 185-201.

BECKER, RICHARD A; EICK, STEPHEN G; WILKS, ALLAN R. Visualizing network data. IEEE Transactions on visualization and computer graphics 1.1 (1995), pp. 16-28.

BENJAORAN, V; BHOKHA, S. Enhancing visualization of 4D CAD model compared to conventional methods. Engineering, Construction and Architectural Management 16.4 (2009), pp. 392-408. DOI: 10 . 1108/09699980910970860.

BERGMAN, LAWRENCE D; ROGOWITZ, BERNICE E; TREINISH, LLOYD A. A rule-based tool for assisting colormap selection. Proceedings of the 6th conference on Visualization'95. IEEE Computer Society. 1995, p. 118.

BERTINI, E.; TATU, ANDRADA; KEIM, DANIEL. Quality Metrics in High-Dimensional Data Visualization: An Overview and Systematization. IEEE Transactions on Visualization and Computer Graphics 17.12 (2011), pp. 2203-2212. ISSN: 1077-2626. DOI: 10.1109/ TVCG. 2011.229.

BJORK, STAFFAN; HOLMQUIST, LARS ERIK; REDSTROM, JOHAN. A framework for focus + context visualization. Information Visualiza- 
tion, 1999.(Info Vis' 99) Proceedings. 1999 IEEE Symposium on. IEEE. 1999, pp. 53-56.

BJORK, STAFFAN; REDSTROM, JOHAN. Redefining the focus and context of focus + context visualization. Information Visualization, 2000. InfoVis 2000. IEEE Symposium on. IEEE. 2000, pp. 85-89.

BJÖRNFOT, A; JONGELING, R. Application of line-of-balance and 4D CAD for lean planning. Construction Innovation 7.2 (2007), pp. 200 211. DOI: $10.1108 / 14714170710738559$.

BORGO, RITA; KEHRER, JOHANNES; CHUNG, DAVID HS; MAGUIRE, EAMONN; LARAMEE, ROBERT S; HAUSER, HELWIG; WARD, MATTHEW; CHEN, MIN. Glyph-based Visualization: Foundations, Design Guidelines, Techniques and Applications. Eurographics (STARs). 2013, pp. 39-63.

BORIAH, SHYAM; CHANDOLA, VARUN; KUMAR, VIPIN. Similarity measures for categorical data: A comparative evaluation. Proceedings of the 2008 SIAM International Conference on Data Mining. SIAM. 2008, pp. 243-254.

BORKIN, MICHELLE A et al. What Makes a Visualization Memorable? ieeexplore.ieee.org 19.12 (2013), pp. 2306-2315.

BOSCHÉ, F; GUILLEMET, A; TURKAN, Y; HAAS, C T; HAAS, R. Tracking the built status of MEP works: Assessing the value of a Scan-vs-BIM system. Journal of Computing in Civil Engineering 28.4 (2014). DOI: 10.1061/ (ASCE) CP. 1943-5487.0000343.

BOTON, C; KUBICKI, S; HALIN, G. Designing adapted visualization for collaborative 4D applications. English. Automation in Construction 36 (2013), pp. 152-167. ISSN: 09265805 (ISSN). DOI: 10.1016/j . autcon. 2013.09 .003 .

BOTON, CONRAD; HALIN, GILLES; KUBICKI, SYLVAIN. A metamodel to describe $\mathrm{nD}$ CAD visualization as coordinated multiple views. International Conference on Cooperative Design, Visualization and Engineering. Springer. 2012, pp. 219-226.

BOTON, CONRAD; KUBICKI, SYLVAIN; HALIN, GILLES. Method to design coordinated multiple views adapted to user's business requirements in $4 \mathrm{D}$ collaborative tools in AEC. Information Visualisation (IV), 2011 15th International Conference on. IEEE. 2011, pp. $96-101$.

BOUCHLAGHEM, DINO; SHANG, HUIPING; WHYTE, JENNIFER; GANAH, ABDULKADIR. Visualisation in architecture, engi- 
neering and construction (AEC). Automation in construction 14.3 (2005), pp. 287-295.

BOYER, STUART A. SCADA: supervisory control and data acquisition. International Society of Automation, 2009.

BRAUN, A; TUTTAS, S; BORRMANN, A; STILLA, U. A concept for automated construction progress monitoring using BIM-based geometric constraints and photogrammetric point clouds. English. Journal of Information Technology in Construction 20 (2015), pp. 68-79. ISSN: 14036835 (ISSN).

BRODLIE, KENNETH W; CARPENTER, LA; EARNSHAW, RA; GALLOP, JR; HUBBOLD, RJ; MUMFORD, AM; OSLAND, CD; QUARENDON, PETER. Scientific visualization: techniques and applications. Springer Science \& Business Media, 2012.

BRUCKNER, STEFAN; GROLLER, M EDUARD. Exploded views for volume data. IEEE Transactions on Visualization and Computer Graphics 12.5 (2006).

BRYDE, DAVID; BROQUETAS, MARTÍ; VOLM, JÜRGEN MARC. The project benefits of Building Information Modelling (BIM). International Journal of Project Management 31.7 (2013), pp. 971-980. ISSN: 0263-7863. DOI: 10.1016/J . I JPROMAN . 2012.12.001.

BUDGEN, DAVID; BRERETON, PEARL. Performing systematic literature reviews in software engineering. Int. Conf. Soft. Engin. (2006), p. 1051. ISSN: 1595933751. DOI: $10.1145 / 1134285$. 1134500. arXiv: 1304.1186 .

BUILDINGSMART. buildingSMART, Technical Vision. 2017.

BUJA, ANDREAS; MCDONALD, JOHN ALAN; MICHALAK, JOHN; STUETZLE, WERNER. Interactive data visualization using focusing and linking. Visualization, 1991. Visualization'91, Proceedings., IEEE Conference on. IEEE. 1991, pp. 156-163.

BURCH, MICHAEL; KONEVTSOVA, NATALIA; HEINRICH, JULIAN; HOEFERLIN, MARKUS; WEISKOPF, DANIEL. Evaluation of traditional, orthogonal, and radial tree diagrams by an eye tracking study. IEEE Transactions on Visualization and Computer Graphics 17.12 (2011), pp. 2440-2448.

BURGER, K.; KRUGER, J.; WESTERMANN, R. Direct Volume Editing. IEEE Transactions on Visualization and Computer Graphics 14.6 (2008), pp. 1388-1395. ISSN: 1077-2626. DOI: 10.1109/TVCG.2008.120.

BURNHAM, JUDY F. Scopus database: a review. Biomedical digital libraries 3.1 (2006), p. 1. 
CAMERON, STEPHEN. Collision detection by four-dimensional intersection testing. IEEE Transactions on Robotics and Automation 6.3 (1990), pp. 291-302.

CANDELARIO GARRIDO, A; GARCÍA-SANZ-CALCEDO, J; SALGADO, D R; GONZÁlEZ, A G. Planning, monitoring and control of mechanics projects by the BIM. Engineering Transactions 65.1 (2017), pp. 25-30.

CASTRONOVO, FADI; LEE, SANGHOON; NIKOLIC, DRAGANA; MESSNER, JOHN I. Visualization in 4D Construction Management Software: A Review of Standards and Guidelines. Computing in Civil and Building Engineering (2014). Reston, VA: American Society of Civil Engineers, 2014, pp. 315-322. ISBN: 9780784413616. DOI: 10.1061/9780784413616.040.

CEROVSEK, T. A review and outlook for a 'Building Information Model' (BIM): A multi-standpoint framework for technological development. Advanced Engineering Informatics 25.2 (2011), pp. 224 244. DOI: $10.1016 / \mathrm{j}$.aei.2010.06.003.

CHAN, A P C; SCOTT, D; CHAN, A P L. Factors affecting the success of a construction project. Journal of Construction Engineering and Management 130.1 (2004), pp. 153-155. DOI: 10 . 1061 / (ASCE) $0733-$ 9364 (2004) $130: 1$ (153).

CHANG, HAN-SHUO; KANG, SHIH-CHUNG; CHEN, PO-HAN. Systematic procedure of determining an ideal color scheme on $4 \mathrm{D}$ models. Advanced Engineering Informatics 23.4 (2009), pp. 463-473. ISSN: 1474-0346. DOI: 10.1016/J . AEI . 2009.05.002.

CHANG, REMCO; WESSEL, GINETTE; KOSARA, ROBERT; SAUDA, ERIC; RIBARSKY, WILLIAM. Legible cities: Focus-dependent multi-resolution visualization of urban relationships. IEEE transactions on visualization and computer graphics 13.6 (2007), pp. 1169 1175 .

CHAU, K W; ANSON, M; ZHANG, J P. Four-dimensional visualization of construction scheduling and site utilization. Journal of construction engineering and management 130.4 (2004), pp. 598-606.

CHEN, L; LUO, H. A BIM-based construction quality management model and its applications. Automation in Construction 46 (2014), pp. 64-73. DOI: $10.1016 / \mathrm{j}$. autcon.2014.05.009.

CHIN, S; YOON, S; CHOI, C; CHO, C. RFID+4D CAD for progress management of structural steel works in high-rise buildings. 
Journal of Computing in Civil Engineering 22.2 (2008), pp. 74-89. DOI: 10.1061/(ASCE) 0887-3801 (2008) 22:2(74).

CHUA, D K H; KOG, Y C. Critical success factors for different project objectives. Journal of Construction Engineering \& Management 125.3 (1999), p. 142. ISSN: 0733-9364. DOI: 10.1061/(ASCE) 0733-9364 (1999) $125: 3(142)$. arXiv: 2826233.

CIPRIANO, G.; GLEICHER, M. Text Scaffolds for Effective Surface Labeling. IEEE Transactions on Visualization and Computer Graphics 14.6 (2008), pp. 1675-1682. ISSN: 1077-2626. DOI: 10.1109/TVCG. 2008. 168.

CIRIBINI, A L C; MASTROLEMBO VENTURA, S; PANERONI, M. Implementation of an interoperable process to optimise design and construction phases of a residential building: A BIM Pilot Project. Automation in Construction 71 (2016), pp. 62-73. DOI: 10.1016/j. autcon.2016.03.005.

CLARK, WALLACE; POLAKOV, WALTER NICHOLAS; TRABOLD, FRANK W. The Gantt chart: A working tool of management. Ronald Press Company, 1922.

COCKBURN, ANDY; MCKENZIE, BRUCE. Evaluating the effectiveness of spatial memory in $2 \mathrm{D}$ and $3 \mathrm{D}$ physical and virtual environments. Proceedings of the SIGCHI conference on Human factors in computing systems. ACM. 2002, pp. 203-210.

COLE, FORRESTER; FINKELSTEIN, ADAM. Two fast methods for high-quality line visibility. IEEE transactions on visualization and computer graphics 16.5 (2010), pp. 707-717.

COLLIER, E; FISCHER, M. Four-dimensional modeling in design and construction. Tech. rep. 101. Center for Integrated Facility Engineering - \{CIFE\}, Stanford University, 1995, pp. 1-76.

COLLINS, CHRISTOPHER; CARPENDALE, SHEELAGH. VisLink: Revealing relationships amongst visualizations. IEEE Transactions on Visualization and Computer Graphics 13.6 (2007), pp. 1192-1199.

COOPER, LYNN A; PODGORNY, PETER. Mental transformations and visual comparison processes: Effects of complexity and similarity. Journal of Experimental Psychology: Human Perception and Performance 2.4 (1976), p. 503.

COUNCIL, US GREEN BUILDING. Green building facts. US Green Building Council. www. usgbc. org/ShowFile. aspx (2008).

CRAWLEY, DRURY B; HAND, JON W; KUMMERT, MICHAËL; GRIFFITH, BRENT T. Contrasting the capabilities of building energy 
performance simulation programs. Building and environment 43.4 (2008), pp. 661-673.

DA XU, LI; WANG, CHENGEN; BI, ZHUMING; YU, JIAPENG. AutoAssem: an automated assembly planning system for complex products. IEEE Transactions on Industrial Informatics 8.3 (2012), pp. 669-678.

DE OLIVEIRA, MC FERREIRA; LEVKOWITZ, HAIM. From visual data exploration to visual data mining: a survey. IEEE Transactions on Visualization and Computer Graphics 9.3 (2003), pp. 378-394.

DING, L; ZHOU, Y; AKINCI, B. Building Information Modeling (BIM) application framework: The process of expanding from $3 \mathrm{D}$ to computable nD. Automation in Construction 46 (2014), pp. 82-93. DOI: $10.1016 / j$.autcon.2014.04.009.

DOLOI, HEMANTA; SAWHNEY, ANIL; IYER, K.C.; RENTALA, SAMEER. Analysing factors affecting delays in Indian construction projects. International Journal of Project Management 30.4 (2012), pp. 479-489. ISSN: 0263-7863. DOI: 10.1016/J. I JPROMAN.2011.10.004. DRAGO, FRÉDÉRIC; MYSZKOWSKI, KAROL; ANNEN, THOMAS; CHIBA, NORISHIGE. Adaptive logarithmic mapping for displaying high contrast scenes. Computer Graphics Forum. Vol. 22. 3. Wiley Online Library. 2003, pp. 419-426.

DRISKILL, ELENA; COHEN, ELAINE. Interactive design, analysis, and illustration of assemblies. Proceedings of the 1995 symposium on Interactive 3D graphics. ACM. 1995, pp. 27-34.

DURKIN, JACK; DURKIN, JOHN. Expert systems: design and development. Prentice Hall PTR, 1998.

DYKES, JASON; MACEACHREN, ALAN M; KRAAK, M-J. Exploring geovisualization. Elsevier, 2005.

EADIE, R; BROWNE, M; ODEYINKA, H; MCKEOWN, C; MCNIFF, S. BIM implementation throughout the UK construction project lifecycle: An analysis. Automation in Construction 36 (2013), pp. 145151. DOI: $10.1016 / \mathrm{j}$. autcon. 2013.09.001.

EADIE, ROBERT; ODEYINKA, HENRY; BROWNE, MIKE; MCKEOWN, CLARE; YOHANIS, MICHAEL. Building Information Modelling Adoption: An Analysis of the Barriers to Implementation. Journal of Engineering and Architecture 2.1 (2014), pp. 77-101.

EAST, E WILLIAM. Construction operations building information exchange (Cobie): Requirements definition and pilot implementation standard. Tech. rep. ENGINEER RESEARCH and DEVELOP- 
MENT CENTER CHAMPAIGN IL CONSTRUCTION ENGINEERING RESEARCH LAB, 2007.

EASTMAN, CM; EASTMAN, C; TEICHOLZ, P; SACKS, R. BIM handbook: A guide to building information modeling for owners, managers, designers, engineers and contractors. 2011.

ELBELTAGI, E; DAWOOD, M. Integrated visualized time control system for repetitive construction projects. English. Automation in Construction 20.7 (2011), pp. 940-953. ISSN: 09265805 (ISSN). DOI: 10. 1016/j. autcon.2011.03.012.

ELLIS, GEOFFREY; DIX, ALAN. A taxonomy of clutter reduction for information visualisation. IEEE transactions on visualization and computer graphics 13.6 (2007), pp. 1216-1223.

ELMQVIST, NIKLAS; FEKETE, JEAN-DANIEL. Hierarchical aggregation for information visualization: Overview, techniques, and design guidelines. IEEE Transactions on Visualization and Computer Graphics 16.3 (2010), pp. 439-454.

ELMQVIST, NIKLAS; TSIGAS, PHILIPPAS. A taxonomy of 3d occlusion management for visualization. IEEE Transactions on Visualization and Computer Graphics 14.5 (2008), pp. 1095-1109.

ELSEVIER. Mendeley. [Online; accessed 07-March-2018]. 2018. URL: \%7Bhttps: //www. mendeley.com/\%7D.

EVERETT, JOHN G.; FRANK, PETER B. Costs of Accidents and Injuries to the Construction Industry. Journal of Construction Engineering and Management 122.2 (1996), pp. 158-164. ISSN: 0733-9364. DOI: 10.1061/(ASCE) 0733-9364(1996)122:2(158).

EVERITT, CASS. Interactive order-independent transparency. White paper, nVIDIA 2.6 (2001), p. 7.

FALAGAS, MATTHEW E.; PITSOUNI, ELENI I.; MALIETZIS, GEORGE A.; PAPPAS, GEORGIOS. Comparison of PubMed, Scopus, Web of Science, and Google Scholar: strengths and weaknesses. The FASEB Journal 22.2 (2008), pp. 338-342. ISSN: 0892-6638. DOI: 10 .1096/ fj. 07-9492LSF.

FARIDI, ARSHI SHAKEEL; EL-SAYEGH, SAMEH MONIR. Significant factors causing delay in the UAE construction industry. Construction Management and Economics 24.11 (2006), pp. 1167-1176. ISSN: 0144-6193. DOI: $10.1080 / 01446190600827033$.

FARNSWORTH, C B; BEVERIDGE, S; MILLER, K R; CHRISTOFFERSON, J P. Application, Advantages, and Methods Associated with Using BIM in Commercial Construction. English. Inter- 
national Journal of Construction Education and Research 11.3 (2015), pp. 218-236. ISSN: 15578771 (ISSN). DOI: 10 . 1080/15578771 . 2013. 865683.

FEW, STEPHEN C. Now you see it: simple visualization techniques for quantitative analysis. Analytics Press, 2009, p. 329. ISBN: 0970601980. FISCHER, MARTIN A; AALAMI, FLORIAN. Scheduling with computerinterpretable construction method models. Journal of Construction Engineering and Management 122.4 (1996), pp. 337-347.

FREDRIKSON, ANNA; NORTH, CHRIS; PLAISANT, CATHERINE; SHNEIDERMAN, BEN. Temporal, geographical and categorical aggregations viewed through coordinated displays: a case study with highway incident data. The Craft of Information Visualization. Elsevier, 2003, pp. 22-30.

FREITAS, CARLA M. D. S.; LUZZARDI, PAULO R. G.; CAVA, RICARDO A.; WINCKLER, MARCO; PIMENTA, MARCELO S.; NEDEL, LUCIANA P. On evaluating information visualization techniques. Proceedings of the Working Conference on Advanced Visual Interfaces - AVI '02. New York, New York, USA: ACM Press, 2002, p. 373. ISBN: 1581135378. DOI: 10.1145/1556262.1556326.

FROESE, T M. The impact of emerging information technology on project management for construction. Automation in Construction 19.5 (2010), pp. 531-538. DOI: 10.1016/j . autcon.2009.11.004.

FUCHS, JOHANNES; ISENBERG, PETRA; BEZERIANOS, ANASTASIA; KEIM, DANIEL. A systematic review of experimental studies on data glyphs. IEEE Transactions on Visualization and Computer Graphics 23.7 (2017), pp. 1863-1879.

GALLAHER, MICHAEL P; O'CONOR, ALAN C; DETTBARN, JOHN L; GILDAY, LINDA T. Cost Analysis of Inadequate Interoperability in the U.S. Capital Facilities Industry. Nist (2004), pp. 1-210. ISSN: $<$ null>. DOI: 10.6028/NIST.GCR.04-867.

GARG, AMIK; DESHMUKH, SG. Maintenance management: literature review and directions. Journal of quality in maintenance engineering 12.3 (2006), pp. 205-238.

GATALSKY, PETER; ANDRIENKO, NATALIA; ANDRIENKO, GENNADY. Interactive analysis of event data using space-time cube. Information Visualisation, 2004. IV 2004. Proceedings. Eighth International Conference on. IEEE. 2004, pp. 145-152.

GEBKEN, RICHARD J.; GIBSON, G. EDWARD. Quantification of Costs for Dispute Resolution Procedures in the Construction Indus- 
try. Journal of Professional Issues in Engineering Education and Practice 132.3 (2006), pp. 264-271. ISSN: 1052-3928. DOI: 10.1061/(ASCE) 10523928 (2006) 132:3(264).

GELISEN, G; GRIFFIS, F H. Automated productivity-based schedule animation: Simulation-based approach to time-cost trade-off analysis. Journal of Construction Engineering and Management 140.4 (2014). DOI: 10.1061/(ASCE) C0.1943-7862.0000674.

GERGES, M; AUSTIN, S; MAYOUF, M; AHIAKWO, O; JAEGER, M; SAAD, A; GOHARY, T.-E. An investigation into the implementationof building information modelingin the middle east. English. Journal of Information Technology in Construction 22 (2017), pp. 1-15. ISSN: 18744753 (ISSN).

GERRISH, T; RUIKAR, K; COOK, M; JOHNSON, M; PHILLIP, M; LOWRY, C. BIM application to building energy performance visualisation and managementChallenges and potential. Energy and Buildings 144 (2017), pp. 218-228. DOI: 10.1016/j .enbuild. 2017. 03.032.

GHAFFARIANHOSEINI, ALI; TOOKEY, JOHN; GHAFFARIANHOSEINI, AMIRHOSEIN; NAISMITH, NICOLA; AZHAR, SALMAN; EFIMOVA, OLIA; RAAHEMIFAR, KAAMRAN. Building Information Modelling (BIM) uptake: Clear benefits, understanding its implementation, risks and challenges. Renewable and Sustainable Energy Reviews 75 (2017), pp. 1046-1053. ISSN: 18790690. DOI: $10.1016 / \mathrm{j}$. rser.2016.11.083.

GHOLIZADEH, P; ESMAEILI, B; GOODRUM, P. Diffusion of building information modeling functions in the construction industry. English. Journal of Management in Engineering 34.2 (2018). ISSN: 0742597X (ISSN). DOI: 10.1061/ (ASCE) ME. 1943-5479.0000589.

GIBSON, JAMES J. The perception of the visual world. (1950).

GLANDER, TASSILO; DÖLLNER, JÜRGEN. Abstract representations for interactive visualization of virtual 3D city models. Computers, Environment and Urban Systems 33.5 (2009), pp. 375-387.

GLEDSON, B J; GREENWOOD, D J. Surveying the extent and use of 4D BIM in the UK. English. Journal of Information Technology in Construction 21 (2016), pp. 57-71. ISSN: 18744753 (ISSN).

GLEICHER, MICHAEL; ALBERS, DANIELLE; WALKER, RICK; JUSUFI, ILIR; HANSEN, CHARLES D; ROBERTS, JONATHAN C. Visual comparison for information visualization. Information Visualization 10.4 (2011), pp. 289-309. 
GOLPARVAR-FARD, M; PEÑA-MORA, F; SAVARESE, S. Integrated sequential as-built and as-planned representation with $\mathrm{D}$ 4AR tools in support of decision-making tasks in the AEC/FM industry. Journal of Construction Engineering and Management 137.12 (2011), pp. 1099-1116. DOI: 10.1061/(ASCE)CO.1943-7862.0000371.

GOLPARVAR-FARD, M; TANG, P; CHO, Y K; SIDDIQUI, M K. Grand challenges in data and information visualization for the architecture, engineering, construction, and facility management industries. Computing in Civil Engineering - Proceedings of the 2013 ASCE International Workshop on Computing in Civil Engineering. Dept. of Civil and Environmental Eng., University of Illinois at UrbanaChampaign, United States, 2013, pp. 849-856.

GOVINDARAJU, NAGA K; LLOYD, BRANDON; YOON, SUNG-EUI; SUD, AVNEESH; MANOCHA, DINESH. Interactive shadow generation in complex environments. ACM Transactions on Graphics (TOG). Vol. 22. 3. ACM. 2003, pp. 501-510.

GRAHAM, MARTIN; KENNEDY, JESSIE. A survey of multiple tree visualisation. Information Visualization 9.4 (2010), pp. 235-252.

GRILO, A; JARDIM-GONCALVES, R. Value proposition on interoperability of BIM and collaborative working environments. Automation in Construction 19.5 (2010), pp. 522-530. DOI: 10.1016/j .autcon. 2009.11 .003$.

GU, NING; LONDON, KERRY. Understanding and facilitating BIM adoption in the AEC industry. Automation in Construction 19.8 (2010), pp. 988-999. ISSN: 0926-5805. DOI: 10 . 1016/ J . AUTCON . 2010 . 09.002.

GUIDE, AIA. Integrated project delivery: A guide. American Institute of Architects, California (2007).

GUO, HONGLING; YU, YANTAO; SKITMORE, MARTIN. Visualization technology-based construction safety management: A review. Automation in Construction 73 (2017), pp. 135-144. ISSN: 09265805. DOI: 10.1016/j.autcon.2016.10.004.

GUO, SY-JYE. Identification and resolution of work space conflicts in building construction. Journal of construction engineering and management 128.4 (2002), pp. 287-295.

GUREVICH, U; SACKS, R; SHRESTHA, P. BIM adoption by public facility agencies: impacts on occupant value. English. Building Research and Information 45.6 (2017), pp. 610-630. ISSN: 09613218 (ISSN). DOI: 10.1080/09613218.2017.1289029. 
HABER, ROBERT B; MCNABB, DAVID A. Visualization idioms: A conceptual model for scientific visualization systems. Visualization in scientific computing 74 (1990), p. 93.

HAINING, ROBERT P. Spatial data analysis: theory and practice. Cambridge University Press, 2003.

HALLBERG, D; TARANDI, V. On the use of open bim and $4 \mathrm{D}$ visualisation in a predictive life cycle management system for construction works. Electronic Journal of Information Technology in Construction 16 (2011), pp. 445-466.

HAMLEDARI, H; MCCABE, B; DAVARI, S; SHAHI, A. Automated Schedule and Progress Updating of IFC-Based 4D BIMs. English. Journal of Computing in Civil Engineering 31.4 (2017). ISSN: 08873801 (ISSN). DOI: 10.1061/(ASCE) CP. 1943-5487.0000660.

HAN, K K; CLINE, D; GOLPARVAR-FARD, M. Formalized knowledge of construction sequencing for visual monitoring of work-inprogress via incomplete point clouds and low-LoD 4D BIMs. Advanced Engineering Informatics 29.4 (2015), pp. 889-901. DOI: 10 . $1016 / j$. aei . 2015.10.006

HAN, K K; GOLPARVAR-FARD, M. Appearance-based material classification for monitoring of operation-level construction progress using 4D BIM and site photologs. English. Automation in Construction 53 (2015), pp. 44-57. ISSN: 09265805 (ISSN). DOI: 10.1016/j . autcon.2015.02.007.

- Potential of big visual data and building information modeling for construction performance analytics: An exploratory study. English. Automation in Construction 73 (2017), pp. 184-198. ISSN: 09265805 (ISSN). DOI: 10.1016/j.autcon.2016.11.004.

HARDIN, B; MCCOOL, D. BIM and construction management: proven tools, methods, and workflows. 2015.

HARROWER, MARK; BREWER, CYNTHIA A. ColorBrewer. org: an online tool for selecting colour schemes for maps. The Cartographic Journal 40.1 (2003), pp. 27-37.

HARTMANN, T; GAO, J; FISCHER, M. Areas of application for 3D and 4D models on construction projects. Journal of Construction Engineering and Management 134.10 (2008), pp. 776-785. DOI: 10.1061/ (ASCE) 0733-9364 (2008) $134: 10$ (776).

HARTMANN, TIMO; VAN MEERVELD, HENDRIK; VOSSEBELD, NIELS; ADRIAANSE, ARJEN. Aligning building information model tools 
and construction management methods. Automation in construction 22 (2012), pp. 605-613.

HE, J; HOYANO, A; ASAWA, T. A numerical simulation tool for predicting the impact of outdoor thermal environment on building energy performance. English. Applied Energy 86.9 (2009), pp. 1596 1605. ISSN: 03062619 (ISSN). DOI: 10.1016/j .apenergy . 2008.12.034.

HEALEY, CHRISTOPHER G. Choosing effective colours for data visualization. Visualization'96. Proceedings. IEEE. 1996, pp. 263-270.

HEALEY, CHRISTOPHER; ENNS, JAMES. Attention and visual memory in visualization and computer graphics. IEEE transactions on visualization and computer graphics 18.7 (2012), pp. 1170-1188.

HEER, JEFFREY; ROBERTSON, GEORGE. Animated transitions in statistical data graphics. IEEE transactions on visualization and computer graphics 13.6 (2007), pp. 1240-1247.

HEESOM, DAVID; MAHDJOUBI, LAMINE. Trends of 4D CAD applications for construction planning. Construction Management and Economics 22.2 (2004), pp. 171-182. ISSN: 0144-6193. DOI: 10.1080 / 0144619042000201376.

HERMAN, IVAN; MELANÇON, GUY; MARSHALL, M SCOTT. Graph visualization and navigation in information visualization: A survey. IEEE Transactions on visualization and computer graphics 6.1 (2000), pp. 24-43.

HM GOVERNMENT. 2-Construction 2025. Industrial Strategy: Government and industry in partnership. UK Government July (2013), p. 78. ISSN: 14740346. DOI: HMGovernment..

HOCHHEISER, HARRY; SHNEIDERMAN, BEN. Dynamic query tools for time series data sets: timebox widgets for interactive exploration. Information Visualization 3.1 (2004), pp. 1-18.

HOLTEN, DANNY. Hierarchical edge bundles: Visualization of adjacency relations in hierarchical data. IEEE Transactions on visualization and computer graphics 12.5 (2006), pp. 741-748.

HOWARD, R; BJÖRK, B.-C. Building information modelling - Experts' views on standardisation and industry deployment. Advanced Engineering Informatics 22.2 (2008), pp. 271-280. DOI: $10.1016 / \mathrm{j}$. aei.2007.03.001.

HOWELL, IAN; BATCHELER, BOB. Building Information Modeling Two Years Later - Huge Potential , Some Success and Several Limitations. Newforma (2003), p. 9. ISSN: 1471-4175. DOI: 10.1108 / 14714171111104637. 
HU, Z; ZHANG, J. BIM- and 4D-based integrated solution of analysis and management for conflicts and structural safety problems during construction: 2. Development and site trials. Automation in Construction 20.2 (2011), pp. 155-166. DOI: 10 . $1016 / \mathrm{j}$. autcon . 2010.09 .013 .

HUBBARD, PHILIP MARTYN. Collision detection for interactive graphics applications. IEEE Transactions on Visualization and Computer Graphics 1.3 (1995), pp. 218-230.

HUK, THOMAS. Who benefits from learning with 3D models? The case of spatial ability. Journal of computer assisted learning 22.6 (2006), pp. 392-404.

HWANG, B.-G.; THOMAS, S R; HAAS, C T; CALDAS, C H. Measuring the impact of rework on construction cost performance. Journal of Construction Engineering and Management 135.3 (2009), pp. 187-198. DOI: 10.1061/ (ASCE) 0733-9364 (2009) 135:3(187).

ISENBERG, TOBIAS; FREUDENBERG, BERT; HALPER, NICK; SCHLECHTWEG, STEFAN; STROTHOTTE, THOMAS. A developer's guide to silhouette algorithms for polygonal models. IEEE Computer Graphics and Applications 23.4 (2003), pp. 28-37.

ISENBERG, TOBIAS; ISENBERG, PETRA; CHEN, JIAN; SEDLMAIR, MICHAEL; MÖLLER, TORSTEN. A systematic review on the practice of evaluating visualization. IEEE Transactions on Visualization and Computer Graphics 19.12 (2013), pp. 2818-2827.

JARKAS, A M; BITAR, C G. Factors affecting construction labor productivity in Kuwait. Journal of Construction Engineering and Management 138.7 (2014), pp. 811-820. DOI: 10.1061/(ASCE)C0.19437862.0000501.

JAVED, W; MCDONNEL, B; ELMQVIST, N. Graphical Perception of Multiple Time Series. IEEE Transactions on Visualization and Computer Graphics 16.6 (2010), pp. 927-934. ISSN: 1077-2626. DOI: 10.1109/ TVCG . 2010.162.

JEONG, W; KIM, J B; CLAYTON, M J; HABERL, J S; YAN, W. A framework to integrate object-oriented physical modelling with building information modelling for building thermal simulation. Journal of Building Performance Simulation 9.1 (2016), pp. 50-69. DOI: 10.1080/19401493.2014.993709.

JIMÉNEZ, PABLO; THOMAS, FEDERICO; TORRAS, CARME. 3D collision detection: a survey. Computers \& Graphics 25.2 (2001), pp. 269 285. 
JONGELING, ROGIER; OLOFSSON, THOMAS. A method for planning of work-flow by combined use of location-based scheduling and 4D CAD. Automation in Construction 16.2 (2007), pp. 189-198.

JOSEPHSON, PER-ERIK; LARSSON, BENGT; LI, HENG. Illustrative Benchmarking Rework and Rework Costs in Swedish Construction Industry. Journal of Management in Engineering 18.2 (2002), pp. 76-83. ISSN: 0742-597X. DOI: 10.1061/(ASCE) 0742-597X (2002) 18: $2(76)$.

JUNG, Y; JOO, M. Building information modelling (BIM) framework for practical implementation. Automation in Construction 20.2 (2011), pp. 126-133. DOI: 10.1016/j .autcon.2010.09.010.

KALIBA, C; MUYA, M; MUMBA, K. Cost escalation and schedule delays in road construction projects in Zambia. International Journal of Project Management 27.5 (2009), pp. 522-531. DOI: 10 . 1016 / j . ijproman.2008.07.003.

KAM, C; FISCHER, M; HÄNNINEN, R; KARJALAINEN, A; LAITINEN, J. The product model and fourth dimension project. Electronic Journal of Information Technology in Construction 8 (2003), pp. 137166.

KANG, L S; KIM, S.-K.; MOON, H S; KIM, H S. Development of a 4D object-based system for visualizing the risk information of construction projects. Automation in Construction 31 (2013), pp. 186-203. DOI: $10.1016 / j$. autcon.2012.11.038.

KANG, L.-S.; MOON, H.-S.; PARK, S.-Y.; KIM, C.-H.; LEE, T S. Improved link system between schedule data and 3D object in $4 \mathrm{D}$ CAD system by using WBS code. KSCE Journal of Civil Engineering 14.6 (2010), pp. 803-814. DOI: 10.1007/s12205-010-0960-4.

KARTAM, NABIL A.; KARTAM, SAIED A. Risk and its management in the Kuwaiti construction industry: a contractors' perspective. International Journal of Project Management 19.6 (2001), pp. 325-335. ISSN: 0263-7863. DOI: $10.1016 / \mathrm{S} 0263-7863(00) 00014-4$.

KEEFE, DANIEL; EWERT, MARCUS; RIBARSKY, WILLIAM; CHANG, REMCO. Interactive coordinated multiple-view visualization of biomechanical motion data. IEEE transactions on visualization and computer graphics 15.6 (2009), pp. 1383-1390.

KEHRER, JOHANNES; HAUSER, HELWIG. Visualization and visual analysis of multifaceted scientific data: A survey. IEEE transactions on visualization and computer graphics 19.3 (2013), pp. 495-513. 
KEIM, D.A. Information visualization and visual data mining. IEEE Transactions on Visualization and Computer Graphics 8.1 (2002), pp. 18. ISSN: 10772626. DOI: 10.1109/2945.981847.

KEIM, D.A.; MANSMANN, F.; SCHNEIDEWIND, J.; ZIEGLER, H. Challenges in Visual Data Analysis. Tenth International Conference on Information Visualisation (IV'06). IEEE, 2006, pp. 9-16. ISBN: 0-76952602-0. DOI: $10.1109 /$ IV . 2006.31.

KHANZODE, A; FISCHER, M; REED, D. Benefits and lessons learned of implementing Building Virtual Design and Construction (VDC) technologies for coordination of Mechanical, Electrical, and Plumbing (MEP) systems on a large Healthcare project. Electronic Journal of Information Technology in Construction 13 (2008), pp. 324-342.

KHOSROWSHAHI, F; ARAYICI, Y. Roadmap for implementation of BIM in the UK construction industry. Engineering, Construction and Architectural Management 19.6 (2012), pp. 610-635. DOI: 10.1108/ 09699981211277531.

KIM, C; KIM, B; KIM, H. 4D CAD model updating using image processing-based construction progress monitoring. English. Automation in Construction 35 (2013), pp. 44-52. ISSN: 09265805 (ISSN). DOI: $10.1016 / j$.autcon.2013.03.005.

KIM, C; KIM, C; SON, H. Automated construction progress measurement using a 4D building information model and 3D data. Automation in Construction 31 (2013), pp. 75-82. DOI: 10.1016/j . autcon. 2012.11 .041$.

KIM, C; KIM, H; PARK, T; KIM, M K. Applicability of 4D CAD in civil engineering construction: Case study of a cable-stayed bridge project. Journal of Computing in Civil Engineering 25.1 (2011), pp. 98 107. DOI: $10.1061 /$ (ASCE) CP. 1943-5487.0000074.

KIM, H; ANDERSON, K; LEE, S; HILDRETH, J. Generating construction schedules through automatic data extraction using open BIM (building information modeling) technology. English. Automation in Construction 35 (2013), pp. 285-295. ISSN: 09265805 (ISSN). DOI: $10.1016 / \mathrm{j}$. autcon.2013.05.020.

KIM, J I; KIM, J; FISCHER, M; ORR, R. BIM-based decision-support method for master planning of sustainable large-scale developments. Automation in Construction 58 (2015), pp. 95-108. DOI: 10 . 1016/j. autcon.2015.07.003. 
KIM, K J; LEE, C K; KIM, U R; SHIN, E Y; CHO, M Y. Collaborative work model under distributed construction environments. Canadian Journal of Civil Engineering 32.2 (2005), pp. 299-313. DOI: 10 . 1139/ 104-061.

KIM, SUNGYE; WOO, INSOO; MACIEJEWSKI, ROSS; EBERT, DAVID S; ROPP, TIMOTHY D; THOMAS, KRYSTAL. Evaluating the effectiveness of visualization techniques for schematic diagrams in maintenance tasks. Proceedings of the 7th Symposium on Applied Perception in Graphics and Visualization. ACM. 2010, pp. 33-40.

KITCHENHAM, BARBARA. Procedures for performing systematic reviews. Keele, UK, Keele University 33.TR/SE-0401 (2004), p. 28. ISSN: 13537776. DOI: 10.1.1.122.3308. arXiv: 339:b2535.

KLEFFNER, DOROTHY A; RAMACHANDRAN, VILAYANUR S. On the perception of shape from shading. Attention, Perception, \& Psychophysics 52.1 (1992), pp. 18-36.

KLOSOWSKI, JAMES T; HELD, MARTIN; MITCHELL, JOSEPH S B; SOWIZRAL, HENRY; ZIKAN, KAREL. Efficient collision detection using bounding volume hierarchies of k-DOPs. IEEE transactions on Visualization and Computer Graphics 4.1 (1998), pp. 21-36.

KONG, S C W. A case study of applying virtual prototyping in construction. World Academy of Science, Engineering and Technology 65 (2010), pp. 226-231.

KOO, B; FISCHER, M. Feasibility study of 4D CAD in commercial construction. Journal of Construction Engineering and Management 126.4 (2000), pp. 251-260. DOI: 10.1061/(ASCE) 0733-9364 (2000)126: 4 (251).

KOUSHKI, P A; AL-RASHID, K; KARTAM, N. Delays and cost increases in the construction of private residential projects in Kuwait. Construction Management and Economics 23.3 (2005), pp. 285-294. DOI: $10.1080 / 0144619042000326710$.

KRAAK, MENNO-JAN; ORMELING, FERDINAND JAN. Cartography: visualization of spatial data. Routledge, 2013.

KRAWCZYK, GRZEGORZ; MYSZKOWSKI, KAROL; SEIDEL, HANSPETER. Perceptual effects in real-time tone mapping. Proceedings of the 21st spring conference on Computer graphics. ACM. 2005, pp. 195-202.

KREIDER, RALPH; MESSNER, JOHN; DUBLER, CRAIG. Determining the frequency and impact of applying BIM for different purposes on building projects. Proceedings of the 6th International 
Conference on Innovation in Architecture, Engineering and Construction (AEC) (2010), pp. 1-10.

KRISTENSSON, PER OLA; DAHLBACK, NILS; ANUNDI, DANIEL; BJORNSTAD, MARIUS; GILLBERG, HANNA; HARALDSSON, JONAS; MARTENSSON, INGRID; NORDVALL, MATHIAS; STAHL, JOSEFINE. An evaluation of space time cube representation of spatiotemporal patterns. IEEE Transactions on Visualization and Computer Graphics 15.4 (2009), pp. 696-702.

KRUGER, JENS; SCHNEIDER, JENS; WESTERMANN, RUDIGER. Clearview: An interactive context preserving hotspot visualization technique. IEEE Transactions on Visualization and Computer Graphics 12.5 (2006).

KUBICKI, SYLVAIN; HALIN, GILLES; GUERRIERO, ANNIE. Multivisualization of the cooperative context in building construction activity A model-based approach to design AEC-specific visualization interfaces. Information Visualization, 2007. IV'07. 11th International Conference. IEEE. 2007, pp. 590-595.

KUCUKVAR, MURAT; TATARI, OMER. Towards a triple bottom-line sustainability assessment of the U.S. construction industry. The International Journal of Life Cycle Assessment 18.5 (2013), pp. 958-972. ISSN: 0948-3349. DOI: $10.1007 /$ s11367-013-0545-9.

KUMARASWAMY, MOHAN M.; CHAN, DANIEL W. M. Contributors to construction delays. Construction Management and Economics 16.1 (1998), pp. 17-29. ISSN: 0144-6193. DOI: 10.1080/014461998372556.

KUO, CHENG-HAN; TSAI, MENG-HAN; KANG, SHIH-CHUNG. A framework of information visualization for multi-system construction. Automation in Construction 20.3 (2011), pp. 247-262.

KWAN, MEI-PO; LEE, JIYEONG. Geovisualization of human activity patterns using 3D GIS: a time-geographic approach. Spatially integrated social science 27 (2004).

LAAKSO, M; KIVINIEMI, A. The IFC standard - A review of history, development, and standardization. Electronic Journal of Information Technology in Construction 17 (2012), pp. 134-161.

LAMBERTI, DONNA M; WALLACE, WILLIAM A. Intelligent interface design: An empirical assessment of knowledge presentation in expert systems. Mis Quarterly (1990), pp. 279-311.

LEITE, F; CHO, Y; BEHZADAN, A H; LEE, S; CHOE, S; FANG, Y; AKHAVIAN, R; HWANG, S. Visualization, Information Modeling, and Simulation: Grand Challenges in the Construction Industry. 
Journal of Computing in Civil Engineering 30.6 (2016). DOI: $10.1061 /$ (ASCE) CP. 1943-5487.0000604.

LEVKOWITZ, HAIM. Color icons-merging color and texture perception for integrated visualization of multiple parameters. Visualization, 1991. Visualization'91, Proceedings., IEEE Conference on. IEEE. 1991, pp. 164-170.

LI, CHUnleI; MCMAHON, CHRIS; NEWNES, LINDA. Annotation in Design Processes: Classification of Approaches. DS 58-8: Proceedings of ICED 09, the 17th International Conference on Engineering Design, Vol. 8, Design Information and Knowledge, Palo Alto, CA, USA, 24.-27.08.2009 (2009).

LI, WILMOT; AGRAWALA, MANEESH; CURLESS, BRIAN; SALESIN, DAVID. Automated generation of interactive 3D exploded view diagrams. ACM Transactions on Graphics (TOG). Vol. 27. 3. ACM. 2008, p. 101.

LIAO, SHU-HSIEN. Expert system methodologies and applications - a decade review from 1995 to 2004. Expert systems with applications 28.1 (2005), pp. 93-103.

LIAPI, KATHERINE A. 4D visualization of highway construction projects. Information Visualization, 2003. IV 2003. Proceedings. Seventh International Conference on. IEEE. 2003, pp. 639-644.

LIN, L; HUANG, M; LI, J; SONG, X; SUN, Y. The application and exploration of the TSTL in construction management based on BIM. English. Journal of Applied Science and Engineering 20.3 (2017), pp. 309-317. ISSN: 15606686 (ISSN). DOI: 10.6180/jase.2017 .20.3.05.

LIU, R; ISSA, R R A. Design for maintenance accessibility using BIM tools. English. Facilities 32.3 (2014), pp. 153-159. ISSN: 02632772 (ISSN). DOI: $10.1108 / \mathrm{F}-09-2011-0078$.

LOUGHLIN, MARIA M.; HUGHES, JOHN F. An annotation system for $3 \mathrm{D}$ fluid flow visualization. Procedings of the Coneference on Visualization'94. IEEE Comput. Soc. Press, 1994, pp. 273-279. ISBN: 0-8186-6627-7. DOI: 10 .1109/VISUAL . 1994 . 346309.

LOVE, P E D. Influence of project type and procurement method on rework costs in building construction projects. Journal of Construction Engineering and Management 128.1 (2002), pp. 18-29. DOI: 10.1061/ (ASCE) 0733-9364 (2002) 128:1 (18).

LOVE, P E D; IRANI, Z; EDWARDS, D J. A rework reduction model for construction projects. IEEE Transactions on Engineering Management 51.4 (2004), pp. 426-440. DOI: 10.1109/TEM.2004.835092. 
LOVE, P E D; MANUAL, P; LI, H. Determining the causal structure of rework influences in construction. Construction Management and Economics 17.4 (1999), pp. 505-517. DOI: 10.1080/014461999371420.

LOVE, P E D; MATTHEWS, J; SIMPSON, I; HILL, A; OLATUNJI, O A. A benefits realization management building information modeling framework for asset owners. Automation in Construction 37 (2014), pp. 1-10. DOI: 10.1016/j. autcon.2013.09.007.

LOVE, P E D; SIMPSON, I; HILL, A; STANDING, C. From justification to evaluation: Building information modeling for asset owners. Automation in Construction 35 (2013), pp. 208-216. DOI: $10.1016 / \mathrm{j}$. autcon. 2013.05.008.

LOVE, PETER E. D.; LI, HENG. Quantifying the causes and costs of rework in construction. Construction Management and Economics 18.4 (2000), pp. 479-490. ISSN: 0144-6193. DOI: 10 . 1080 / 01446190050024897.

LU, WEISHENG; FUNG, ADA; PENG, YI; LIANG, CONG; ROWLINSON, STEVE. Demystifying construction project time-effort distribution curves: BIM and non-BIM comparison. Journal of Management in Engineering 31.6 (2015), p. 04015010.

LUFT, THOMAS; COLDITZ, CARSTEN; DEUSSEN, OLIVER. Image enhancement by unsharp masking the depth buffer. ACM SIGGRAPH 2006 Papers on - SIGGRAPH '06. Vol. 25. 3. ACM, 2006, p. 1206. ISBN: 1595933646. DOI: 10.1145/1179352.1142016.

LUPTON, RICHARD CHARLES; ALLWOOD, JULIAN MARK. Hybrid Sankey diagrams: Visual analysis of multidimensional data for understanding resource use. Resources, Conservation and Recycling 124 (2017), pp. 141-151.

MACKINLAY, JOCK; HANRAHAN, PAT; STOLTE, CHRIS. Show me: Automatic presentation for visual analysis. IEEE transactions on visualization and computer graphics 13.6 (2007).

MADSEN, JACOB BOESEN; TATZQERN, MARKUS; MADSEN, CLAUS B.; SCHMALSTIEG, DIETER; KALKOFEN, DENIS. Temporal Coherence Strategies for Augmented Reality Labeling. IEEE Transactions on Visualization and Computer Graphics 22.4 (2016), pp. 14151423. ISSN: 1077-2626. DOI: 10.1109/TVCG. 2016.2518318.

MAHALINGAM, A; KASHYAP, R; MAHAJAN, C. An evaluation of the applicability of $4 \mathrm{D} \mathrm{CAD}$ on construction projects. Automation in Construction 19.2 (2010), pp. 148-159. DOI: 10.1016/j .autcon. 2009. 11.015 . 
MALCOLM, DONALD G; ROSEBOOM, JOHN H; CLARK, CHARLES E; FAZAR, WILLARD. Application of a technique for research and development program evaluation. Operations research 7.5 (1959), pp. 646-669.

MCGLINN, K; YUCE, B; WICAKSONO, H; HOWELL, S; REZGUI, Y. Usability evaluation of a web-based tool for supporting holistic building energy management. English. Automation in Construction 84 (2017), pp. 154-165. ISSN: 09265805 (ISSN). DOI: 10.1016/j . autcon . 2017.08 .033$.

MCGUIRE, MORGAN; BAVOIL, LOUIS. Weighted blended orderindependent transparency. Journal of Computer Graphics Techniques (2013).

MCKINNEY, K; FISCHER, M. Generating, evaluating and visualizing construction schedules with CAD tools. Automation in Construction 7.6 (1998), pp. 433-447.

MCKINNEY, KATHLEEN; FISCHER, MARTIN; KUNZ, JOHN. Visualization of construction planning information. International Conference on Intelligent User Interfaces, Proceedings IUI. Dep of Civil Engineering, 1998, pp. 135-138.

MCKINNEY, KATHLEEN; KIM, JENNIFER; FISCHER, MARTIN; HOWARD, CRAIG. Interactive 4D-CAD. Computing in Civil Engineering (New York) (1996), pp. 383-389.

MENG, X. The effect of relationship management on project performance in construction. International Journal of Project Management 30.2 (2012), pp. 188-198. DOI: 10.1016/j.ijproman.2011.04.002.

MIETTINEN, REIJO; PAAVOLA, SAMI. Beyond the BIM utopia: Approaches to the development and implementation of building information modeling. Automation in Construction 43 (2014), pp. 8491. ISSN: 09265805. DOI: 10.1016/j .autcon.2014.03.009.

MILLER, HARVEY J. A measurement theory for time geography. Geographical analysis 37.1 (2005), pp. 17-45.

MILlS, A; LOVE, P E D; WILLIAMS, P. Defect costs in residential construction. Journal of Construction Engineering and Management 135.1 (2009), pp. 12-16. DOI: 10.1061/ (ASCE) 0733-9364(2009) 135 : $1(12)$.

AL-MOMANI, AYMAN H. Construction delay: a quantitative analysis. International Journal of Project Management 18.1 (2000), pp. 51-59. ISSN: 0263-7863. DOI: 10.1016/S0263-7863(98)00060-X. 
MOON, H; KIM, H; KAMAT, V R; KANG, L. BIM-based construction scheduling method using optimization theory for reducing activity overlaps. Journal of Computing in Civil Engineering 29.3 (2015). DOI: $10.1061 /$ (ASCE) CP. 1943-5487.0000342.

MOYA-ANEGÓN， FELIX de; CHINCHILLA-RODRIIGUEZ, ZAIDA; VARGAS-QUESADA, BENJAMIIN; CORERA-ÁLVAREZ, ELENA; MUÑOZ-FERNÁNDEZ, FRANCISCO JOSÉ; GONZÁLEZ-MOLINA, ANTONIO; HERRERO-SOLANA, VICTOR. Coverage analysis of Scopus: A journal metric approach. Scientometrics 73.1 (2007), pp. $53-78$.

MUNZNER, TAMARA; MAGUIRE, EAMONN (GRAPHIC artist). Visualization analysis \& design. 2014, p. 404. ISBN: 9781466508934.

MYERS, DANNY. A review of construction companies' attitudes to sustainability. Construction Management and Economics 23.8 (2005), pp. 781-785. ISSN: 0144-6193. DOI: 10.1080/01446190500184360.

NAKAYA, TOMOKI; YANO, KEIJI. Visualising Crime Clusters in a Space-time Cube: An Exploratory Data-analysis Approach Using Space-time Kernel Density Estimation and Scan Statistics. Transactions in GIS 14.3 (2010), pp. 223-239.

NIEDERAUER, CHRISTOPHER; HOUSTON, MIKE; AGRAWALA, MANEESH; HUMPHREYS, GREG. Non-invasive interactive visualization of dynamic architectural environments. Proceedings of the 2003 symposium on Interactive 3D graphics. ACM. 2003, pp. 55-58.

NIELSEN, YASEMIN; ERDOGAN, BILGE. Information visualization in construction industry; A quality perspective. Proceedings of the 20th Annual Conference of the Association of Researchers in Construction Management, Heriot-Watt University, UK. Vol. 1. 2004, pp. 629 636.

NIELSON, GREGORY; HAGEN, HANS; MULLER, H. Scientific visualization. Institute of Electrical \& Electronics Engineers. 1997.

NORTH, CHRIS; SHNEIDERMAN, BEN. Snap-together visualization: can users construct and operate coordinated visualizations? International Journal of Human-Computer Studies 53.5 (2000), pp. 715739 .

ODEH, ABDALLA M; BATTAINEH, HUSSIEN T. Causes of construction delay: traditional contracts. International Journal of Project Management 20.1 (2002), pp. 67-73. ISSN: 0263-7863. DOI: 10.1016/S0263$7863(00) 00037-5$. 
OGUnLANA, S O; PROMKUNTONG, K; JEARKJIRM, V. Construction delays in a fast-growing economy: Comparing Thailand with other economies. International Journal of Project Management 14.1 (1996), pp. 37-45. DOI: 10.1016/0263-7863(95)00052-6.

OKPALA, D C; ANIEKWU, A N. Causes of high costs of construction in Nigeria. Journal of Construction Engineering and Management 114.2 (1988), pp. 233-244. DOI: 10 . 1061 / (ASCE ) 0733-9364(1988) 114 : 2(214).

ORTIZ, OSCAR; CASTELLS, FRANCESC; SONNEMANN, GUIDO. Sustainability in the construction industry: A review of recent developments based on LCA. Construction and Building Materials 23.1 (2009), pp. 28-39. ISSN: 0950-0618. DOI: 10 .1016/J . CONBUILDMAT . 2007. 11.012.

OTI, A H; TIZANI, W; ABANDA, F H; JALY-ZADA, A; TAH, J H M. Structural sustainability appraisal in BIM. Automation in Construction 69 (2016), pp. 44-58. DOI: 10.1016/j . autcon.2016.05.019.

PARK, J; CAI, H; DUNSTON, P S; GHASEMKHANI, H. DatabaseSupported and Web-Based Visualization for Daily 4D BIM. English. Journal of Construction Engineering and Management 143.10 (2017). ISSN: 07339364 (ISSN). DOI: 10 .1061/(ASCE) CO . 1943-7862 . 0001392.

PARK, J; KIM, B; KIM, C; KIM, H. 3D/4D CAD applicability for lifecycle facility management. Journal of Computing in Civil Engineering 25.2 (2011), pp. 129-138. DOI: 10.1061/(ASCE) CP. 1943-5487.0000067.

PATACAS, J; DAWOOD, N; GREENWOOD, D; KASSEM, M. Supporting building owners and facility managers in the validation and visualisation of asset information models (aim) through open standards and open technologies. Journal of Information Technology in Construction 21 (2016), pp. 434-455.

PEARLMAN, JEROME. Engineering program planning and control through the use of PERT. IRE transactions on engineering management 4 (1960), pp. 125-134.

PÉREZ-LOMBARD, LUIS; ORTIZ, JOSÉ; GONZÁLEZ, ROCIIO; MAESTRE, ISMAEL R. A review of benchmarking, rating and labelling concepts within the framework of building energy certification schemes. Energy and Buildings 41.3 (2009), pp. 272-278. PETTICREW, M; ROBERTS, H. Systematic reviews in the social sciences: A practical guide. 2008. 
PHUA, FLORENCE T.T.; ROWLINSON, STEVE. How important is cooperation to construction project success? A grounded empirical quantification. Engineering, Construction and Architectural Management 11.1 (2004), pp. 45-54. ISSN: 0969-9988. DOI: 10 . 1108 / 09699980410512656.

PIERCE, DAVID R. Line of Balance Scheduling. Project Scheduling and Management for Construction, Fourth Edition (), pp. 169-191.

PILGRIM, MATTHEW; BOUCHLAGHEM, DINO; LOVEDAY, DENNIS; HOLMES, MICHAEL. Abstract data visualisation in the built environment. Information Visualization, 2000. Proceedings. IEEE International Conference on. IEEE. 2000, pp. 126-134.

PLAISANT, CATHERINE; CATHERINE. The challenge of information visualization evaluation. Proceedings of the working conference on Advanced visual interfaces - AVI '04. New York, New York, USA: ACM Press, 2004, p. 109. ISBN: 1581138679. DOI: 10.1145/989863.989880.

PORWAL, A; HEWAGE, K N. Building Information Modeling (BIM) partnering framework for public construction projects. Automation in Construction 31 (2013), pp. 204-214. DOI: 10.1016/j . autcon . 2012.12 .004$.

PRESLEY, ADRIEN; MEADE, LAURA. Benchmarking for sustainability: an application to the sustainable construction industry. Benchmarking: An International Journal 17.3 (2010). Ed. by JOSEPH SARKIS, pp. 435-451. ISSN: 1463-5771. DOI: 10 . 1108 / 14635771011049380.

QU, HUAMIN; WANG, HAOMIAN; CUI, WEIWEI; WU, YINGCAI; CHAN, MING-YUEN. Focus + context route zooming and information overlay in 3D urban environments. IEEE Transactions on Visualization and Computer Graphics 15.6 (2009), pp. 1547-1554.

RAHMANI ASL, M; ZARRINMEHR, S; BERGIN, M; YAN, W. BPOpt: A framework for BIM-based performance optimization. English. Energy and Buildings 108 (2015), pp. 401-412. ISSN: 03787788 (ISSN). DOI: $10.1016 / \mathrm{j}$.enbuild.2015.09.011.

REINHARD, ERIK; STARK, MICHAEL; SHIRLEY, PETER; FERWERDA, JAMES. Photographic tone reproduction for digital images. ACM transactions on graphics (TOG) 21.3 (2002), pp. 267-276.

ROBERTS, JONATHAN C. State of the art: Coordinated \& multiple views in exploratory visualization. Coordinated and Multiple Views in Exploratory Visualization, 2007. CMV'07. Fifth International Conference on. IEEE. 2007, pp. 61-71. 
ROBERTSON, GEORGE G; CARD, STUART K; MACKINLAY, JACK D. Information visualization using $3 \mathrm{D}$ interactive animation. Communications of the ACM 36.4 (1993), pp. 57-71.

ROBERTSON, GEORGE; FERNANDEZ, ROLAND; FISHER, DANYEL; LEE, BONGSHIN; STASKO, JOHN. Effectiveness of animation in trend visualization. IEEE Transactions on Visualization and Computer Graphics 14.6 (2008).

ROSVALL, MARTIN; BERGSTROM, CARL T. Mapping change in large networks. PloS one 5.1 (2010), e8694.

RUSSELL, A; STAUB-FRENCH, S; TRAN, N; WONG, W. Visualizing high-rise building construction strategies using linear scheduling and 4D CAD. Automation in Construction 18.2 (2009), pp. 219 236. DOI: $10.1016 / j$. autcon. 2008.08.001.

SACKS, R; KOSKELA, L; DAVE, B A; OWEN, R. Interaction of lean and building information modeling in construction. Journal of Construction Engineering and Management 136.9 (2010), pp. 968-980. DOI: $10.1061 /$ (ASCE) C0.1943-7862.0000203.

SACKS, R; TRECKMANN, M; ROZENFELD, O. Visualization of work flow to support lean construction. Journal of Construction Engineering and Management 135.12 (2009), pp. 1307-1315. DOI: 10.1061/ (ASCE) C0.1943-7862.0000102.

SAMBASIVAN, MURALI; SOON, YAU WEN. Causes and effects of delays in Malaysian construction industry. International Journal of Project Management 25.5 (2007), pp. 517-526. ISSN: 0263-7863. DOI: 10.1016/J . I JPROMAN . 2006.11.007.

SANTOS, PAULO IVSON NETTO; CELES FILHO, WALDEMAR. Instanced rendering of massive cad models using shape matching. Graphics, Patterns and Images (SIBGRAPI), 2014 27th SIBGRAPI Conference on. IEEE. 2014, pp. 335-342.

EL-SAYEGH, SAMEH MONIR. Risk assessment and allocation in the UAE construction industry. International Journal of Project Management 26.4 (2008), pp. 431-438. ISSN: 0263-7863. DOI: $10.1016 / \mathrm{J}$. I JPROMAN . 2007.07.004.

SCHLUETER, ARNO; THESSELING, FRANK. Building information model based energy/exergy performance assessment in early design stages. Automation in construction 18.2 (2009), pp. 153-163.

SEBASTIAN, R. Changing roles of the clients, architects and contractors through BIM. Engineering, Construction and Architectural Management 18.2 (2011), pp. 176-187. DOI: 10.1108/09699981111111148. 
SEDLMAIR, MICHAEL; MEYER, MIRIAH; MUNZNER, TAMARA. Design Study Methodology: Reflections from the Trenches and the Stacks. IEEE Transactions on Visualization and Computer Graphics 18.12 (2012), pp. 2431-2440. ISSN: 1077-2626. DOI: 10.1109/TVCG. 2012.213.

SEMMO, AMIR; TRAPP, MATTHIAS; KYPRIANIDIS, JAN ERIC; DÖLLNER, JÜRGEN. Interactive visualization of generalized virtual 3D city models using level-of-abstraction transitions. Computer Graphics Forum. Vol. 31. 3pt1. Wiley Online Library. 2012, pp. 885-894.

SEMPLE, C; HARTMAN, F T; JERGEAS, G. Construction claims and disputes: Causes and cost/time overruns. Journal of Construction Engineering and Management 120.4 (1994), pp. 785-795. DOI: $10.1061 /$ (ASCE) 0733-9364(1994) 120:4(785).

SHALABI, F; TURKAN, Y. IFC BIM-Based Facility Management Approach to Optimize Data Collection for Corrective Maintenance. Journal of Performance of Constructed Facilities 31.1 (2017). DOI: $10.1061 /$ (ASCE) CF . 1943-5509.0000941.

SHANMUGAM, PERUMAAL; ARIKAN, OKAN. Hardware accelerated ambient occlusion techniques on GPUs. Proceedings of the 2007 symposium on Interactive 3D graphics and games. ACM. 2007, pp. 7380.

SHIRAVI, HADI; SHIRAVI, ALI; GHORBANI, ALI A. A survey of visualization systems for network security. IEEE Transactions on visualization and computer graphics 18.8 (2012), pp. 1313-1329.

SHNEIDERMAN, BEN. The eyes have it: A task by data type taxonomy for information visualizations. Visual Languages, 1996. Proceedings., IEEE Symposium on. IEEE. 1996, pp. 336-343.

- Why not make interfaces better than 3D reality? IEEE Computer Graphics and Applications 23.6 (2003), pp. 12-15.

SILVA, SAMUEL; SANTOS, BEATRIZ SOUSA; MADEIRA, JOAQUIM. Using color in visualization: A survey. Computers \& Graphics 35.2 (2011), pp. 320-333.

SMITH, D K; TARDIFF, M. Building Information Modeling: A Strategic Implementation Guide for Architects, Engineers, Constructors, and Real Estate Asset Managers. 2009, pp. 1-186. DOI: 10. 1002/9780470432846.

SON, H; KIM, C; KWON CHO, Y. Automated Schedule Updates Using As-Built Data and a 4D Building Information Model. Journal of 
Management in Engineering 33.4 (2017). DOI: 10.1061/(ASCE) ME.19435479.0000528 .

SOVACOOL, BENJAMIN K.; NUGENT, DANIEL; GILBERT, ALEX. Construction Cost Overruns and Electricity Infrastructure: An Unavoidable Risk? The Electricity Journal 27.4 (2014), pp. 112-120. ISSN: 1040-6190. DOI: 10.1016/ J.TEJ .2014.03.015.

STAUB-FRENCH, S; KHANZODE, A. 3D and 4D modeling for design and construction coordination: Issues and lessons learned. Electronic Journal of Information Technology in Construction 12 (2007), pp. 381-407.

STAUB-FRENCH, S; RUSSELL, A; TRAN, N. Linear scheduling and 4D visualization. Journal of Computing in Civil Engineering 22.3 (2008), pp. 192-205. DOI: $10.1061 /$ (ASCE) 0887-3801(2008) 22:3(192).

STERNE, J.A.C.; EGGER, M; MOHER, D; HIGGINS, J.P.T.; GREEN, S. Cochrane handbook for systematic reviews of interventions. null (2011), null.

SUCCAR, BILAL. Building information modelling framework: A research and delivery foundation for industry stakeholders. Automation in Construction 18.3 (2009), pp. 357-375. ISSN: 0926-5805. DOI: 10.1016/J . AUTCON . 2008 . 10.003.

SWEIS, G.; SWEIS, R.; ABU HAMMAD, A.; SHBOUL, A. Delays in construction projects: The case of Jordan. International Journal of Project Management 26.6 (2008), pp. 665-674. ISSN: 0263-7863. DOI: 10.1016/J . I JPROMAN . 2007.09.009.

TAI, NAN-CHING; INANICI, MEHLIKA. Luminance contrast as depth cue: investigation and design applications. Computer-Aided Design and Applications 9.5 (2012), pp. 691-705.

TALBOT, JUSTIN; SETLUR, VIDYA; ANAND, ANUSHKA. Four experiments on the perception of bar charts. IEEE transactions on visualization and computer graphics 20.12 (2014), pp. 2152-2160.

TANG, TRAN DUC. Algorithms for collision detection and avoidance for five-axis NC machining: a state of the art review. ComputerAided Design 51 (2014), pp. 1-17.

TANYER, A M; AOUAD, G. Moving beyond the fourth dimension with an IFC-based single project database. Automation in Construction 14.1 (2005), pp. 15-32. DOI: 10.1016/j.autcon.2004.06.002.

TARINI, MARCO; CIGNONI, PAOLO; MONTANI, CLAUDIO. Ambient occlusion and edge cueing for enhancing real time molecular vi- 
sualization. IEEE transactions on visualization and computer graphics 12.5 (2006).

TAUSCHER, H; SCHERER, R J. Specifying complex visualization configurations withhierarchically nested mapping rule sets. Journal of Information Technology in Construction 20 (2015), pp. 40-50.

TAYLOR, J E; BERNSTEIN, P G. Paradigm trajectories of building information modeling practice in project networks. Journal of Management in Engineering 25.2 (2009), pp. 69-76. DOI: $10.1061 /$ (ASCE) 0742-597X (2009) 25:2(69).

TEZEL, A; AZIZ, Z. From conventional to it based visual management: A conceptual discussion for lean construction. English. Journal of Information Technology in Construction 22 (2017), pp. 220-246. ISSN: 18744753 (ISSN).

TOMINSKI, CHRISTIAN; GLADISCH, STEFAN; KISTER, ULRIKE; DACHSELT, RAIMUND; SCHUMANN, HEIDRUN. Interactive lenses for visualization: An extended survey. Computer Graphics Forum. Vol. 36. 6. Wiley Online Library. 2017, pp. 173-200.

TOMINSKI, CHRISTIAN; SCHUMANN, HEIDRUN; ANDRIENKO, GENNADY; ANDRIENKO, NATALIA. Stacking-based visualization of trajectory attribute data. IEEE Transactions on visualization and Computer Graphics 18.12 (2012), pp. 2565-2574.

TORY, MELANIE; MOLLER, TORSTEN. Human factors in visualization research. IEEE transactions on visualization and computer graphics 10.1 (2004), pp. $72-84$.

TORY, MELANIE; STAUB-FRENCH, SHERYL; HUANG, DANDAN; CHANG, YU-LING; SWINDELLS, COLIN; POTTINGER, RACHEL. Comparative visualization of construction schedules. Automation in Construction 29 (2013), pp. 68-82.

TOURAN, ALI; LOPEZ, RAMON. Modeling Cost Escalation in Large Infrastructure Projects. Journal of Construction Engineering and Management 132.8 (2006), pp. 853-860. ISSN: 0733-9364. DOI: 10.1061/ (ASCE) 0733-9364(2006) 132:8(853).

TRAPP, MATTHIAS; GLANDER, TASSILO; BUCHHOLZ, HENRIK; DÖLLNER, JÜRGEN. 3D generalization lenses for interactive focus + context visualization of virtual city models. Information Visualisation, 2008. IV'08. 12th International Conference. IEEE. 2008, pp. 356-361.

TREBBE, M; HARTMANN, T; DORÉE, A. 4D CAD models to support the coordination of construction activities between contractors. 
English. Automation in Construction 49.PA (2015), pp. 83-91. ISSN: 09265805 (ISSN). DOI: 10.1016/j . autcon.2014.10.002.

TSAI, M.-H.; KANG, S.-C.; HSIEH, S.-H. Lessons learnt from customization of a BIM tool for a design-build company. Journal of the Chinese Institute of Engineers, Transactions of the Chinese Institute of Engineers,Series A/Chung-kuo Kung Ch'eng Hsuch K'an 37.2 (2014), pp. 189-199. DOI: 10.1080/02533839.2013.781791.

TSE, TAO CHIU KENNY; WONG, KAM DIN ANDY; WONG, KWAN WAH FRANCIS. The utilisation of Building Information Models in nD modelling: A study of data interfacing and adoption barriers. Electronic Journal of Information Technology in Construction 10 (2005). ISSN: 14006529.

TSERNG, H.-P.; HO, S.-P.; JAN, S.-H. Developing BIM-assisted as-built schedule management system for general contractors. Journal of Civil Engineering and Management 20.1 (2014), pp. 47-58. DOI: 10 . $3846 / 13923730.2013 .851112$.

TUFTE, E.R. The visual display of quantitative information. (1983). cited By 2253.

TURKAN, Y; BOSCHÉ, F; HAAS, C T; HAAS, R. Tracking of secondary and temporary objects in structural concrete work. Construction Innovation 14.2 (2014), pp. 145-167. DOI: 10.1108/CI-12-2012-0063.

UGWU, O.O.; HAUPT, T.C. Key performance indicators and assessment methods for infrastructure sustainability - a South African construction industry perspective. Building and Environment 42.2 (2007), pp. 665-680. ISSN: 0360-1323. DOI: 10.1016/J . BUILDENV . 2005. 10.018.

VIOLA, IVAN; KANITSAR, ARMIN; GROLLER, M EDUARD. Importance-driven feature enhancement in volume visualization. IEEE Transactions on Visualization and Computer Graphics 11.4 (2005), pp. 408-418.

VOLK, REBEKKA; STENGEL, JULIAN; SCHULTMANN, FRANK. Building Information Modeling (BIM) for existing buildings - Literature review and future needs. Automation in Construction 38 (2014), pp. 109-127. ISSN: 09265805. DOI: 10.1016/j . autcon.2013.10.023.

VRIES, B de; HARINK, J M J. Generation of a construction planning from a 3D CAD model. Automation in Construction 16.1 (2007), pp. 13-18. DOI: $10.1016 / \mathrm{j}$. autcon.2005.10.010.

WAEHRER, GEETHA M.; DONG, XIUWEN S.; MILLER, TED; HAILE, ELIZABETH; MEN, YURONG. Costs of occupational injuries in 
construction in the United States. Accident Analysis \& Prevention 39.6 (2007), pp. 1258-1266. ISSN: 0001-4575. DOI: 10.1016/ J . AAP . 2007. 03.012

WALD, INGO; JOHNSON, GREGORY P; AMSTUTZ, J; BROWNLEE, CARSON; KNOLL, AARON; JEFFERS, J; GÜNTHER, J; NAVRATIL, P. OSPRay-A CPU Ray Tracing Framework for Scientific Visualization. IEEE transactions on visualization and computer graphics 23.1 (2017), pp. 931-940.

WALD, INGO; WOOP, SVEN; BENTHIN, CARSTEN; JOHNSON, GREGORY S; ERNST, MANFRED. Embree: a kernel framework for efficient CPU ray tracing. ACM Transactions on Graphics (TOG) 33.4 (2014), p. 143.

WANG BALDONADO, MICHELLE Q; WOODRUFF, ALLISON; KUCHINSKY, ALLAN. Guidelines for using multiple views in information visualization. Proceedings of the working conference on Advanced visual interfaces. ACM. 2000, pp. 110-119.

WANG, H; LI, L; JIAO, Y.-Y.; GE, X.-R.; LI, S.-C. A relationship-based and object-oriented software for monitoring management during geotechnical excavation. English. Advances in Engineering Software 71 (2014), pp. 34-45. ISSN: 09659978 (ISSN). DOI: 10 . $1016 / \mathrm{j}$. advengsoft.2014.02.001.

WANG, LUJIN; GIESEN, JOACHIM; MCDONNELL, KEVIN T; ZOLLIKER, PETER; MUELLER, KLAUS. Color design for illustrative visualization. IEEE Transactions on Visualization and Computer Graphics 14.6 (2008), pp. 1739-1754.

WANG, X; LOVE, P E D; KIM, M J; PARK, C.-S.; SING, C.-P.; HOU, L. A conceptual framework for integrating building information modeling with augmented reality. English. Automation in Construction 34 (2013), pp. 37-44. ISSN: 09265805 (ISSN). DOI: 10 . $1016 / \mathrm{j}$. autcon.2012.10.012.

WANG, Y; WANG, X; WANG, J; YUNG, P; JUN, G. Engagement of facilities management in design stage through BIM: Framework and a case study. English. Advances in Civil Engineering 2013 (2013). ISSN: 16878086 (ISSN). DOI: 10.1155/2013/189105.

WARD, MATTHEW O. A taxonomy of glyph placement strategies for multidimensional data visualization. Information Visualization 1.34 (2002), pp. 194-210.

WARE, COLIN. Information Visualization, 2nd Edition Perception for Design. Morgan Kaufmann, 2004, p. 486. ISBN: 1558608192. 
WARE, COLIN; MITCHELL, PETER. Visualizing graphs in three dimensions. ACM Transactions on Applied Perception (TAP) 5.1 (2008), p. 2.

WEHREND, STEPHEN; LEWIS, CLAYTON. A problem-oriented classification of visualization techniques. Visualization, 1990. Visualization'90., Proceedings of the First IEEE Conference on. IEEE. 1990, pp. 139-143.

WEISKOPF, DANIEL. On the role of color in the perception of motion in animated visualizations. Visualization, 2004. IEEE. IEEE. 2004, pp. 305-312.

WILLIAMS, G; GHEISARI, M; CHEN, P.-J.; IRIZARRY, J. BIM2MAR: An efficient BIM translation to mobile augmented reality applications. English. Journal of Management in Engineering 31.1 (2014). ISSN: 0742597X (ISSN). DOI: 10.1061/(ASCE) ME. 1943-5479.0000315.

WILSON, JAMES M. Gantt charts: A centenary appreciation. European Journal of Operational Research 149.2 (2003), pp. 430-437.

WON, J; LEE, G; DOSSICK, C; MESSNER, J. Where to focus for successful adoption of building information modeling within organization. Journal of Construction Engineering and Management 139.11 (2013). DOI: 10.1061/(ASCE) C0.1943-7862.0000731.

WONG, JOHNNY KWOK WAI; ZHOU, JASON. Enhancing environmental sustainability over building life cycles through green BIM: A review. Automation in Construction 57 (2015), pp. 156-165. ISSN: 09265805. DOI: $10.1016 / \mathrm{j}$. autcon.2015.06.003.

WONG, PAK CHUNG; BERGERON, R DANIEL. 30 years of multidimensional multivariate visualization. Scientific Visualization 2 (1994), pp. $3-33$.

WOOD, JO; DYKES, JASON; SLINGSBY, AIDAN; CLARKE, KEITH. Interactive visual exploration of a large spatio-temporal dataset: Reflections on a geovisualization mashup. IEEE transactions on visualization and computer graphics 13.6 (2007), pp. 1176-1183.

WU, I.-C.; CHANG, S. Visual Req calculation tool for green building evaluation in Taiwan. Automation in Construction 35 (2013), pp. 608 617. DOI: $10.1016 / j$. autcon. 2013.01.006.

WYMAN, CHRIS. Exploring and expanding the continuum of OIT algorithms. Proceedings of High Performance Graphics. Eurographics Association. 2016, pp. 1-11.

WYMAN, CHRIS; HOETZLEIN, RAMA; LEFOHN, AARON. Frustumtraced raster shadows: Revisiting irregular z-buffers. Proceedings 
of the 19th Symposium on Interactive 3D Graphics and Games. ACM. 2015, pp. 15-23.

XIE, W; FU, W; LYU, B; LI, Z; HUANG, J; XU, F. Incorporating building information modeling (BIM) into the super high-rise industrialized housing project: A case study. English. Boletin Tecnico/Technical Bulletin 55.13 (2017), pp. 234-243. ISSN: 0376723X (ISSN).

YALCINKAYA, M; SINGH, V. Patterns and trends in Building Information Modeling (BIM) research: A Latent Semantic Analysis. Automation in Construction 59 (2015), pp. 68-80. DOI: 10 . $1016 / \mathrm{j}$. autcon. 2015.07.012.

YANG, JASON C; HENSLEY, JUSTIN; GRÜN, HOLGER; THIBIEROZ, NICOLAS. Real-Time Concurrent Linked List Construction on the GPU. Computer Graphics Forum. Vol. 29. 4. Wiley Online Library. 2010, pp. 1297-1304.

YANG, X; ERGAN, S. Design and Evaluation of an Integrated Visualization Platform to Support Corrective Maintenance of HVAC Problem-Related Work Orders. Journal of Computing in Civil Engineering 30.3 (2016). DOI: 10.1061/(ASCE)CP.1943-5487.0000510.

YANG, XUE; ERGAN, SEMIHA. Evaluation of visualization techniques for use by facility operators during monitoring tasks. Automation in Construction 44 (2014), pp. 103-118.

YI, JI SOO; KANG, YOUN ah; STASKO, JOHN. Toward a deeper understanding of the role of interaction in information visualization. IEEE transactions on visualization and computer graphics 13.6 (2007), pp. $1224-1231$.

ZHANG, S; SULANKIVI, K; KIVINIEMI, M; ROMO, I; EASTMAN, C M; TEIZER, J. BIM-based fall hazard identification and prevention in construction safety planning. Safety Science 72 (2015), pp. 31-45. DOI: $10.1016 /$ j.ssci.2014.08.001.

ZHANG, X. Critical success factors for public-private partnerships in infrastructure development. Journal of Construction Engineering and Management 131.1 (2005), pp. 3-14. DOI: 10.1061/(ASCE) 07339364 (2005) $131: 1$ (3).

ZHOU, LIANG; HANSEN, CHARLES D. A survey of colormaps in visualization. IEEE transactions on visualization and computer graphics 22.8 (2016), pp. 2051-2069.

ZHOU, W; GEORGAKIS, P; HEESOM, D; FENG, X. Model-based groupware solution for distributed real-time collaborative $4 \mathrm{D}$ plan- 
ning through teamwork. Journal of Computing in Civil Engineering 26.5 (2012), pp. 597-611. DOI: 10.1061/ (ASCE) CP. 1943-5487. 0000153. ZHOU, W; HEESOM, D; GEORGAKIS, P; TAH, J H M. User-centred design for collaborative 4D modelling. Construction Innovation 14.4 (2014), pp. 493-517. DOI: 10.1108/CI-01-2014-0008.

ZHOU, W; WHYTE, J; SACKS, R. Construction safety and digital design: A review. English. Automation in Construction 22 (2012), pp. 102-111. ISSN: 09265805 (ISSN). DOI: $10.1016 / \mathrm{j}$. autcon . 2011. 07.005 .

ZHOU, Y; DING, L; WANG, X; TRUIJENS, M; LUO, H. Applicability of $4 \mathrm{D}$ modeling for resource allocation in mega liquefied natural gas plant construction. Automation in Construction 50.C (2015), pp. 50-63. DOI: 10.1016/j . autcon.2014.10.016.

ZUK, TORRE; SCHLESIER, LOTHAR; NEUMANN, PETRA; HANCOCK, MARK S.; CARPENDALE, SHEELAGH. Heuristics for information visualization evaluation. Proceedings of the 2006 AVI workshop on BEyond time and errors novel evaluation methods for information visualization - BELIV '06. New York, New York, USA: ACM Press, 2006, p. 1. ISBN: 1595935622. DOI: 10.1145/1168149.1168162.

ZUO, JIAN; ZHAO, ZHEN-YU. Green building research-current status and future agenda: A review. Renewable and sustainable energy reviews 30 (2014), pp. 271-281. 